\title{
Multiphase Carbon-14
} Transport in a Near-Field-Scale Unsaturated Column of Natural Sediments

\author{
Don T. Fox \\ Mitchell A. Plummer \\ Larry C. Hull \\ D. Craig Cooper
}

March 2004

Idaho National Engineering and Environmental Laboratory Bechtel BWXT Idaho, LLC 
INEEL/EXT-04-01793

\title{
Multiphase Carbon-14 Transport in a Near-Field-Scale Unsaturated Column of Natural Sediments
}

\author{
Don T. Fox \\ Mitchell A. Plummer \\ Larry C. Hull \\ D. Craig Cooper
}

March 2004

Idaho National Engineering and Environmental Laboratory Idaho Falls, Idaho 83415 


\section{ABSTRACT}

Wastes buried at the Subsurface Disposal Area (SDA) of the Idaho National Engineering and Environmental Laboratory include activated metals that release radioactive carbon-14 $\left({ }^{14} \mathrm{C}\right)$ as they corrode. To better understand ${ }^{14} \mathrm{C}$ phase partitioning and transport in the SDA sediments, we conducted a series of transport experiments using ${ }^{14} \mathrm{C}$ (radio-labeled sodium carbonate) and nonreactive gas (sulfur hexafluoride) and aqueous (bromide and tritiated water) tracers in a large (2.6-m high by $0.9-\mathrm{m}$ diameter) column of sediments similar to those used as cover material at the SDA. We established steady-state unsaturated flow prior to injecting tracers into the column. Tracer migration was monitored using pore-water and pore-gas samples taken from co-located suction lysimeters and gas ports inserted at $\sim 0.3-\mathrm{m}$ intervals along the column's length.

Measurements of ${ }^{14} \mathrm{C}$ discharged from the sediment to the atmosphere (i.e., ${ }^{14} \mathrm{CO}_{2}$ flux) indicate a positive correlation between $\mathrm{CO}_{2}$ partial pressure $\left(\mathrm{pCO}_{2}\right)$ in the column and changes in ${ }^{14} \mathrm{CO}_{2}$ flux. Though ${ }^{14} \mathrm{CO}_{2}$ diffusion is expected to be independent of $\mathrm{pCO}_{2}$, changes of $\mathrm{pCO}_{2}$ affect pore water chemistry sufficiently to affect aqueous/gas phase ${ }^{14} \mathrm{C}$ partitioning and consequently ${ }^{14} \mathrm{C}_{2}$ flux. Pore-water and -gas ${ }^{14} \mathrm{C}$ activity measurements provide an average aqueous/gas partitioning ratio, $\mathrm{K}_{\mathrm{ag}}$, of $4.5( \pm 0.3)$. This value is consistent with that calculated using standard carbonate equilibrium expressions with measured $\mathrm{pH}$, suggesting the ability to estimate $\mathrm{K}_{\mathrm{ag}}$ from carbonate equilibrium. One year after the ${ }^{14} \mathrm{C}$ injection, the column was cored and solid-phase ${ }^{14} \mathrm{C}$ activity was measured. The average aqueous/solid partition coefficient, $\mathrm{K}_{\mathrm{d}},\left(1.6 \mathrm{~L} \mathrm{~kg}^{-1}\right)$ was consistent with those derived from small-scale and short-term batch and column experiments using SDA sediments, suggesting that bench-scale measurements are a valid means of estimating aqueous/solid partitioning at the much larger spatial scale considered in these meso-scale experiments. However, limitations at the bench scale prevent observation of spatially- and temporally-varying parameters that affect contaminant transport in the natural environment. In addition to a temporally-variable ${ }^{14} \mathrm{CO}_{2}$ flux, in response to changes of $\mathrm{pCO}_{2}$, we observed non-uniformities in $K_{a g}$ and $K_{d}$ that were not observed in bench-scale studies. Our results suggest that ${ }^{14} \mathrm{C}$ transport is effectively controlled by gas diffusion with minimal retardation by partitioning onto the solid phase, and little long-term retention. The implication for the SDA is that ${ }^{14} \mathrm{C}$ released via corrosion of activated metals is primarily transported by gas-phase diffusion rather than by liquid-phase advection. Calculations show that, because the atmospheric boundary is so much closer than the aquifer boundary at the SDA, most of the ${ }^{14} \mathrm{C}$ will diffuse upward to the atmosphere. 


\section{EXECUTIVE SUMMARY}

Radioactive carbon released as gaseous ${ }^{14} \mathrm{CO}_{2}$ from wastes emplaced in the unsaturated surface (vadose zone) can be transported in both aqueous and gas form and may thus impact the overlying atmosphere and underlying groundwater. The presence of an estimated $500 \mathrm{Ci}$ of ${ }^{14} \mathrm{C}$ buried in the Subsurface Disposal Area (SDA) of the Idaho National Engineering and Environmental Laboratory's Radioactive Waste Management Complex has led to analysis of ${ }^{14} \mathrm{C}$ release rates to both the air and water.

A radiological performance assessment completed in 2000 conservatively assumed that all ${ }^{14} \mathrm{C}$ released from the SDA would migrate downward, with infiltrating soil moisture, to eventually reach the Snake River Plain aquifer. Conversely, in assessing atmospheric exposures, all ${ }^{14} \mathrm{C}$ was assumed to migrate upward in the gas phase. In addition to these extreme simplifications of transport processes, the assessment omitted the effect of partitioning between aqueous and solid phases during liquid transport. To provide data for more realistic modeling of ${ }^{14} \mathrm{C}$ releases from the SDA, and thereby provide a stronger scientific basis for regulatory decisions, we conducted a series of transport experiments with conservative gas and liquid tracers as well as ${ }^{14} \mathrm{C}$.

Parameters for contaminant transport modeling are typically based on bench-scale laboratory experiments. To determine flow and transport parameters at a spatial scale more applicable to the SDA, we conducted a set of transport experiments at unsaturated flow conditions in a near-field-scale (meso-scale) column filled with the sediment from the SDA. The column provides a physical model of vadose zone conditions at the SDA that allows us to monitor aqueousand gas-phase transport over relatively long distances. Results of these transport experiments form the basis for future modeling efforts to determine the ability of transport parameters derived from small-scale and short-term experiments to predict ${ }^{14} \mathrm{C}$ behavior at scales approaching that of the field.

The meso-scale column consisted of a 2.9-m high by 0.91-m diameter stainless steel cylinder, sealed at both ends. The column contained approximately $1.7 \mathrm{~m}^{3}$ of sediment, reaching a height of $2.6 \mathrm{~m}$. We used SDA sediment, which is mineralogically relevant and assures geochemical variability commensurate with conditions at the SDA that have a major influence on ${ }^{14} \mathrm{C}$ partitioning and transport. The sealed headspace above the sediment was connected to an automated $\mathrm{CO}_{2}$ and $\mathrm{O}_{2}$ concentration monitoring and gas flow control system. Ambient air was circulated through the headspace at a rate of $\sim 7 \mathrm{~L} \mathrm{~min}^{-1}$. The circulation system allowed $\mathrm{O}_{2}$ to diffuse into the sediment at atmospheric pressure and prevented accumulation of $\mathrm{CO}_{2}$, thus providing a constant concentration boundary condition at the sediment surface (i.e., the sediment/atmosphere interface) for gas phase components. The column was instrumented at $30.5-\mathrm{cm}$ intervals along its length. Instrumentation included four tensiometers, four water content reflectometers, eight water sampling lysimeters, eight gas sampling ports, and eight thermocouples.

The column was fitted with three separate injection arrays, each capable of injecting gas or liquid. Each array comprised twenty-four stainless steel tubes that could deliver fluid to evenly spaced locations in a horizontal plane within the 
column. The uppermost array, on the sediment surface, supplied influent water. The two remaining arrays were situated within the sediment at 1.07 and $1.98 \mathrm{~m}$ above the bottom. Solutions for aqueous-phase transport experiments were injected into the middle array (at $1.98 \mathrm{~m}$ ) to minimize nonuniform flow effects due to the periodic application of water at the sediment surface. Gas-phase tracers were injection into the bottom array (1.07-m height).

The sediment surface array used 24 syringe-pump-fed tubes to uniformly apply water to the surface at intervals of $40 \mathrm{~min}$. This water was synthetic vadose zone water, formulated to approximate the composition of natural infiltrating soil moisture at the SDA. To limit microbial growth, the water was sterilized by autoclaving and treated with ultraviolet radiation immediately preceding application. Water application began at a hydraulic flux of $\sim 5 \mathrm{~L} \mathrm{day}^{-1}$. After the wetting front reached the effluent lysimeters at the bottom of the column, the flux was reduced to $\sim 1 \mathrm{~L} \mathrm{day}^{-1}$ and held at that rate for the remainder of the experiments. To withdraw the infiltrating water, constant tension was applied to four 1.0-bar suction lysimeters located in a horizontal plane $\sim 15 \mathrm{~cm}$ above the bottom. Thus, unsaturated hydraulic flow conditions in the column were maintained through application of a consistent flux at the top of the column and constant potential in the lysimeters. We tracked column water balance via periodic measurements of the column inflow, effluent water mass, mass removed for liquid sampling, and evaporative loss from the sediment surface. The latter was calculated from relative humidity measurements of ambient air and column headspace, combined with the headspace ventilation rate.

Prior to conducting the transport experiment with ${ }^{14} \mathrm{C}$, we performed a set of experiments to examine the movement of water, gas, and conservative solute through the sediment. These experiments used injections of a highly insoluble gas tracer, sulfur hexafluoride, both before and after initiation of hydraulic flow, as well as injections of conservative liquid tracers, bromide and tritium, after reaching a quasi steady-state flow condition. Data from these experiments was used to estimate characteristics of the unsaturated flow system that would affect transport of ${ }^{14} \mathrm{C}$, including average linear seepage velocity, dispersivity, and aqueous- and gas-phase diffusion coefficients. The ${ }^{14} \mathrm{C}$ transport test began with injection of an aqueous $1610( \pm 16)$ microCi ${ }^{14} \mathrm{C}$-labeled bicarbonate solution $0.6 \mathrm{~m}$ below the sediment surface, through the middle injection array $(1.98-\mathrm{m}$ height). For the next $\sim 12$ month, we monitored headspace and pore gas $\mathrm{CO}_{2}$ and $\mathrm{O}_{2}$ concentrations, sediment surface ${ }^{14} \mathrm{CO}_{2}$ flux, pore gas and pore water ${ }^{14} \mathrm{C}$ migration, pore water chemistry, sediment water content, hydraulic head and/or matric potential, and sediment temperature profiles. During the ${ }^{14} \mathrm{C}$ transport experiment, aqueous/gas ${ }^{14} \mathrm{C}$ partitioning ratios $\left(K_{a g}\right)$ were calculated using two separate methods: aqueous and gas phase activity measurements and standard carbonate equilibrium expressions with measured $\mathrm{pH}$. At conclusion of the $\sim 12$ month monitoring period, we cored the column and measured solid-phase ${ }^{14} \mathrm{C}$ sorption for calculation of the aqueous/solid ${ }^{14} \mathrm{C}$ sorption coefficient $\left(K_{d}\right)$ and ${ }^{14} \mathrm{C}$ mass balance.

We determined seepage velocity and hydrodynamic dispersion coefficients by fitting analytical solutions to observed bromide $\left(\mathrm{Br}^{-}\right)$breakthrough curves at each water sampling lysimeter. Consistent with the column's design, and despite its size, the $\mathrm{Br}^{-}$breakthrough curves indicate that flow in the column was 
effectively one-dimensional with an average linear seepage velocity of $0.52 \mathrm{~cm} \mathrm{day}^{-1}$ and an aqueous diffusion coefficient of $1.8 \times 10^{-5} \mathrm{~cm}^{2} \mathrm{sec}^{-1}$ during the transport experiments. We calculated an average hydraulic dispersion coefficient of $5.7 \times 10^{-6} \mathrm{~cm}^{2} \mathrm{sec}^{-1}$ and average volumetric water content of $28 \%$ $( \pm 3 \%)$. This water content range agrees well with the reflectometer and mass balance data. Additionally, the reflectometer and mass balance data indicate that this water content was relatively constant throughout the experiments. Calculated hydraulic dispersivity was effectively negligible, ranging from 0 to $7 \mathrm{~mm}$. This is consistent with the results of Hull and Hohorst, who conducted saturated $\mathrm{Br}^{-}$and tritium $\left({ }^{3} \mathrm{H}\right)$ transport tests with SDA sediment in 31-cm columns and found that dispersivity was on the order of $0.5 \mathrm{~mm}$.

In aqueous systems ${ }^{3} \mathrm{H}$ readily partitions into water as ${ }^{3} \mathrm{H}_{2} \mathrm{O}$; therefore, the ${ }^{3} \mathrm{H}$ transport velocity is expected to be equivalent to that of the associated water. In our $\mathrm{Br}^{-}$and ${ }^{3} \mathrm{H}$ tracer tests, the rate of ${ }^{3} \mathrm{H}$ transport was significantly slower than that of $\mathrm{Br}^{-}$. Results of a second $\mathrm{Br}^{-}$and ${ }^{3} \mathrm{H}$ tracer test indicate that anion (i.e., $\mathrm{Br}^{-}$) exclusion was not the cause of this discrepancy. Furthermore, the good agreement between $\mathrm{Br}^{-}$breakthrough curve results and independent water content determinations validates the use of $\mathrm{Br}^{-}$data for flow system characterization. Therefore, the ${ }^{3} \mathrm{H}$ data was not considered in estimation of aqueous transport characteristics. We fit an analytical solution to observed ${ }^{3} \mathrm{H}$ breakthrough curves and calculated a ${ }^{3} \mathrm{H}$ sorption (retardation) coefficient, $K_{d}$, of $\sim 0.08 \mathrm{~mL} \mathrm{~g}^{-1}$. Measurement of ${ }^{3} \mathrm{H}$ retardation is significant because ${ }^{3} \mathrm{H}$ is commonly used as a conservative, nonreactive tracer in aqueous system studies. While the explicit mechanisms controlling ${ }^{3} \mathrm{H}$ retardation are unclear at this time, retardation is assumed due to the fixation of ${ }^{3} \mathrm{H}$ on clays and other common hydrated sediment minerals.

The sulfur hexafluoride $\left(\mathrm{SF}_{6}\right)$ gas tracer migrated rapidly through the column, with peak concentrations arriving at gas sampling ports located $\sim 15-\mathrm{cm}$ above and below the injection plane between 0.5 and $2 \mathrm{~h}$ following injection. Maximum late-time $\mathrm{SF}_{6}$ concentrations are significantly higher in the second set of tests, performed under the higher water content associated with the quasi steady-state flow condition. This reflects the increased concentration gradient that developed in response to the increase in gas phase tortuosity with higher water content. Under this condition, least-squares analyses of $\mathrm{SF}_{6}$ breakthrough curves using the standard Millington expression for gas phase tortuosity indicate a gaseous diffusion coefficient of $1.1 \times 10^{-1} \mathrm{~cm}^{2} \mathrm{sec}^{-1}$ and a volumetric water content of $25 \%$. The water content indicated by these analyses agrees relatively well with the other, more direct, measures of water content. Hull and Hohorst's experiments using air-dried SDA sediments in small-scale columns indicated that the reduction in the free-air diffusion coefficient due to tortuosity was slightly greater than that described by the Millington expression. However, we find that the standard Millington expression, with the commonly used $m$ value of $7 / 3$ or 2.33 , provides an accurate description of $\mathrm{SF}_{6}$ transport behavior in SDA sediments.

Gas-phase ${ }^{14} \mathrm{C}$ breakthrough curves at virtually all levels in the column display the same characteristic shape as the $\mathrm{SF}_{6}$ curves, but lagged, consistent with gas-diffusion-dominated transport retarded by exchanges with other phases.

${ }^{14} \mathrm{C}$ concentrations at the nearest ports, for example, peaked after approximately 
one day, as opposed to about an hour for $\mathrm{SF}_{6}$. This ${ }^{14} \mathrm{CO}_{2}$ diffusion, with aqueous/gas phase exchange, allowed ${ }^{14} \mathrm{C}$ to distribute between pore-water and -gas volumes throughout the column within 7 days of the injection. Rapid diffusion produced a maximum ${ }^{14} \mathrm{CO}_{2}$ surface flux $\left(22.37\right.$ microCi m${ }^{-2}$ day $\left.^{-1}\right)$ within 25 days of the injection. After approximately one year, ${ }^{14} \mathrm{C}$ migration from the column was by surface flux $(66.0 \%)$ and discharge of water from the bottom of the column $(3.7 \%)$. Of the $21.6 \%$ of the total injected activity remaining in the column, $81.5 \%$ sorbed to the solid phase. Mass balances calculated from measurements of sorbed activity, aqueous and gaseous activities at the eight sampling levels, ${ }^{14} \mathrm{C}$ removed via gas and liquid samples, ${ }^{14} \mathrm{C}$ activity exiting via the lysimeters at the bottom, and ${ }^{14} \mathrm{C}$ venting into the headspace account for $93 \%$ of the injected ${ }^{14} \mathrm{C}$ activity. The inability to account for all of the injected activity is due to variability of sediment surface sample activities $\left(1.2 \times 10^{-4} \pm 33 \%\right.$ picoCi $\mathrm{g}^{-1}$ sediment), activity remaining within injection tubing, and cumulative measurement error.

In evaluation of ${ }^{14} \mathrm{CO}_{2}$ surface flux data, we observed a correlation between ${ }^{14} \mathrm{CO}_{2}$ flux and sediment temperature fluctuations. This observation is supported by a conceptual model that relates sediment temperature, which is the primary variable controlling microbial $\mathrm{CO}_{2}$ production and thus $\mathrm{CO}_{2}$ partial pressure $\left(\mathrm{pCO}_{2}\right)$ in the column, to the control of ${ }^{14} \mathrm{CO}_{2}$ aqueous/gas phase partitioning. Although gas-phase ${ }^{14} \mathrm{CO}_{2}$ diffusion is independent of $\mathrm{pCO}_{2}$, changes in $\mathrm{pCO}_{2}$ affect pore water chemistry (i.e., $\mathrm{pH}$ ) sufficiently to affect aqueous/gas phase ${ }^{14} \mathrm{CO}_{2}$ partitioning. In the conceptual model, a decrease in sediment temperature causes a decline in $\mathrm{pCO}_{2}$ that allows more partitioning of ${ }^{14} \mathrm{CO}_{2}$ to the aqueous phase than to the gas phase causing ${ }^{14} \mathrm{CO}_{2}$ flux out of the column to decrease. Conversely, an increase in sediment temperature allows more ${ }^{14} \mathrm{CO}_{2}$ to partition to the gas phase than to the aqueous phase and ${ }^{14} \mathrm{CO}_{2}$ flux out of the column increases. Therefore, a positive correlation between sediment temperature, $\mathrm{pCO}_{2}$, and ${ }^{14} \mathrm{CO}_{2}$ flux is observed. Furthermore, microbial consumption of natural organic matter and $\mathrm{O}_{2}$, and respiration of $\mathrm{CO}_{2}$, produced an approximately exponential increase in $\mathrm{pCO}_{2}$ with depth. The effect of nonuniform $\mathrm{pCO}_{2}$ and, therefore, $\mathrm{pH}$ is observed in measurements of ${ }^{14} \mathrm{C}$ phase activity distributions.

${ }^{14} \mathrm{C}$ activity distributions are represented by aqueous/gas $\left(K_{a g}\right)$ and aqueous/solid $\left(K_{d}\right)$ partitioning ratios. We calculated $K_{a g}$ using both aqueous- and gas-phase ${ }^{14} \mathrm{C}$ activity measurements at each co-located pore-water and -gas sampling port and measured $\mathrm{pH}$ with standard carbonate equilibrium expressions. $K_{\mathrm{d}}$ is calculated from aqueous- and solid-phase activity measurements at the time of coring. Typical $\mathrm{pH}$ values ranged from $\sim 7.4$ near the top of the column to $\sim 6.9$ near the bottom. This nonuniformity produced an increase in both $K_{a g}$ and $K_{d}$ near the top of the column, as significantly more ${ }^{14} \mathrm{C}$ was measured in the aqueous phase than in either the gas or solid phase near the top of the column. $K_{a g}$ values ranged from $\sim 9.0$ near the top of the column to $\sim 4.0$ near the bottom. This range is consistent with that calculated using measured $\mathrm{pH}$ and standard carbonate equilibrium expressions, suggesting the ability to estimate $K_{a g}$ based solely on carbonate equilibrium. $K_{d}$ values range from $2.4 \mathrm{~L} \mathrm{~kg}^{-1}$ near the top of the column to $0.8 \mathrm{~L} \mathrm{~kg}^{-1}$ near the bottom. This range of $K_{d}$ values is consistent with those derived from small-scale and short-term batch and column experiments using SDA sediments, suggesting that bench-scale measurements 
are a valid means of estimating aqueous/solid partitioning at the much larger spatial scales considered in these meso-scale experiments. However, the effect of spatially-variable $\mathrm{pH}$ on $K_{a g}$ and $K_{d}$ was not observed in previous bench-scale studies. This is due largely to the size constraints of bench-scale studies. Subsequent to this report, the effect of a spatially-variable $\mathrm{pH}$ on ${ }^{14} \mathrm{C}$ transport parameters will be incorporated with numerical simulations of the column. These simulations form the basis for comparing meso-scale and bench-scale parameter estimations as well as extending ${ }^{14} \mathrm{C}$ behavior in those column studies to SDA transport problems.

Evaluations of our initial results suggest that ${ }^{14} \mathrm{C}$ transport in the column may be described by reactive diffusive transport in the gas phase with negligible aqueous phase transport. As estimated infiltration rates at the SDA are lower than that maintained in the column, gas movement also probably dominates ${ }^{14} \mathrm{C}$ transport at the SDA. Whether or not that includes an advective component, the flux to the atmosphere would be expected to be greater than the flux to the aquifer. Not only are these experimental conditions directly applicable to the vadose zone environment at the SDA, the sediment used is largely typical of the arid western United States. Therefore, the findings of this study may be useful for other vadose zone waste disposal sites where contaminant risk assessments or remedial efforts are under consideration.

In addition to describing ${ }^{14} \mathrm{C}$ behavior and transport model parameters, a secondary goal of this study was to identify the challenges of operating an unsaturated flow column at the meso scale. To constrain system variables, we sought to measure flow and transport parameters and ${ }^{14} \mathrm{C}$ migration under steady-state geochemical and hydraulic conditions. No significant challenges were encountered to prevent these measurements. However, establishing and maintaining steady-state conditions required consideration of four primary factors: excessive leaching of salts, stabilization of the hydraulic potential gradient, adequate sediment temperature control, and long-term depletion of microbial substrate.

Though an initial high infiltration rate minimized the time required to remove excess dissolved salts (i.e., nitrate) and to establish unsaturated flow, an extended period of steady hydraulic flux was needed to stabilize the hydraulic potential gradient following the initial high flux period. Stabilizing pore water chemistry (i.e., dissolved inorganic species) and establishing a quasi steady-state hydraulic potential gradient required 397 days. Quasi steady state was defined primarily by lysimeter properties and the hydraulic conductivity of sediments used $\left(K_{\text {sat }} \cong 4 \times 10^{-5} \mathrm{~cm} \mathrm{sec}^{-1}\right)$.

Sediment temperature and the availability of microbial substrate (i.e., easily metabolized organic carbon) affect microbial $\mathrm{CO}_{2}$ production, which in turn is the primary variable affecting $\mathrm{pH}$ and ${ }^{14} \mathrm{CO}_{2}$ phase partitioning and transport. Due to rapid ${ }^{14} \mathrm{CO}_{2}$ discharge from the column, the long-term depletion of microbial substrate was relatively insignificant in these experiments. However, substrate depletion may impact studies sensitive to long-term $\mathrm{pH}$ and/or $\mathrm{pCO}_{2}$ changes, such as the study of uranium mobility. Therefore, long-term reactive transport studies may find it necessary to control microbial substrate. Conversely, short-term temperature fluctuations produced significant fluctuations of ${ }^{14} \mathrm{CO}_{2}$ 
flux from the column. Therefore, as a spatial variable, $\mathrm{pH}$ affects $K_{a g}$ and $K_{d}$ uniformity, so a temperature-induced and temporally-variable $\mathrm{pH}$ should be considered when assessing ${ }^{14} \mathrm{C}$ transport in the near subsurface where variation of temperature with season and/or climate has the potential to affect $K_{a g}$ and $K_{d}$.

Though considerable cost and time are required for meso-scale experiments, they provide a valuable means of observing complex behavior under conditions applicable to the field with control that is not possible in the field. In this study, we observed nonuniformities of $K_{a g}$ and $K_{d}$ that demonstrated the ability of meso-scale experiments to represent spatially-variable conditions that affect contaminant transport in the natural environment. Such transport parameters are typically measured with bench-scale experiments due to cost. However, the consistency of transport parameter estimations from previous bench-scale experiments and our meso-scale experiment demonstrates the value of meso-scale methods for extending bench-scale understanding to transport problems at the SDA and elsewhere. 


\section{ACKNOWLEDGEMENTS}

The authors wish to thank Carolyn Bishop, Tim Kaser, Joe Lord, and Terri Nelson-Ireland for their commitment to the successful completion of this study. 


\section{CONTENTS}

ABSTRACT

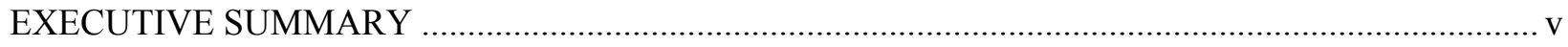

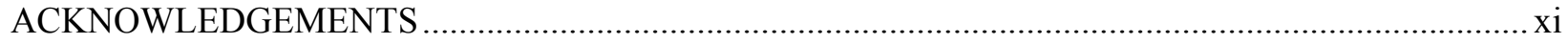

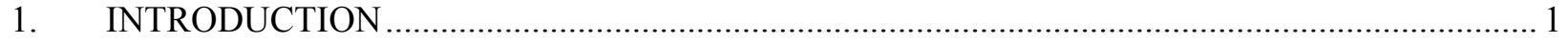

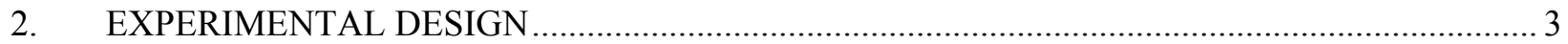

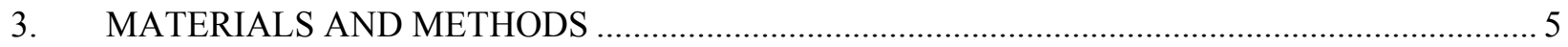

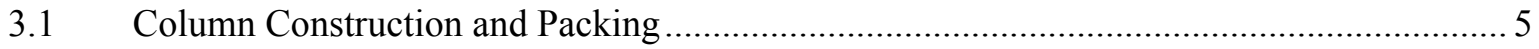

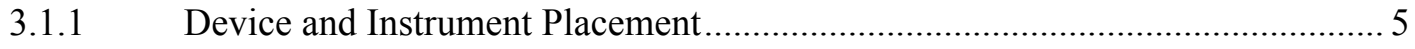

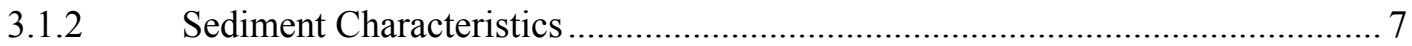

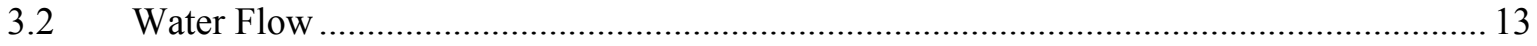

3.2.1 Water Preparation and Composition ........................................................ 13

3.2.2 Establishing and Maintaining Unsaturated Flow .......................................... 14

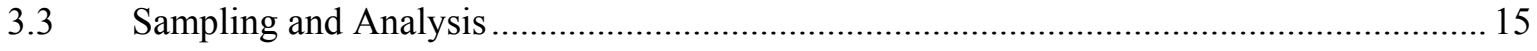

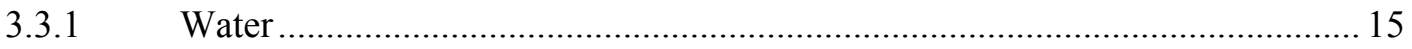

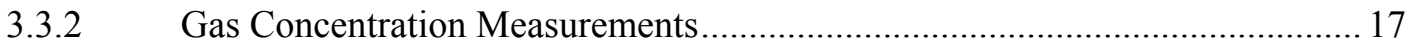

3.3.3 Water Content Determination ........................................................................ 19

3.4 Tracer Preparation, Injection, and Analysis ........................................................... 24

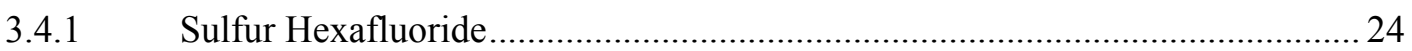

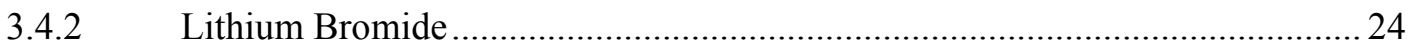

3.4.3 Uranium, Carbon-14, and Tritium Injection ............................................ 25

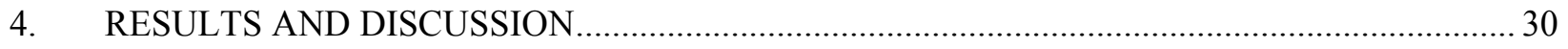

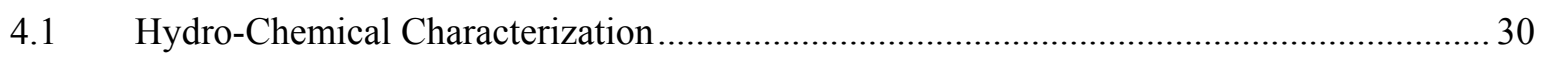

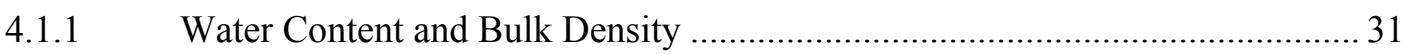

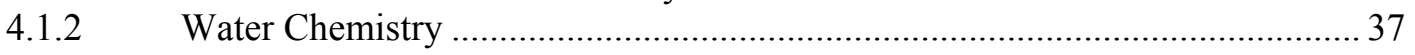

4.1.3 $\quad \mathrm{CO}_{2}$ and $\mathrm{O}_{2}$ Gas Concentration Monitoring ................................................... 44

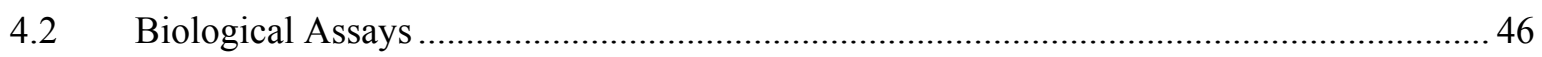

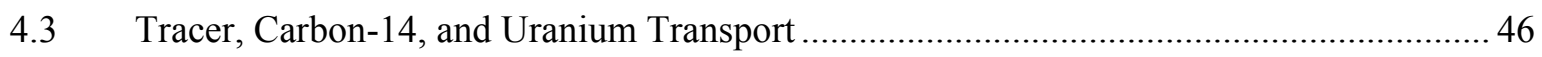

4.3.1 Gas Tracer-Sulfur Hexafluoride ….............................................................. 46

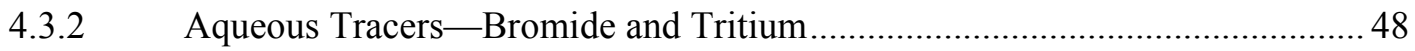

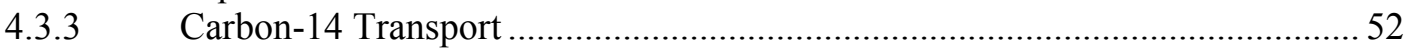




\section{FIGURES}

1. Relative locations of the INEEL, SDA/RWMC, and Snake River Plain aquifer

2. Timeline of key events in this research.

3. Meso-scale column after packing (left) and during experiment (right)

4. Delivery point locations for injection arrays (plan view)

5. Elevation view of device placement. Note, the absolute bottom is $259.08-\mathrm{cm}$ below the column surface. While level numbers indicate distance upward from the absolute bottom, Level " 0 " is actually at the mid-point between Level 1 and the absolute bottom.

6. Placement of monitoring and sampling devices at each level (plan view)

7. Syringe pump system for infiltration water delivery. Syringes and tubing are shown without pump motor housings.

8. Pore water $\mathrm{pH}$ measurement using inline electrode. Stainless steel lysimeter tubing and shut off valves are shown extending from the column

9. Linear fits used for low- and high-range $\mathrm{CO}_{2}$ measurement corrections. Data points represent average gas standard measurements

10. Column coring for gravimetric water content and solid phase ${ }^{14} \mathrm{C}$ activity determinations

11. Injection of the ${ }^{14} \mathrm{C}$, tritium, and uranium cocktail solution .....

12. Influent and effluent flow rates with effluent lysimeter head 33

13. Mass balance based cumulative volumetric water content .33

14. Moisture characteristic curve (a) and tensiometer and effluent lysimeter hydraulic heads (b) 34

15. Reflectometer (TDR probe) data. (a) volumetric water content and effluent-lysimeter hydraulic head, (b) wetting/dissolved-salts front breakthrough curves recorded by TDR probes, and (c) electrical conductivity time series

16. Aqueous chemistry and sediment $\mathrm{CO}_{2}$ gas profiles (legend on next page)

17. Average $\mathrm{CO}_{2}, \mathrm{O}_{2}$, and $\mathrm{pH}$ profiles during ${ }^{14} \mathrm{C}$ transport study (dotted lines represent gas concentration ranges during the $\sim 107$ week study) 
18. Sediment gas $\mathrm{CO}_{2}$ and $\mathrm{O}_{2}$ concentration time series at each column level.

19. Bulk $\mathrm{CO}_{2}$ surface flux.

20. $\mathrm{SF}_{6}$ concentration in primary and replicate tests at packing $(\sim 10 \%)$ and experimental $(\sim 30 \%)$ water contents

21. Comparison of primary $\mathrm{SF}_{6}$ tests at packing $(\sim 10 \%)$ and experimental $(\sim 30 \%)$ volumetric water content. (characters $=\sim 30 \%$ test; lines $=\sim 10 \%$ test $)$

22. Least-squares fit of $\mathrm{SF}_{6}$ breakthrough curves at $\sim 30 \%$ volumetric water content (i.e., the water content during transport study).

23. Bromide $\left(\mathrm{Br}^{-}\right)$breakthrough curves and CXTFIT2 fit ..... 50

24. Bromide $\left(\mathrm{Br}^{-}\right)$and tritium $\left({ }^{3} \mathrm{H}\right)$ breakthrough curves. .51

25. Measured sediment gas ${ }^{14} \mathrm{C}$ breakthrough curves at all eight column levels . 52

26. ${ }^{14} \mathrm{C}$ sediment gas (a) and sediment water (b) activity profiles .53

27. ${ }^{14} \mathrm{C}$ surface flux (a), $\mathrm{CO}_{2}$ surface flux (b), barometric pressure (c), and average sediment temperature (d) time series.

28. Early time aqueous/gas phase partition ratios $\left(K_{a g}\right)$ based on ${ }^{14} \mathrm{C}$ activity partitioning (a) and carbonate equilibrium (b) with $\mathrm{pH}$ (c) 56

29. Solid phase ${ }^{14} \mathrm{C}$ activity profile at end of study. 57

30. Aqueous and gas phase ${ }^{14} \mathrm{C}$ activity profiles at end of study .58

31. Graphic representation of ${ }^{14} \mathrm{C}$ activity mass balance .59

32. $K_{d}, K_{a g}(\mathrm{a}), \mathrm{pH}(\mathrm{b})$, bicarbonate alkalinity (c), and $\mathrm{CO}_{2}$ (d) profiles at time of coring 60

\section{TABLES}

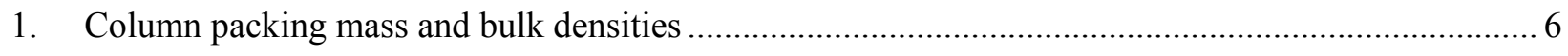

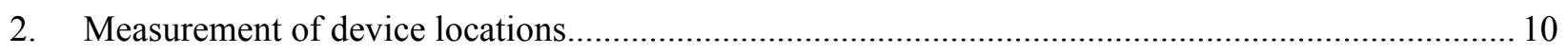

3. Measurement of initial (packing) water content, dry bulk density, wet bulk density, and porosity at time of column packing.

4. Sediment drainage characteristics, from saturation ............................................................ 11

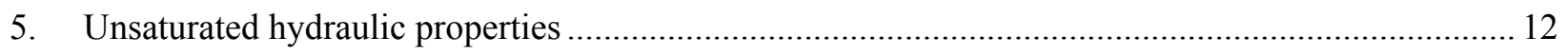

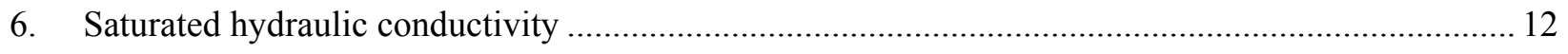

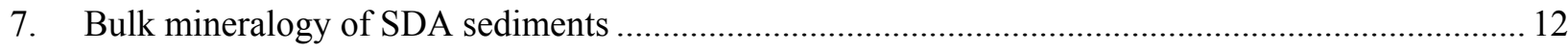




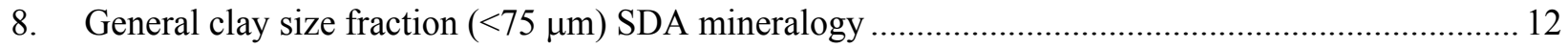

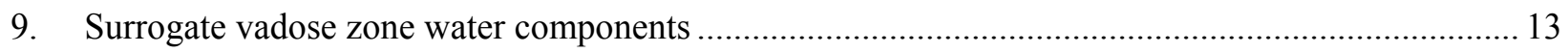

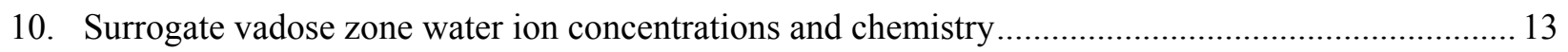

11. Average measured values of gas standards used for low- and high-range $\mathrm{CO}_{2}$ measurement corrections.

12. Tensiometer pressure transducer calibration expressions .......................................................... 22

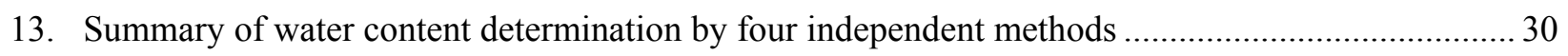

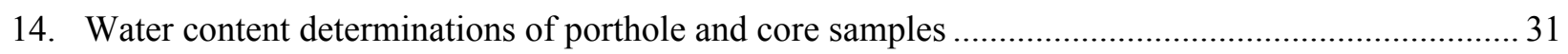

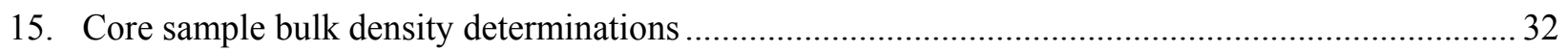

16. Water chemistry and pore gas $\mathrm{CO}_{2}$ concentration profiles relative to $\mathrm{Br}^{-}$and isotope injections ....... 38

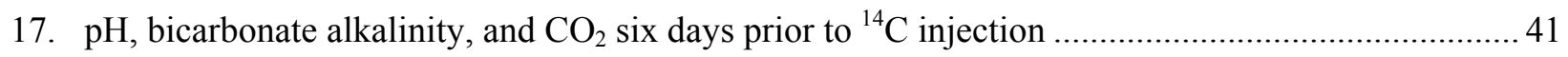

18. Average $\mathrm{pH}, \mathrm{CO}_{2}, \mathrm{O}_{2}$, and bicarbonate profiles during transport study …...................................... 41

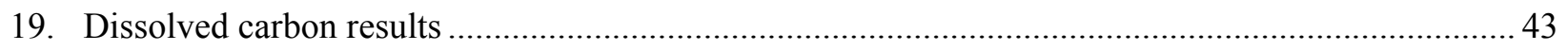

20. Transport parameters used to model $\mathrm{SF}_{6}$ and $\mathrm{Br}^{-}$tracer breakthrough .......................................... 49

21. Summary of transport parameters determined from CXTFIT2 analysis of conservative

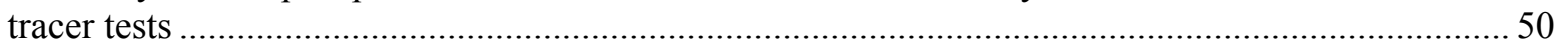

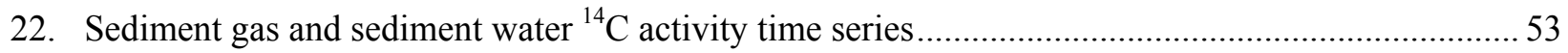

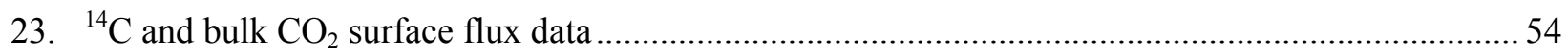

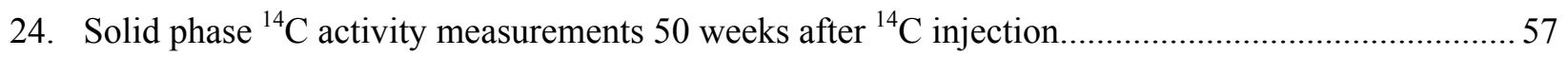

25. Aqueous, gas, and solid phase ${ }^{14} \mathrm{C}$ activity measurements at end of study ...................................5 58

26. ${ }^{14} \mathrm{C}$ activity injected, released, removed, and retained (mass balance determination) .......................59

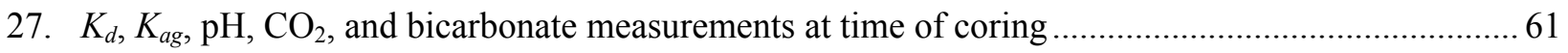




\section{Multiphase Carbon-14 Transport in a Near-Field-Scale Unsaturated Column of Natural Sediments}

\section{INTRODUCTION}

Since the 1950s, radioactive and hazardous wastes have been buried at the 40-hectare Subsurface Disposal Area (SDA) in the Idaho National Engineering and Environmental Laboratory's (INEEL) Radioactive Waste Management Complex (RWMC). Figure 1 shows the relative locations of the INEEL, SDA/RWMC, and the Snake River Plain aquifer. Wastes buried at the SDA include approximately 500 curries of carbon- $14\left({ }^{14} \mathrm{C}\right)$ in materials such as beryllium reflector blocks and reactor core pieces (Case et al. 2000, McCarthy et al. 2000). As the beryllium reflector blocks $\left(\sim 20 \%\right.$ of the total ${ }^{14} \mathrm{C}$ inventory) corrode, they release ${ }^{14} \mathrm{C}$ as carbon dioxide $\left({ }^{14} \mathrm{CO}_{2}\right)$. This released ${ }^{14} \mathrm{C}$ is the focus of a Comprehensive Environmental Response, Compensation, and Liability Act (CERCLA) risk assessment and a radiological performance assessment ordered by the Department of Energy. Current methods of assessing risk and performance assume, when considering the aquifer, that all the ${ }^{14} \mathrm{C}$ released will migrate downward, in a liquid and, when considering the atmosphere, that it will all migrate upward, as gas. This simplification ignores partitioning among solid, liquid, and gas phases in the unsaturated subsurface (vadose zone). While solid and liquid phase partitioning retard ${ }^{14} \mathrm{C}$ migration, gas phase partitioning is expected to increase vadose zone ${ }^{14} \mathrm{C}$ mobility (Thorstenson et al. 1983). Thus, a more realistic prediction of vadose zone ${ }^{14} \mathrm{C}$ migration would include multiphase partitioning and the effect of geochemistry on partitioning and transport.

Our primary goal was to define the relationships between multiphase partitioning and migration of

${ }^{14} \mathrm{C}$ within unsaturated SDA sediments at spatial-temporal scales sufficient to observe partitioning effects. A secondary goal was to identify the complications in operating an unsaturated flow column at a scale approaching that of the field (i.e., meso scale). We examined the movement of ${ }^{14} \mathrm{C}$, water, gas, and conservative tracers in a meso-scale column of sediment similar to that used as SDA backfill, a playa-derived calcareous silty-clay. Our results will be used to calibrate contaminant transport models used to estimate ${ }^{14} \mathrm{C}$ inventories, assess risk, and evaluate remedial alternatives at active and inactive SDA waste burial sites. While these experimental conditions are directly applicable to the vadose zone environment at the SDA, the sediment used is largely typical of the arid western United States. Therefore, our findings may be useful for other vadose zone waste disposal sites where ${ }^{14} \mathrm{C}$ risk assessments are performed.

This report describes our experimental procedures, presents the results, and estimates ${ }^{14} \mathrm{C}$ specific factors, such as aqueous/gas $\left(K_{\mathrm{ag}}\right)$ and aqueous/solid $\left(K_{d}\right)$ partitioning parameters, as well as factors that describe more general controls on the advective and diffusive transport of aqueous and gas phase contaminants. 


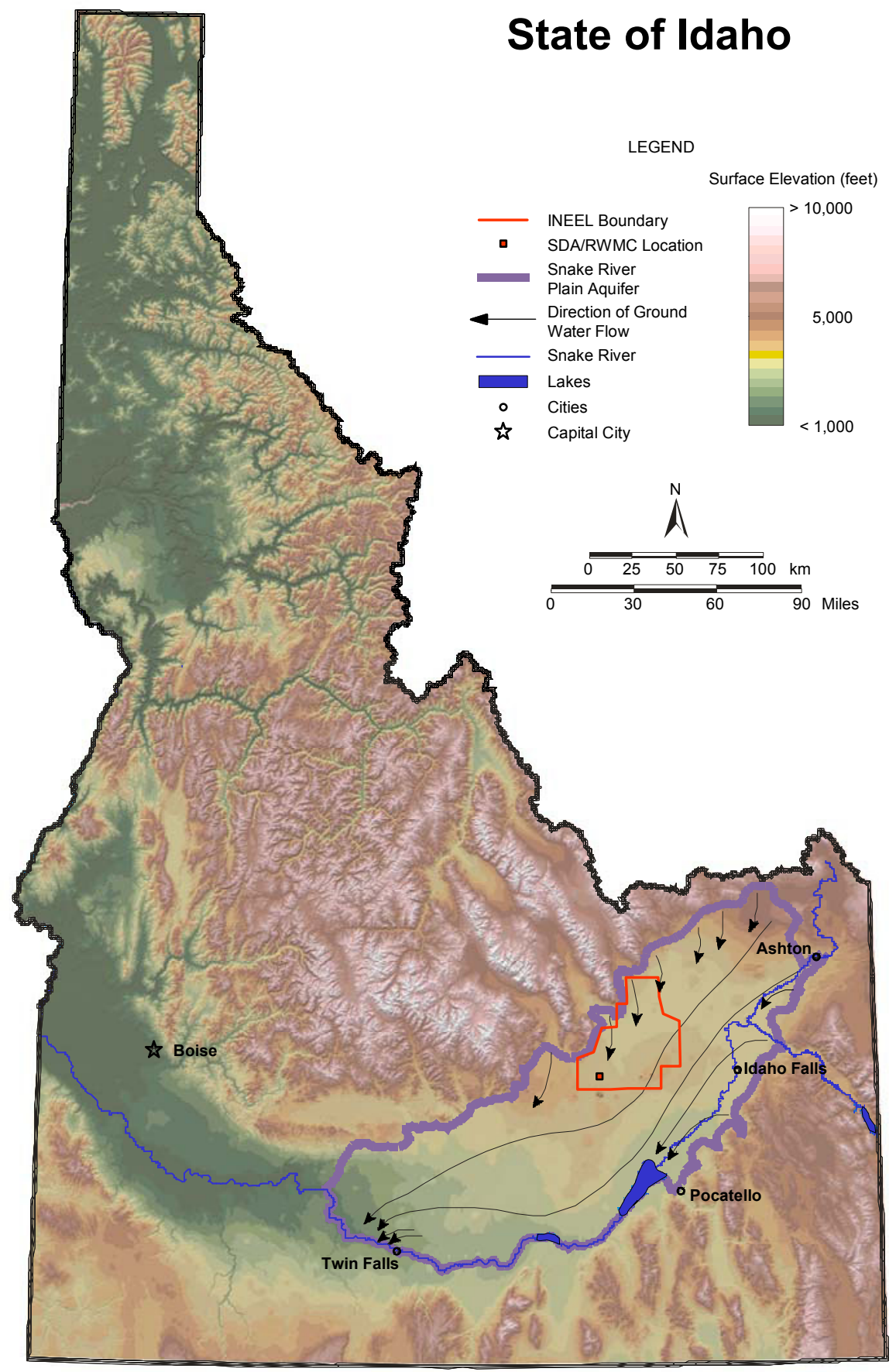

Figure 1. Relative locations of the INEEL, SDA/RWMC, and Snake River Plain aquifer. 


\section{EXPERIMENTAL DESIGN}

We built a meso-scale column of SDA sediment and examined the movement of ${ }^{14} \mathrm{C}$, water, gas, and conservative tracers. The column size $-2.6-\mathrm{m}$ high by $0.9-\mathrm{m}$ diameter - was large enough to replicate field conditions while limiting the time required for data generation. We expected it to achieve proposed saturation conditions $(\sim 70 \%)$ in 300 to 500 days. Using SDA sediments (playa-derived calcareous silty-clay) was not only mineralogically relevant, it also assured an active microbial community producing a sediment-gas $\mathrm{CO}_{2}$ profile commensurate with vadose zone conditions at the SDA.

The column's ends were sealed to form an enclosed headspace over the sediment surface; ambient air was circulated through the headspace to prevent accumulation of $\mathrm{CO}_{2}$ and provide a constant concentration boundary condition at the sediment surface. Surrogate vadose zone water was applied to 24 evenly-distributed locations across the sediment surface. Downward unsaturated flow was maintained by vacuum applied to suction lysimeters located at the bottom of the column.

The column was instrumented in 30-cm intervals along its length with pore gas and pore water sampling ports. Four data and sample collection systems were used. The first system monitored hydrologic and temperature profiles. The second measured $\mathrm{pH}$ under nitrogen gas as water samples were taken (i.e., in situ $\mathrm{pH}$ ). The third, an automated system, measured $\mathrm{CO}_{2}$ and $\mathrm{O}_{2}$ concentrations of ambient, headspace, and sediment gases. The fourth system captured headspace $\mathrm{CO}_{2}$ gas for ${ }^{14} \mathrm{C}$ analysis.

As these systems indicated the approach of hydraulic and geochemical steady state, we performed experiments to estimate characteristics of the unsaturated flow system that affect ${ }^{14} \mathrm{C}$ transport, including average linear seepage velocity, dispersivity, and aqueous- and gas-phase tortuosity. These experiments included an infiltration test; injections of a highly insoluble gas tracer (sulfur hexafluoride, $\mathrm{SF}_{6}$ ), both before water infiltration and after achieving steady-state hydraulic flow; and injection of conservative liquid tracers (tritium and lithium bromide) after reaching steady-state hydraulic flow. We injected $1610( \pm 16)$ microCi of radiolabeled bicarbonate $\left({ }^{14} \mathrm{C}\right)$ into the column and monitored it for 350 days, after which we took core samples and measured solid phase ${ }^{14} \mathrm{C}$ sorption. A timeline of key events, relative to the start of water infiltration on July 11, 2001, is given in Figure 2. Boundary conditions for this work are listed below.

Effective column height $\quad 2.44 \mathrm{~m}$ (between water application and extraction)

Headspace

$0.2 \mathrm{~m}^{3}$; air was circulated through the headspace at $\sim 7 \mathrm{~L} \mathrm{~min}^{-1}$

Influent water

Average applied hydraulic flux of $0.93 \mathrm{~L} \mathrm{day}^{-1}$ during ${ }^{14} \mathrm{C}$ tracer study; applied at 24 surface locations; average calculated seepage velocity of $\sim 0.5 \mathrm{~cm}$ day $^{-1}$ sustained by suction lysimeters at extraction point

Effluent water

Average extracted hydraulic flux of $0.74 \mathrm{~L} \mathrm{day}^{-1}$ during ${ }^{14} \mathrm{C}$ tracer study 


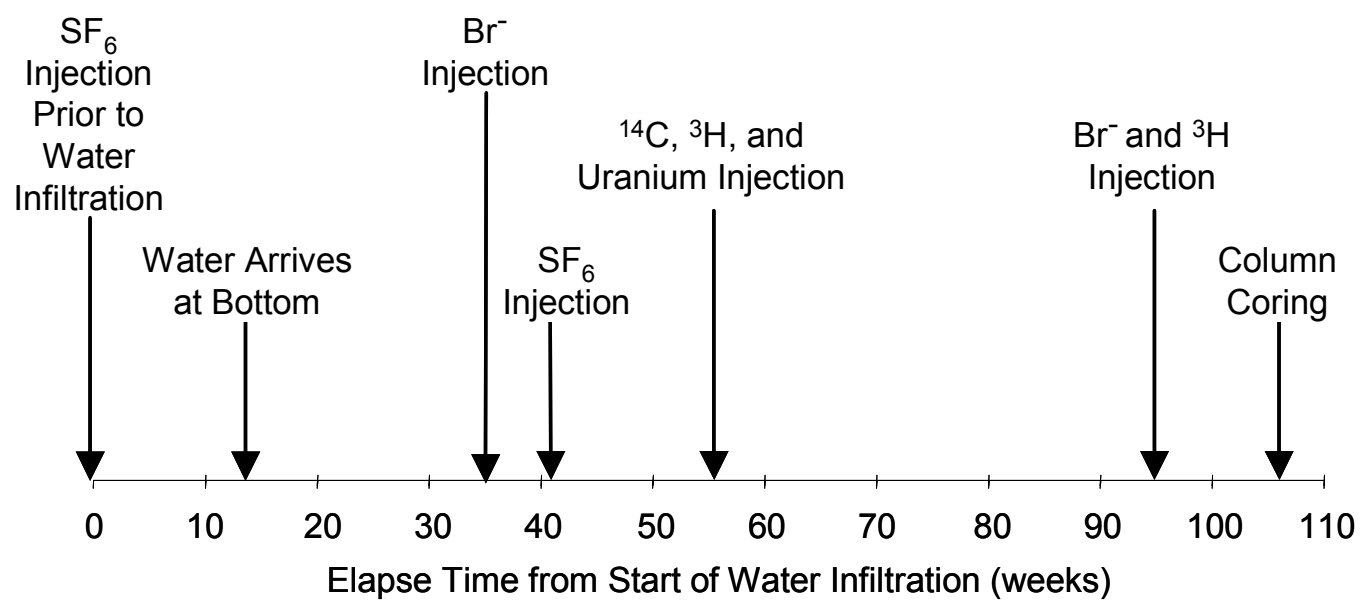

Figure 2. Timeline of key events in this research. 


\section{MATERIALS AND METHODS}

This chapter describes each component of the study, from construction of the column to monitoring of injected tracers. We begin with column construction and packing, which includes the location of sampling, sensing, and injecting devices as well as soil characteristics. Next, we describe the methods used to prepare surrogate vadose zone water and the water and gas analysis methods. Then the process and systems used to establish and maintain unsaturated flow are described, followed by the methods used to monitor and determine soil water content. Finally, we outline tracer preparation, injection, and analysis. (The relative accuracies of analytic methods described in this chapter are given in Appendix A.)

\subsection{Column Construction and Packing}

Two 2.9-m high by 0.9-m diameter stainless steel (ASTM 240) cylinders were constructed in 1998. ${ }^{\text {a }}$ Our experiment used one of these cylinders, which was located in the INEEL Engineering Demonstration Facility (IEDF). In 1999, the cylinder was packed with sediment from the Long Term Corrosion Test berm at the SDA that is representative of sediments used to backfill pits and trenches at the SDA. Sensors and sampling devices were placed in the sediment column during packing. The column was not used from 1999 to 2001. During this time, the headspace was continually purged with atmospheric air to maintain the exchange of atmospheric $\mathrm{O}_{2}$ and microbially-generated $\mathrm{CO}_{2}$ to and from the sediment, respectively. This study began in July 2001.

To facilitate homogenous packing of the cylinder, large fragments of plant roots were removed by passing the sediment through a 13-mm sieve. Only organic debris was removed, so the column represented SDA surface sediment particle sizes and mineral composition. The sieved sediment was placed in 208-L steel drums. The drums were sealed, then transported to the meso-scale column test site (IF-IEDF-E4, Bldg. 657). Air-dry sediment was transferred from the drums to the experimental cylinder using 19-L plastic buckets. The weight of sediment in each bucket was recorded. The sediment was manually compacted in $\sim 15-\mathrm{cm}$ lifts. Lift surfaces were scarified to avoid layering or segregation of soil by particle size prior to placing the next lift. Bulk density was calculated for the weight and volume of each lift. Sediment mass and bulk densities are presented in Table 1. In situ sensors and sampling devices were positioned on scarified surfaces; their tubes and/or wires were passed through adjacent cylinder portholes, which were sealed prior to placing the next lift. Portholes not used by devices were used as access for extracting sediment samples. The cylinder was filled to within $30.5-\mathrm{cm}$ of the top flange, resulting in a 2.6-meter sediment column. A $0.2 \mathrm{~m}^{3}$ headspace was created by sealing a $1.9-\mathrm{cm}$ thick Plexiglas cover to the cylinder's top flange with silicone adhesive and C-clamps. Gas ports were positioned on opposing sides to allow atmospheric air and head gasses to mix prior to being evacuated from the headspace. The column was leak tested by applying $\sim 34 \mathrm{kPa}$ of gas pressure to the headspace. The column leaked down to $\sim 14 \mathrm{kPa}$ over a 10-hour period. Pictures of the column just after packing and during the study are given in Figure 3.

\subsubsection{Device and Instrument Placement}

The column was fitted with one influent water array, at the column surface, and two tracer injection arrays below the surface. Each array consists of a bundle of 24 stainless steel tubes (1.6-mm ID) that pass into the column through a $7-\mathrm{cm}$ long stainless steel port $(2.54-\mathrm{cm}$ ID). The space between the tube bundle and the port's inside surface was sealed with epoxy. Within the column, the tubes spread out in a plane

a. LMITCO design drawing 454090, Lysimeter Mechanical Design Vessel Assembly. 
Table 1. Column packing mass and bulk densities.

\begin{tabular}{|c|c|c|c|}
\hline Column Level & $\begin{array}{l}\text { Mass of Dry Sediment in } \\
\text { Lift, adjusted for moisture } \\
(\mathrm{kg})\end{array}$ & $\begin{array}{l}\text { Dry Bulk Density } \\
\qquad\left(\mathrm{g} \mathrm{cm}^{-3}\right)\end{array}$ & $\begin{array}{c}\text { Average Lift Dry Bulk } \\
\text { Density } \\
\left(\mathrm{g} \mathrm{cm}^{-3}\right) \\
\end{array}$ \\
\hline \multirow[t]{2}{*}{1} & 128.1 & 1.28 & \multirow[t]{2}{*}{1.39} \\
\hline & 150.5 & 1.50 & \\
\hline \multirow[t]{2}{*}{2} & 137.9 & 1.38 & \multirow[t]{2}{*}{1.20} \\
\hline & 102.6 & 1.03 & \\
\hline \multirow[t]{2}{*}{3} & 125.2 & 1.25 & \multirow[t]{2}{*}{1.26} \\
\hline & 126.7 & 1.27 & \\
\hline \multirow[t]{2}{*}{4} & 118.7 & 1.19 & \multirow[t]{2}{*}{1.28} \\
\hline & 136.7 & 1.37 & \\
\hline \multirow[t]{2}{*}{5} & 123.9 & 1.24 & \multirow[t]{2}{*}{1.26} \\
\hline & 127.6 & 1.35 & \\
\hline \multirow[t]{2}{*}{6} & 135.2 & 1.57 & \multirow[t]{2}{*}{1.46} \\
\hline & 156.8 & 1.38 & \\
\hline \multirow[t]{2}{*}{7} & 137.9 & 1.29 & \multirow[t]{2}{*}{1.34} \\
\hline & 129.6 & 1.31 & \\
\hline \multirow[t]{2}{*}{8 to surface } & 130.9 & 1.22 & 1.26 \\
\hline & 273.6 & 1.36 & 1.36 \\
\hline Average Lift Density & & & $1.31( \pm 0.05)$ \\
\hline Total Sediment Mass & 2241.9 & & \\
\hline
\end{tabular}

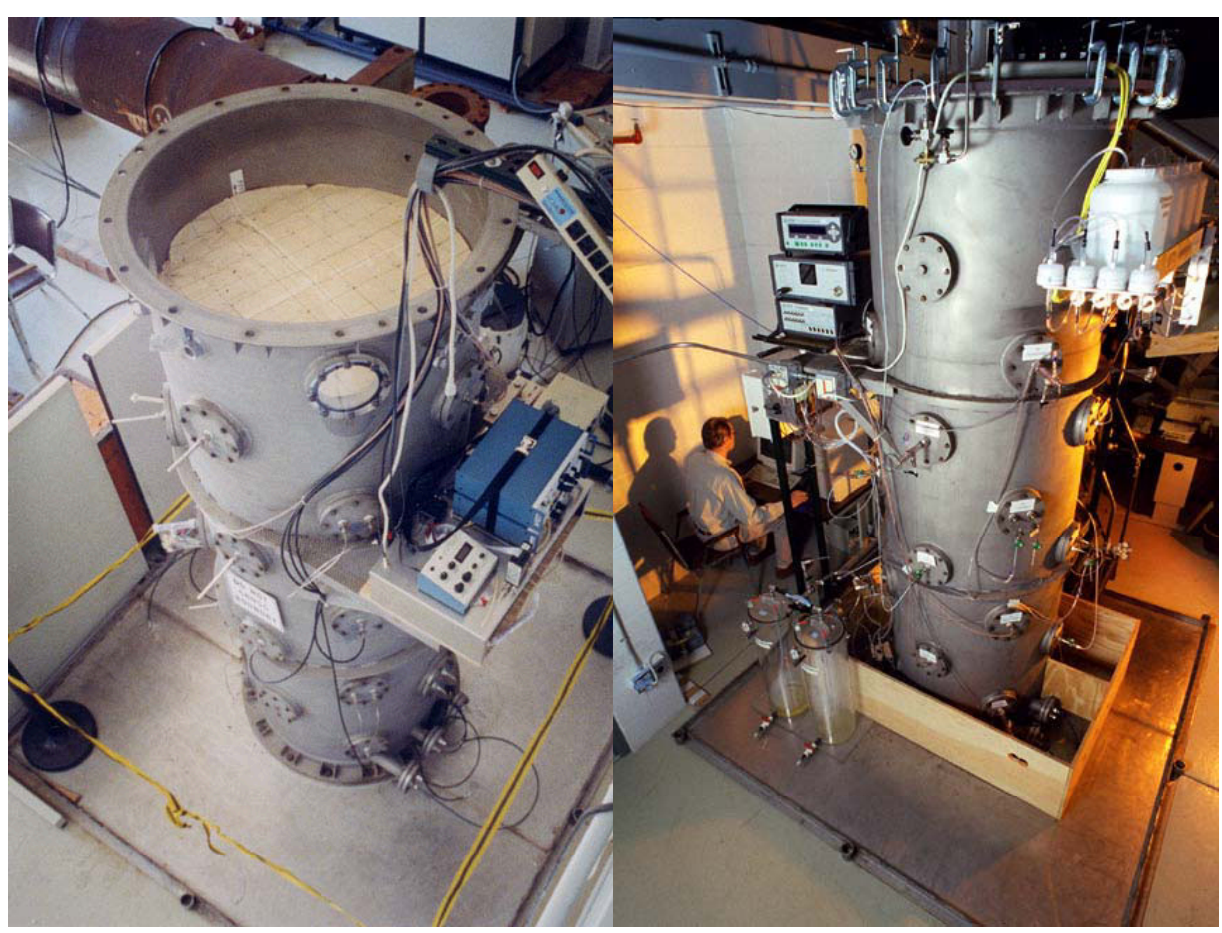

Figure 3. Meso-scale column after packing (left) and during experiment (right). 
parallel to the sediment surface. The tube ends are placed as a grid with minimum intersection separation distances of $15 \mathrm{~cm}$. The end point (i.e., delivery point) of each tube was recorded relative to numbers affixed to the tube-end extending outside of the column (see Figure 4).

The column was fitted with various devices for monitoring conditions and extracting samples. Drawings of the column with the vertical and circumferential placement of devices are given in Figures 5 and 6; the positions of each type of device are listed in Table 2.

\subsubsection{Sediment Characteristics}

To a large extent, the physical, mineral, and biological characteristics of a soil control transport. This section provides a brief discussion of the hydraulic characteristic of the sediment used in this study along with a general mineralogy description of surface sediments common to INEEL's SDA.

3.1.2.1 Hydraulic Properties. Water content, bulk density, and porosity determinations were performed, at the INEEL, for 265 sediment samples taken from 16 of the 18 drums of sediment used to pack the column. Standard methods and laboratory procedures for volume and mass measurements were used to determine water contents (ASTM D 2216-98) and bulk densities. Porosity was calculated using an average bulk density of $1.31 \mathrm{~g} \mathrm{~cm}^{-3}$ and an assumed particle density of $2.65 \mathrm{~g} \mathrm{~cm}^{-3}$. Independent laboratory ${ }^{\mathrm{b}}$ determinations of water content, bulk density, porosity, saturated drainage characteristics,

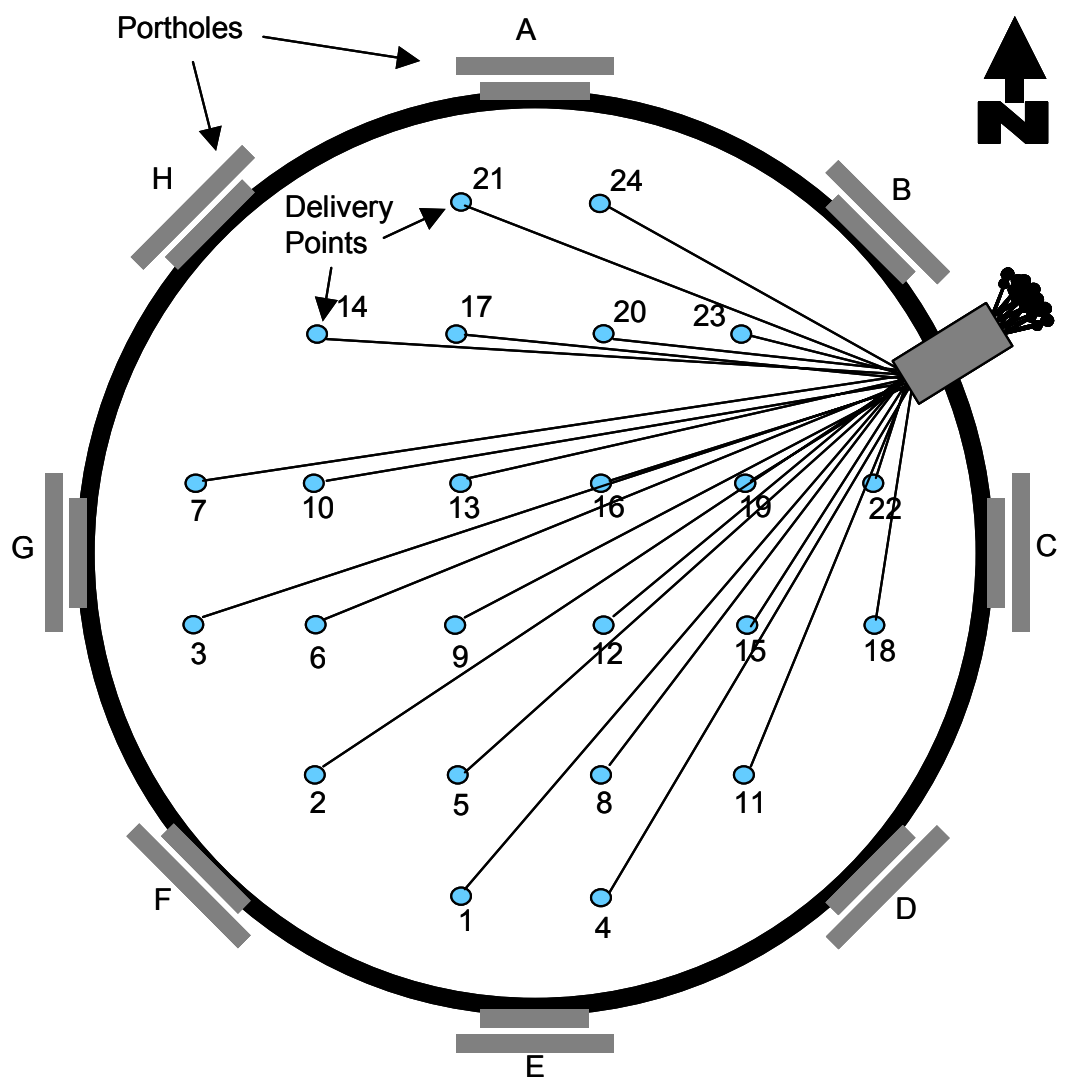

Figure 4. Delivery point locations for injection arrays (plan view). Letters A through H indicate geographic location.

b. D. B. Stevens, Albuquerque, N.M., January 22, 2002. 

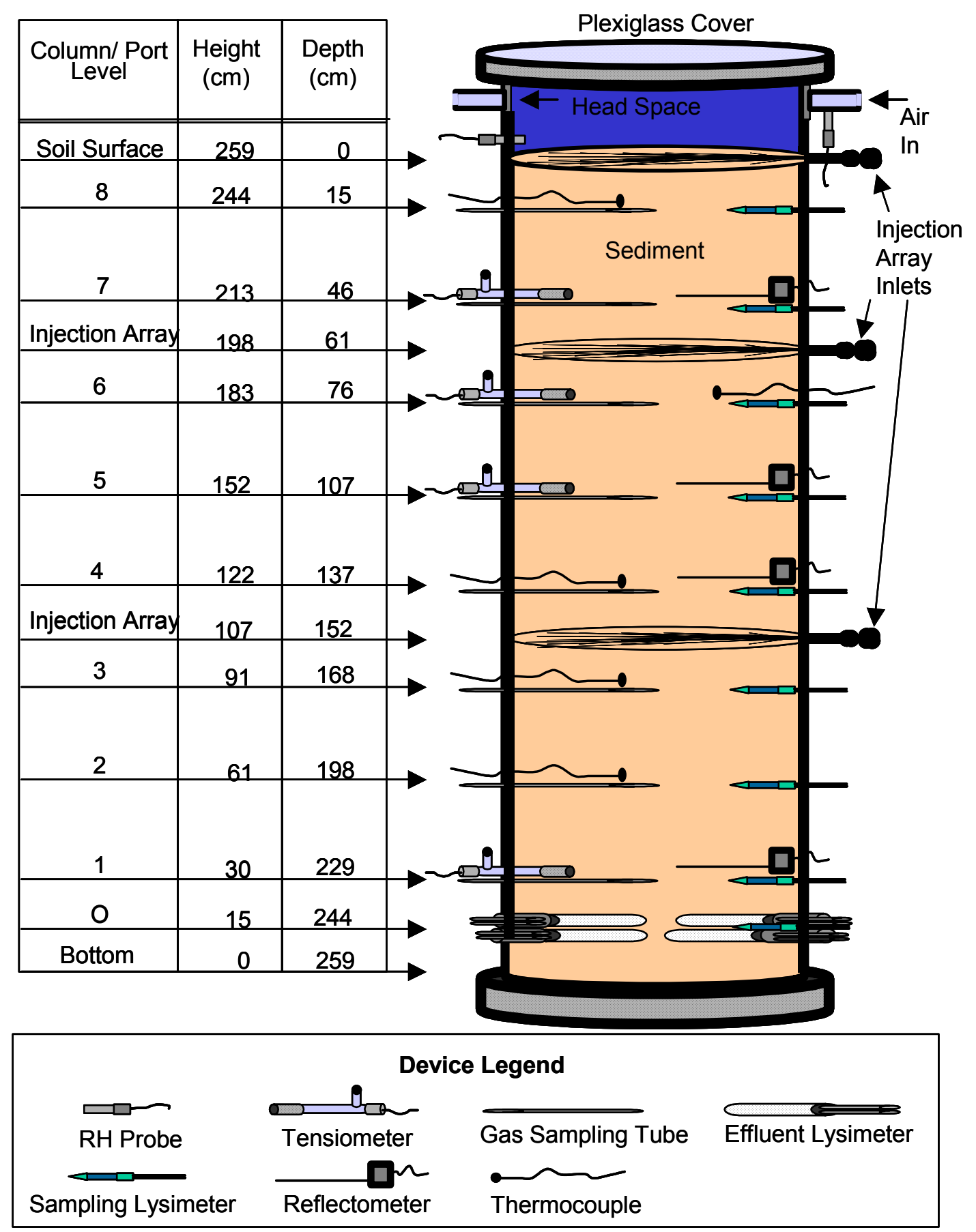

Figure 5. Elevation view of device placement. Note, the absolute bottom is $259.08-\mathrm{cm}$ below the column surface. While level numbers indicate distance upward from the absolute bottom, Level " 0 " is actually at the mid-point between Level 1 and the absolute bottom. 

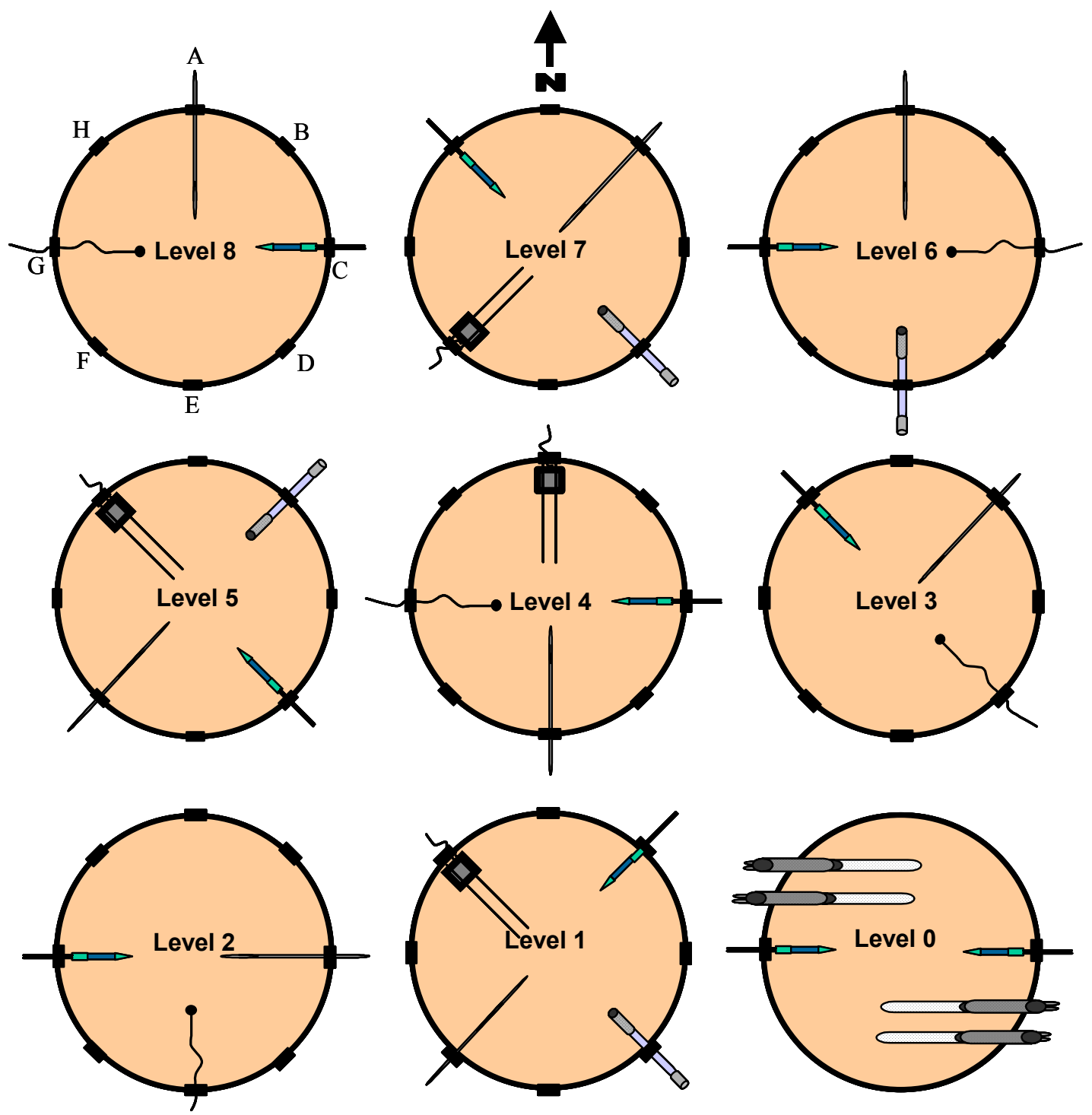

Figure 6. Placement of monitoring and sampling devices at each level (plan view). Letters A through $\mathrm{H}$ indicate geographic orientation. Effluent lysimeter positions are given in North-South and East-West coordinates. Note, although level numbers indicate distance upward from the absolute bottom, Level " 0 " is actually at the mid-point between Level 1 and the absolute bottom. See Figure 5 legend for device identification. 
Table 2. Measurement of device locations.

\begin{tabular}{|c|c|c|c|}
\hline Sensor/Sampler Type & $\begin{array}{l}\text { Column Level } \\
\text { (approximate } \\
\text { distance from } \\
\text { bottom in feet) }\end{array}$ & $\begin{array}{l}\text { Depth Below Column } \\
\text { Surface } \\
(\mathrm{cm})\end{array}$ & $\begin{array}{c}\text { Distance from } \\
\text { Vertical Axis to } \\
\text { Device } \\
\text { Mid-Point } \\
(\mathrm{cm})\end{array}$ \\
\hline $\begin{array}{l}\text { Tensiometers } \\
\text { (Soilmoisture Equip. Corp., } \\
\text { Model 2710A) }\end{array}$ & $7,6,5$, and 1 & $\begin{array}{l}45.72,76.20,106.68 \text {, and } \\
228.60\end{array}$ & $\sim 30$ \\
\hline $\begin{array}{l}\text { Water Content Reflectometers (TDRs) } \\
\text { (Campbell Scientific, Model 615) }\end{array}$ & $7,5,4$, and 1 & $\begin{array}{l}45.72,106.68,137.16, \\
\text { and } 228.60\end{array}$ & $\sim 27$ \\
\hline $\begin{array}{l}\text { Thermocouples } \\
\text { (common T-type) }\end{array}$ & $8,6,4,3$, and 2 & $\begin{array}{l}\text { 15.24, 76.20, 137.16, } \\
167.64, \text { and } 198.12\end{array}$ & $\sim 15$ \\
\hline Soil Sampling Portholes & 2,3 , and 8 & $\begin{array}{l}198.12,167.64, \text { and } \\
15.24\end{array}$ & \\
\hline $\begin{array}{l}\text { Lysimeters, Pore Water Sampling } \\
\text { (Soil Measurement Systems, Model } \\
\text { SW-074) }\end{array}$ & $\begin{array}{l}8,7,6,5,4,3,2, \\
1, \mathrm{OC}, \text { and } \mathrm{OG}\end{array}$ & $\begin{array}{l}15.24,45.72,76.20 \\
106.68,137.16,167.64, \\
198.12,228.60,243.84, \\
\text { and } 243.84\end{array}$ & $\sim 35$ \\
\hline $\begin{array}{l}\text { Effluent Lysimeters } \\
\text { (Soilmoisture Equip. Corp., } \\
\text { Model 1922) }\end{array}$ & $\begin{array}{l}\text { O } \\
(6 \text {-in above the } \\
\text { bottom })\end{array}$ & 4 at 243.84 & $\begin{array}{l}2 \text { at } \sim 20 \text { and } \\
2 \text { at } \sim 30\end{array}$ \\
\hline $\begin{array}{l}\text { Gas Samplers } \\
\text { (common stainless steel tubing w/ } \\
\text { perforations and nylon filter sleeves.) }\end{array}$ & $\begin{array}{l}8,7,6,5,4,3,2, \\
\text { and } 1\end{array}$ & $\begin{array}{l}15.24,45.72,76.20 \\
106.68,137.16,167.64 \\
198.12, \text { and } 228.60\end{array}$ & $\sim 8$ \\
\hline
\end{tabular}

unsaturated hydraulic properties (i.e., van Genuchten parameters), and saturated hydraulic conductivity were performed for three additional samples. Two of these samples were taken from the drums and one, a $6.0-\mathrm{cm}$ high by $5.7-\mathrm{cm}$ diameter core sample, was taken from the top of the sediment column upon completion of packing. Results of gravimetric (weight \%) and volumetric (vol\%) water contents, bulk density, and porosity determinations are given in Table 3. Water potential-moisture content relationships (i.e., saturated drainage characteristics), unsaturated hydraulic property, and saturated hydraulic conductivity determinations are given in Tables 4,5 , and 6 , respectively.

3.1.2.2 Mineralogy. The playa-derived sediments used in this study are representative of those used to cover the wastes buried at the SDA. In the Unified Soil Classification System, these sediments are classified as calcareous silty-clays. The bulk and clay size fraction mineralogy of SDA sediments have been analyzed by x-ray diffraction at the New Mexico Bureau of Mines and Mineralogical Resources; the results are given in Tables 7 and 8. Mixed smectite-illite constitutes $50-70 \%$ of the clay minerals, and kaolinite, illite, and Ca-rich smectite comprise the remaining fraction.

c. Socorro, NM, USA. 
Table 3. Measurement of initial (packing) water content, dry bulk density, wet bulk density, and porosity at time of column packing.

\begin{tabular}{|c|c|c|c|c|c|}
\hline \multirow[b]{2}{*}{ Sample ID } & \multicolumn{2}{|c|}{$\begin{array}{l}\text { Initial (packing) Moisture } \\
\text { Content }\end{array}$} & \multirow{2}{*}{$\begin{array}{c}\text { Dry Bulk } \\
\text { Density } \\
\left(\mathrm{g} \mathrm{cm}^{-3}\right)\end{array}$} & \multirow{2}{*}{$\begin{array}{l}\text { Wet Bulk } \\
\text { Density } \\
\left(\mathrm{g} \mathrm{cm}^{-3}\right)\end{array}$} & \multirow{2}{*}{$\begin{array}{c}\text { Calculated } \\
\text { Porosity } \\
(\%)\end{array}$} \\
\hline & $\begin{array}{c}\text { Gravimetric } \\
\text { (weight \%) }\end{array}$ & $\begin{array}{l}\begin{array}{l}\text { Volumetric } \\
(\text { vol } \%)\end{array} \\
\end{array}$ & & & \\
\hline INEEL Averages, $n=265$ & - & 14.2 & 1.31 & 1.46 & 51.0 \\
\hline \multicolumn{6}{|c|}{ Independent Lab } \\
\hline Drum $\# 1, \mathrm{n}=1$ (repack) & 8.7 & 12.7 & 1.46 & 1.59 & 44.9 \\
\hline Drum $\# 2, n=1$ (repack) & 11.5 & 16.3 & 1.42 & 1.58 & 46.5 \\
\hline Core Sample, $\mathrm{n}=1$ (not repacked) & 10.9 & 15.6 & 1.43 & 1.59 & 46.0 \\
\hline
\end{tabular}

Table 4. Sediment drainage characteristics, from saturation.

\begin{tabular}{|c|c|c|}
\hline Sample ID & $\begin{array}{l}\text { Water Potential } \\
\text { (-cm water) }\end{array}$ & $\begin{array}{c}\text { Moisture Content } \\
(\text { vol\%) }\end{array}$ \\
\hline \multirow{7}{*}{$\begin{array}{l}\text { Drum \#1, n=1 } \\
\text { (repack) }\end{array}$} & 0 & 42.8 \\
\hline & 22 & 42.6 \\
\hline & 52 & 42.2 \\
\hline & 151 & 36.0 \\
\hline & 510 & 26.9 \\
\hline & 17031 & 15.5 \\
\hline & 851293 & 5.9 \\
\hline \multirow{7}{*}{$\begin{array}{l}\text { Drum \#2, n=1 } \\
\text { (repack) }\end{array}$} & 0 & 50.7 \\
\hline & 22 & 50.5 \\
\hline & 52 & 49.8 \\
\hline & 151 & 44.1 \\
\hline & 510 & 30.4 \\
\hline & 17235 & 13.6 \\
\hline & 851293 & 5.5 \\
\hline \multirow{7}{*}{$\begin{array}{l}\text { Core Sample, } \mathrm{n}=1 \\
\text { (not repacked) }\end{array}$} & 0 & 50.2 \\
\hline & 22 & 49.7 \\
\hline & 52 & 48.5 \\
\hline & 151 & 43.6 \\
\hline & 510 & 31.4 \\
\hline & 10096 & 18.7 \\
\hline & 851293 & 5.6 \\
\hline
\end{tabular}


Table 5. Unsaturated hydraulic properties (i.e., van Genuchten parameters).

\begin{tabular}{|c|c|c|c|c|}
\hline Sample ID & $\begin{array}{c}\text { Alpha } \\
\left(\mathrm{cm}^{-1}\right)\end{array}$ & $\begin{array}{c}\mathrm{n} \\
\text { (dimensionless) }\end{array}$ & $\theta_{\mathrm{r}}$ & $\theta_{\mathrm{s}}$ \\
\hline Drum \#1 (repack) & 0.0122 & 1.2311 & 0.0165 & 0.4387 \\
\hline Drum \#2 (repack) & 0.0068 & 1.3953 & 0.0493 & 0.5155 \\
\hline Core Sample (not repacked) & 0.0103 & 1.2342 & 0.0000 & 0.5109 \\
\hline
\end{tabular}

Table 6. Saturated hydraulic conductivity.

\begin{tabular}{|c|c|}
\hline Sample ID & $\begin{array}{c}\mathrm{K}_{\mathrm{sat}} \\
\left(\mathrm{cm} \mathrm{sec}^{-1}\right)\end{array}$ \\
\hline Drum \#1 (repack) & 0.000025 \\
\hline Drum \#2 (repack) & 0.000041 \\
\hline Core Sample (not repacked) & 0.000040 \\
\hline
\end{tabular}

Table 7. Bulk mineralogy of SDA sediments.

\begin{tabular}{|l|c|}
\hline \multicolumn{1}{|c|}{ Mineral } & Weight Percent \\
\hline Quartz & 50 to 75 \\
\hline Plagioclase and K-feldspar & 10 to 25 \\
\hline Olivine and Pyroxene & $<5$ \\
\hline Calcite & $<5$ \\
\hline Iron & $<5$ \\
\hline Clay Minerals (primarily mixed smectite-illite, some kaolinite) & 10 to 20 \\
\hline
\end{tabular}

Table 8 . General clay size fraction $(<75 \mu \mathrm{m})$ SDA mineralogy.

\begin{tabular}{|l|l|}
\hline \multicolumn{1}{|c|}{ Mineral } & Weight Percent \\
\hline Quartz & 40 to 55 \\
\hline Plagioclase and K-feldspar & 5 to 10 \\
\hline Calcite & 5 to 10 \\
\hline Clay Minerals & 30 to 45 \\
\hline Iron Oxides & 5 \\
\hline Gypsum and Other Common Minerals & Trace amounts $(<5)$ \\
\hline
\end{tabular}




\subsection{Water Flow}

\subsubsection{Water Preparation and Composition}

A surrogate vadose zone water was formulated to approximate the composition of rainwater with elevated dissolved solids due to concentration by infiltration. We prepared the water by adding accurately weighed $(+0.001 \mathrm{mg})$ reagents to deionized water, see Table 9 . Ion concentrations, both measured and calculated from component amounts, are given in Table 10.

Initially, hydrochloric acid $(\mathrm{HCl})$ was used to adjust the influent water $\mathrm{pH}$ to $8.0( \pm 0.2)$. On December 1, 2001 ( Week 20), this practice was discontinued and influent water $\mathrm{pH}$ was allowed to equilibrate by atmospheric exposure. This exposure occurred while the water was standing in the containers that supplied the pumps.

The influent water was sterilized by autoclave prior to storage and use. The volume of water was measured before and after autoclaving to ensure no volume gain or loss.

Though populations and densities of natural soil microorganisms were expected to out-compete microorganisms introduced by influent water, the introduction of a "foreign" biological component could impact physical and/or chemical properties of the soil. Therefore, a cursory characterization and count of influent water microorganisms was performed. Microbes associated with water storage and delivery systems were evaluated using a Zeiss Epifluorescent microscope with DAPI stain. Relative viability

Table 9. Surrogate vadose zone water components.

\begin{tabular}{|l|c|}
\hline Compound & mg Added per L of Water \\
\hline $\mathrm{NaHCO}_{3}$ & 10.60 \\
\hline $\mathrm{MgCO}_{3}$ & 3.17 \\
\hline $\mathrm{CaCl}_{2}: 2 \mathrm{H}_{2} \mathrm{O}$ & 0.62 \\
\hline $\mathrm{CaSO}_{4}: 2 \mathrm{H}_{2} \mathrm{O}$ & 10.03 \\
\hline $\mathrm{KHCO}_{3}$ & 1.78 \\
\hline
\end{tabular}

Table 10. Surrogate vadose zone water ion concentrations and chemistry. ${ }^{\mathrm{a}}$

\begin{tabular}{|c|c|c|}
\hline Ion & $\begin{array}{l}\text { Calculated Concentration } \\
\left(\mathrm{mg} \mathrm{L}^{-1}\right)\end{array}$ & $\begin{array}{l}\text { Measured Concentration } \\
\left(\mathrm{mg} \mathrm{L}^{-1}\right)\end{array}$ \\
\hline $\mathrm{Na}^{+}$ & 2.90 & 2.7 \\
\hline $\mathrm{HCO}_{3}^{-}$ & 14.15 & 12.0 \\
\hline $\mathrm{Mg}^{+2}$ & 0.90 & 0.9 \\
\hline $\mathrm{Ca}^{+2}$ & 2.51 & 2.6 \\
\hline $\mathrm{Cl}^{-}$ & 0.30 & $1.5^{\mathrm{b}}$ \\
\hline $\mathrm{SO}_{4}^{-2}$ & 5.60 & 5.4 \\
\hline $\mathrm{K}^{+}$ & 0.7 & 0.7 \\
\hline
\end{tabular}


determinations were made using nutrient auger plates. A monoculture of rod-shaped microorganisms having single or double terminal lobes was observed in newly mixed water. The organisms, believed to be mold, were 2 to $3-\mu \mathrm{m}$ wide. They formed multi-cellular chains ranging in length from $5 \mu \mathrm{m}$, in newly mixed water, to $35 \mu \mathrm{m}$, after average storage time. The concentration of this organism was $\sim 1.8 \times 10^{5}$ organisms $\mathrm{mL}^{-1}$ of newly mixed water. During storage, additional filamentous and nonfilamentous organisms appeared in the water. The filamentous organisms were similar in size to the ones previously described and are believed to be mold or fungi. The nonfilamentous organisms are believed to be bacteria normally occurring in the environment. Auger plates of stored water produced statistically significant populations of microorganisms.

Water was delivered to the column surface using four banks of syringe pumps. Water entering each bank passed through a $1 \mathrm{GPH}$ ultraviolet-light water purifier (mean purifier residence time $\sim 40 \mathrm{~min}$ ). Prior to isotope injection, nutrient auger plates were inoculated with water taken downstream from each purifier and incubated at room temperature for 10 days. Three of the four purifiers produced no viable cells. Water taken from a fourth purifier produced one round fleshy-beige colony having a uniform-regular border. In consideration of these results and the potential atmospheric deposition of microorganisms into the relatively open system, it was determined that no additional or unique microorganisms were added to the sediment by the surrogate vadose zone water. It should be noted that irregular green mats $(10 \pm 2$-cm diameter) had colonized the column surface, around the water delivery points, at the time of isotope injection. At conclusion of this study, a community of photosynthesizing organisms had colonized $\sim 80 \%$ of the surface. These organisms did not appear to affect hydraulic permeability.

\subsubsection{Establishing and Maintaining Unsaturated Flow}

Application (infiltration) of water began on July 11, 2001 at 12:00 p.m. This date is used throughout the study as the primary reference point for elapse time calculations. Water was delivered to the column by four syringe pumps (Figure 7). Each pump had six $10-\mathrm{cm}^{3}$ polyethylene syringes with oneway valves, and each syringe delivered water to one surface point via the surface injection array. Using individual syringes assured precise delivery and even distribution of water to the column's surface. The four pumps were programmed to periodically deliver $\sim 29-\mathrm{mL}$ of water to the column surface. Initially, the pumps were set to an eight-minute pause interval, which delivered $\sim 5 \mathrm{~L} \mathrm{day}^{-1}$, to accelerate column wetting. As the wetting front approached the bottom of the column, the pause interval was increased to 41 minutes, delivering $\sim 1 \mathrm{~L} \mathrm{day}^{-1}$; this setting was used for the duration of the study. The mass flow rate was monitored through periodic weighing of the four water supply containers.

To maintain steady-state hydraulic flow, four suction lysimeters ${ }^{\mathrm{d}}$ were located $15 \mathrm{~cm}$ above the bottom of the column. Each lysimeter consisted of a $25.4-\mathrm{cm}$ long by $4.8-\mathrm{cm}$ diameter ceramic cup with a -1.0-bar air entry pressure and a $\sim 2-\mu \mathrm{m}$ pore size. As the wetting front approached the column bottom, water was added to the lysimeters to establish a hydraulic connection between the lysimeter and the surrounding media, then vacuum was slowly increased until flow was established. A vacuum system applied a constant suction to the four lysimeters, continually drawing water from them and collecting the effluent in a container. (Using a common vacuum source potentially allows higher flow rates from lysimeters with higher hydraulic permeability. Nonuniform flow was expected to abate within a relatively short distance from the lysimeters.) The effluent water container was periodically emptied and the average mass flow rate was calculated. Initially, lysimeter suction was increased to maintain equivalent influent and effluent flow rates (i.e., $\sim 1 \mathrm{~L}_{\text {day }}{ }^{-1}$ ). However, on occasion, this suction led to air entry events that perturbed pore gas $\mathrm{O}_{2}$ and $\mathrm{CO}_{2}$ concentrations. Therefore, we did not apply the hydraulic potential

d. Soilmoisture Equipment Corp., Goleta, CA, Model 1922. 


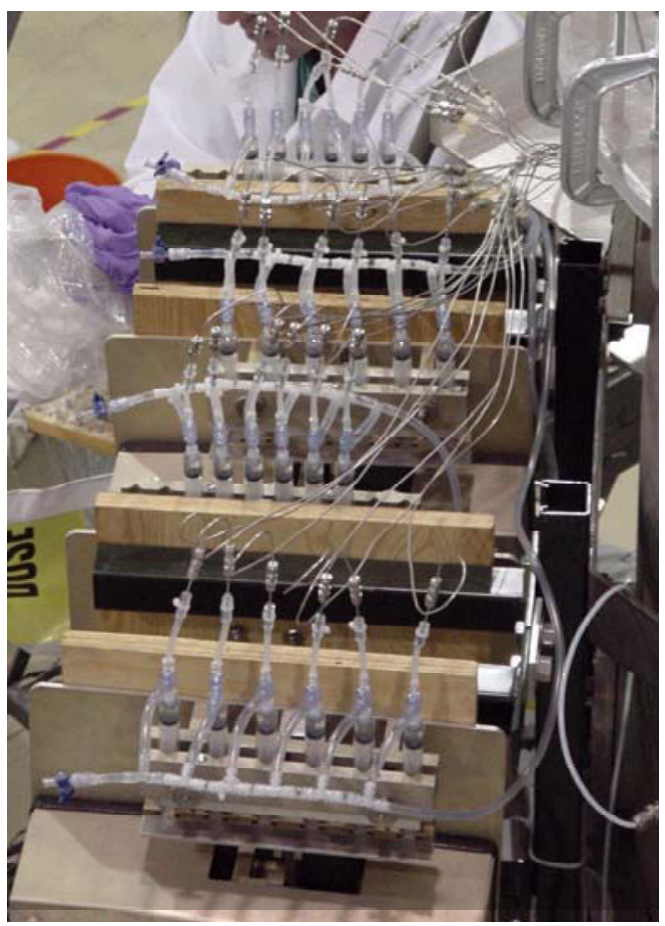

Figure 7. Syringe pump system for infiltration water delivery. Syringes and tubing are shown without pump motor housings.

necessary to maintain equivalent influent and effluent flows. Influent flow was not decreased to compensate for deficit effluent flow because decreased water content would have exacerbated the problem by increasing the lysimeter suction required to maintain equivalent influent and effluent flow. To avoid further pore gas perturbations, lysimeter suction was set at approximately $-750-\mathrm{cm}$ of total hydraulic head, which is just under the apparent air entry value (approximately $-850-\mathrm{cm}$ of total hydraulic head), for the duration of the study. This suction produced an average effluent flow rate of $\sim 0.7 \mathrm{~L} \mathrm{day}^{-1}$, resulting in an inequality of influent and effluent flows. This inequality initially caused oxygen concentration to decline at the bottom of the column. To prevent anaerobic conditions, water was periodically removed from the bottom using the sampling lysimeters at Level 0 . These extractions caused oscillations of matric tension. To avoid potential interference with tracer migration, the supplementary water extractions were discontinued and water content was allowed to equilibrate to the applied hydraulic potential.

\subsection{Sampling and Analysis}

\subsubsection{Water}

Sediment water samples were periodically collected using sampling lysimeters. ${ }^{\mathrm{e}}$ These lysimeters, constructed of stainless steel, have semi-porous walls through which water is drawn into the lysimeter under vacuum ( -0.7 bar published bubbling pressure and an observed maximum pressure of -0.5 bar). Two stainless steel tubes, with shutoff values, extend from the lysimeters to the column's exterior (Figure 8). To extract samples, vacuum was applied, the shutoff values were closed, and sediment water entered until lysimeter vacuum was equilibrated with matric tension. Water samples were extracted under nitrogen gas. This was accomplished by venting one of the two lysimeter tubes to a Tedlar bag containing

e. Soil Measurement Systems, Tucson, AZ. Model SW-074. 


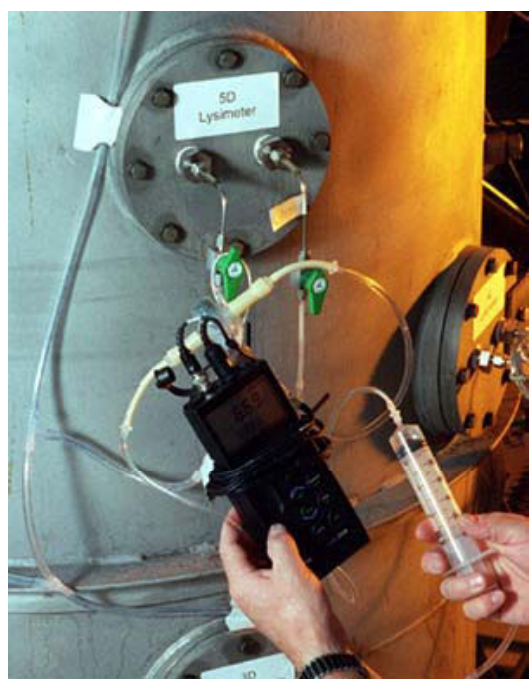

Figure 8. Pore water $\mathrm{pH}$ measurement using inline electrode. Stainless steel lysimeter tubing and shut off valves are shown extending from the column.

nitrogen gas and withdrawing the sample from the remaining tube using a syringe. The horizontal lysimeter orientation permitted the use of light suction for sample extraction. After sample extraction, shutoff valves were closed and the lysimeters were left containing nitrogen gas at neutral pressure.

3.3.1.1 Aqueous Species. Anion and metal analyses of water sample used ion chromatography (IC) and inductively coupled plasma (ICP) methods, respectively. The first three suites of water samples (collected in Weeks 26, 34, and 51) were analyzed at the INEEL Research Center (IRC) using a Dionex series 4500i IC and a Thermo Jarrell Ash IRIS Advantage series ICP. Water samples collected after isotope injection were analyzed at the INEEL Idaho Nuclear Technology and Engineering Center's (INTEC) laboratory. At INTEC, samples were analyzed using a Dionex IC ${ }^{\mathrm{f}}$ and a Jobin Yvon bench top ICP. ${ }^{\mathrm{g}}$ All samples to be analyzed for metals were preserved with nitric acid, at $0.1 \%$ (by volume). To prevent nitrite interference in the nitrate determination, the first three sets of anion samples were preserved with formaldehyde. This method allows samples to be stored for longer periods than with refrigeration alone. Nitrite was not present in the first three sample sets, so formaldehyde was not used with subsequent samples. Instead, anion samples were stored at $4{ }^{\circ} \mathrm{C}$ prior to analysis.

Lysimeter samples were analyzed for dissolved carbon on two occasions. An aggregate Level 0 carbon sample was taken in Week 16 (41 weeks before the ${ }^{14} \mathrm{C}$ injection). This sample was analyzed at the IRC using a carbon analyzer. ${ }^{\mathrm{h}}$ The second sets of carbon samples were taken from lysimeters at each column level in Week 106 or (49 weeks after the ${ }^{14} \mathrm{C}$ injection). These samples were analyzed at INTEC using a carbon analyzer. ${ }^{\mathrm{h}}$

3.3.1.2 Alkalinity, Electrical Conductivity, and $\mathbf{p H}$. Total alkalinity was determined using colorimetric end point titration ${ }^{\mathrm{i}}$ of unfiltered samples; electrical conductivity was measured using a

\footnotetext{
f Model DX-500.

g Model JY 238.

h O.I. Analytical Model 700 College Station, TX.

i HACH digital titrator.
} 
bench-top conductivity meter, ${ }^{\mathrm{j}}$ and soil water $\mathrm{pH}$ was determined using an inline electrode ${ }^{\mathrm{k}}$ with a portable $\mathrm{pH}$ meter. ${ }^{1}$ Syringes were used to draw pore water samples from sampling lysimeters through the $\mathrm{pH}$ electrode, Figure 8 . This configuration provided fast and stable $\mathrm{pH}$ measurements. While the $\mathrm{pH}$ electrode provided a fast response time, the stability of $\mathrm{pH}$ readings was attributed to isolation of water samples from the atmosphere (i.e., analysis under nitrogen gas). To prevent cross contamination, the electrode was rinsed with deionized water between measurements. Acidic solutions, including $\mathrm{pH}$ buffers, were removed from the column area to avoid unintentional release of radiolabeled $\mathrm{CO}_{2}$ gas by acidification of water samples. Buffer solutions of 7.00 and $10.01 \mathrm{pH}$ were used for instrument calibration. Though $\mathrm{pH}$ as low as 6.8 was occasionally measured, most measurements were 7.0 or greater. Therefore, the 7.00 to 10.01 calibration bracket was deemed acceptable.

\subsubsection{Gas Concentration Measurements}

The gas analysis system incorporated an infrared acoustic $\mathrm{CO}_{2}$ analyzer ${ }^{\mathrm{m}}$ and a paramagnetic $\mathrm{O}_{2}$ analyzer. ${ }^{\mathrm{n}}$ A 12-channel switching device ${ }^{\mathrm{o}}$ was used to select the source and route the gas sample to the analyzers. Gas was drawn from the source through the switching device and then into the analyzers by pumps onboard each analyzer. Background samples (i.e., laboratory air) were drawn from the headspace air intake tube. Headspace samples were drawn from the headspace outlet tube. Pore gas samples were drawn from perforated stainless steel tubes inserted in the column $(\sim 36-\mathrm{cm}$ long by $0.6-\mathrm{cm}$ diameter with 44 2-mm diameter perforations covered with woven nylon stocking material). Polyethylene tubing, with $0.16 \mathrm{~cm}$ wall thickness, was used to carry gas samples.

The analyzers and sample-channel selector were controlled by a LabVIEW-program that periodically recorded the $\mathrm{CO}_{2}$ and $\mathrm{O}_{2}$ concentrations of pore gas, headspace gas, and laboratory air samples. Each $\mathrm{CO}_{2}$ measurement began with a sample chamber and tubing purge (3-s high speed, then 10-s low speed). The $\mathrm{CO}_{2}$ analyzer was programmed to perform four measurements for each gas source; the recorded $\mathrm{CO}_{2}$ concentrations are an average of the last three measurements. Discarding the first sample measurement provided stable (i.e., low variation) measurements. Each $\mathrm{O}_{2}$ measurement began with a 15-s tubing and sample chamber purge. The $\mathrm{O}_{2}$ analyzer performed dynamic measurements and reported the concentration every second. Thirty $\mathrm{O}_{2}$ measurements were made from each gas source; the recorded $\mathrm{O}_{2}$ concentrations are an average of these 30 measurements. Care was taken to avoid perturbing pore gas concentrations by excessive sampling. The amount of gas removed from the column during each column profile measurement was determined by measuring the sample exhaust rate of each analyzer. Flow rates were measured using a Gilibrator primary flow calibrator. ${ }^{\mathrm{p}}$ The $\mathrm{CO}_{2}$ analyzer's 3-s tubing and 10 -s sample chamber flow rates were $1713.6-\mathrm{cm}^{3} \mathrm{~min}^{-1}$ and $344.7-\mathrm{cm}^{3} \mathrm{~min}^{-1}$, respectively. The $\mathrm{O}_{2}$ analyzer produced a constant flow rate of $156.0-\mathrm{cm}^{3} \mathrm{~min}^{-1}$ for $45 \mathrm{~s}$. Given these rates and durations, $4.37 \mathrm{~L}$ of pore gas was extracted from the column during each weekly soil profile measurement, compared to a pore gas volume of $356 \mathrm{~L}$ at $30 \%$ volumetric water content.

3.3.2.1 Gas Measurement Corrections. The $\mathrm{CO}_{2}$ analyzer was calibrated by the manufacturer to be linear for $\mathrm{SF}_{6}$ measurement in the range experienced in this study (1\% error). No post measurement

\footnotetext{
j. Denver Instruments, Model 250.

k. Cole-Parmer No. 05992-64.

1. Orion Model 250.

m. INNOVA Model 1312.

n. INNOVA Model 1313.

o. INNOVA Model 1309.

p. INEEL Calibration Lab. \#714817.
} 
$\mathrm{SF}_{6}$ calibrations were performed for reported data. However, duplicate samples were used to determine relative uncertainty of $\mathrm{SF}_{6}$ measurements (Appendix A).

$\mathrm{CO}_{2}$ measurements are nonlinear over the range of concentrations experienced in this study. While the analyzer was equipped with both low ( 0 to $1 \% \mathrm{vol})$ and high (1 to $25 \% \mathrm{vol})$ range $\mathrm{CO}_{2}$ filters, the automated analysis system was not designed to select a $\mathrm{CO}_{2}$ filter based on concentration. This prevents column perturbation by excessive gas sampling. We measured $\mathrm{CO}_{2}$ concentrations using the analyzer's high-range filter and corrected the measurements with periodic measurements of certified $\mathrm{CO}_{2}$ gas standards (Table 11). High-range filter measurements are expected to be linear within both low- and high-concentration ranges. Therefore, low- and high-range correction expressions were developed from linear fits (Figure 9) of the measurements of the certified $\mathrm{CO}_{2}$ standards. These corrections are given in Equations (1) and (2), respectively. Headspace and room air measurements were corrected using Equation (1), while pore gas concentrations were corrected using Equation (2). $\mathrm{CO}_{2}$ concentration measurements used to determine efficiency of the headspace $\mathrm{CO}_{2}$ trap were not corrected because the low-range filter was used exclusively for these measurements.

$$
\begin{aligned}
& \mathrm{CO}_{2_{\text {LowRange }}}=0.90 * \text { Measured } \mathrm{CO}_{2}+45.68 \\
& \mathrm{CO}_{2_{\text {HighRange }}}=0.98 * \text { Measured } \mathrm{CO}_{2}-505.60
\end{aligned}
$$

where $\mathrm{CO}_{2}$ is measured in ppmv.

The $\mathrm{CO}_{2}$ analyzer does not automatically compensate for sample temperature and pressure at the time of each measurement. For this study, it calculated $\mathrm{CO}_{2}$ concentrations based on fixed pressure and temperature values of $84.33 \mathrm{kPa}$ and $25^{\circ} \mathrm{C}$, respectively.

The $\mathrm{O}_{2}$ analyzer was calibrated using ambient air, assumed to be 20.95 volume percent $\mathrm{O}_{2}$, (vol\%) and a pure nitrogen zero gas. The analyzer performs automatic sample temperature and pressure compensation. Measurements are expected to be linear over the range of 0 to $22 \mathrm{vol} \%$ (1\% error). An ambient air measurement was included with each column $\mathrm{O}_{2}$ profile measurement. Ambient air was consistently measured 0.9 to $1.2 \mathrm{vol} \%$ greater than 20.95 vol\%. Prior to reporting $\mathrm{O}_{2}$ concentrations, the differences between measured and assumed (i.e., 20.95 vol\%) ambient air concentrations were subtracted from profile measurements, per Equation (3).

$$
\left[\mathrm{O}_{2}\right]_{\text {Reported }}=\left[\mathrm{O}_{2}\right]_{\text {Measured }}-\left(\left[\mathrm{O}_{2}\right]_{\text {Measured ambient air }}-20.95\right)
$$

Table 11. Average measured values of gas standards used for low- and high-range $\mathrm{CO}_{2}$ measurement corrections.

\begin{tabular}{|c|c|c|c|c|c|c|}
\hline \multirow{2}{*}{ Date } & \multicolumn{6}{|c|}{$\begin{array}{c}\mathrm{CO}_{2} \\
(\mathrm{ppmv})\end{array}$} \\
\cline { 2 - 7 } & Pure N $\mathrm{N}_{2}$ Gas & $1,000 \mathrm{Std}$. & $5,030 \mathrm{Std}$. & 10,100 Std. & 50,300 Std. & 201,000 Std. \\
\hline $10 / 18 / 01$ & 80 & 1,210 & 5,382 & 11,130 & 52,630 & 204,870 \\
\hline $7 / 2 / 02$ & -54 & 913 & 5,390 & 10,811 & 52,287 & 206,810 \\
\hline $8 / 29 / 02$ & -94 & & 5,377 & & 51,317 & \\
\hline $11 / 21 / 02$ & -90 & 1,060 & 5,379 & 11,150 & 52,489 & 205,640 \\
\hline $2 / 27 / 03$ & -95 & & 5,384 & & 51,233 & \\
\hline Averages & -51 & 1,061 & 5,382 & 11,030 & 51,991 & 205,773 \\
\hline
\end{tabular}


Low Range $\mathrm{CO}_{2}$ Correction

$(0-1000 \mathrm{ppmv})$

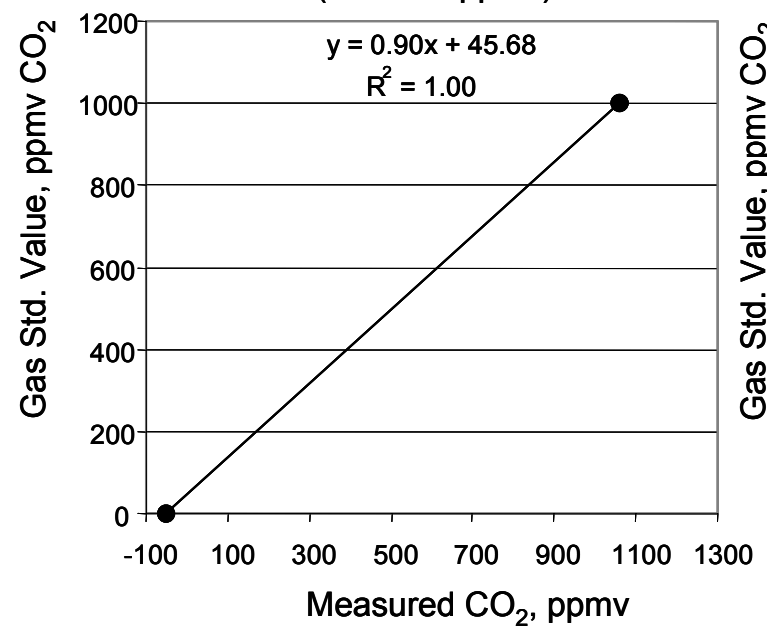

High Range $\mathrm{CO}_{2}$ Correction

$(5,000-20,000$ ppmv $)$

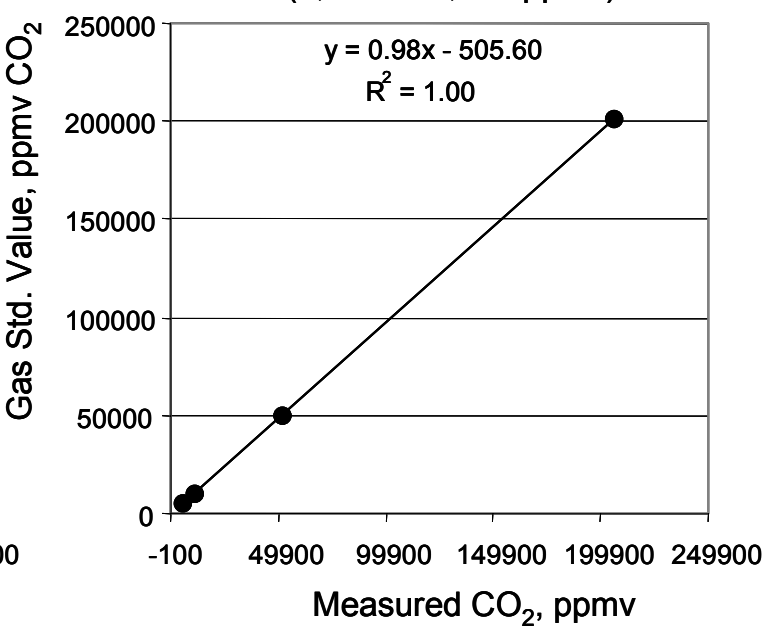

Figure 9. Linear fits used for low- and high-range $\mathrm{CO}_{2}$ measurement corrections. Data points represent average gas standard measurements.

3.3.2.2 $\mathrm{CO}_{2}$ Surface Flux. The surface flux of $\mathrm{CO}_{2}$, by microbial metabolism, is calculated as the change in atmospheric $\mathrm{CO}_{2}$ concentration as it passed through the headspace. We calculated $\mathrm{CO}_{2}$ flux using the universal gas law with the change of $\mathrm{CO}_{2}$ concentration, air temperature, column surface area, headspace ventilation rate, and barometric pressure. The headspace volume is directly proportional to the volume concentration of $\mathrm{CO}_{2}$; therefore, headspace residence time may be ignored in flux calculations, assuming steady state conditions. The headspace ventilation rate was held constant by an MKS mass flow controller $^{\mathrm{q}}$ that was calibrated at operating humidity and temperature by INEEL's Calibration and Standards Laboratory. The ventilation rate was set and recorded manually using the controller's digital display. Maintaining a constant ventilation rate for headspace gas at high relative humidity was complicated by water condensation in the flow controller. Condensation was largely prevented by using heat tape to elevate controller and tubing surface temperatures to $\sim 35^{\circ} \mathrm{C}$.

The barometric pressure used in flux calculations was recorded at the National Oceanic and Atmospheric Administration's station in Idaho Falls. Because a building's heating and ventilation system may affect laboratory air pressure, these barometric pressure measurements may not represent true ambient air pressure. Ambient air pressure measurements were not made in this study.

\subsubsection{Water Content Determination}

Four methods were employed to determine column water content: (1) gravimetric determinations, (2) mass balance of inflow and outflow waters, (3) sediment water (matric) potential, and (4) water content reflectometry. The sensors used in these methods were read every $5 \mathrm{~s}$ and hourly; running averages of theses readings were recorded using a Campbell Scientific data logger ${ }^{\mathrm{r}}$ with a PC208W software interface.

3.3.3.1 Gravimetric Water Content Determinations. Two benchmark water content determinations were made using core samples (ASTM D 2937). Water content and bulk density determinations were made in Week 35 for $6.0-\mathrm{cm}$ high by $5.7-\mathrm{cm}$ diameter horizontal cores taken from

q. Model 1559A-020L-SV.

r. Model CR10X. 
Portholes $8 \mathrm{~B}$ and $2 \mathrm{~F}$, with respective column depths of $\sim 15$ and $\sim 198 \mathrm{~cm}$. In Week 107, six vertical cores were taken to determine water content, bulk density, and solid phase ${ }^{14} \mathrm{C}$ activity (Figure 10). These cores were taken at six injection points along the North-South column transect, identified by numbers 1, 5, 9, 13, 17, and 21 in Figure 4. These cores represent the sediment profile extending from the column surface through the isotope injection plane to Level 6 , a depth of $\sim 76-\mathrm{cm}$. Two core samples, an upper sample (surface to Level 7) and a lower sample (Level 7 to Level 6) were taken from each of the six locations using two separate, $4.5-\mathrm{cm}$ diameter, coring tubes. Additional bulk samples were taken from Portholes $3 \mathrm{~F}$ and $2 \mathrm{~F}$, at respective depths of $\sim 168$ and $\sim 198 \mathrm{~cm}$, one day after the vertical cores. These samples were extracted from porthole areas adjacent to but not disturbed by previous sediment sampling. Vertical cores and bulk samples were used to determine water content at Levels 8,7,6,3, and 2. Bulk densities were determined for upper and lower core samples. Standard laboratory methods were followed for water content (ASTM D 2216-98) and bulk density (ASTM D 2937) determinations.

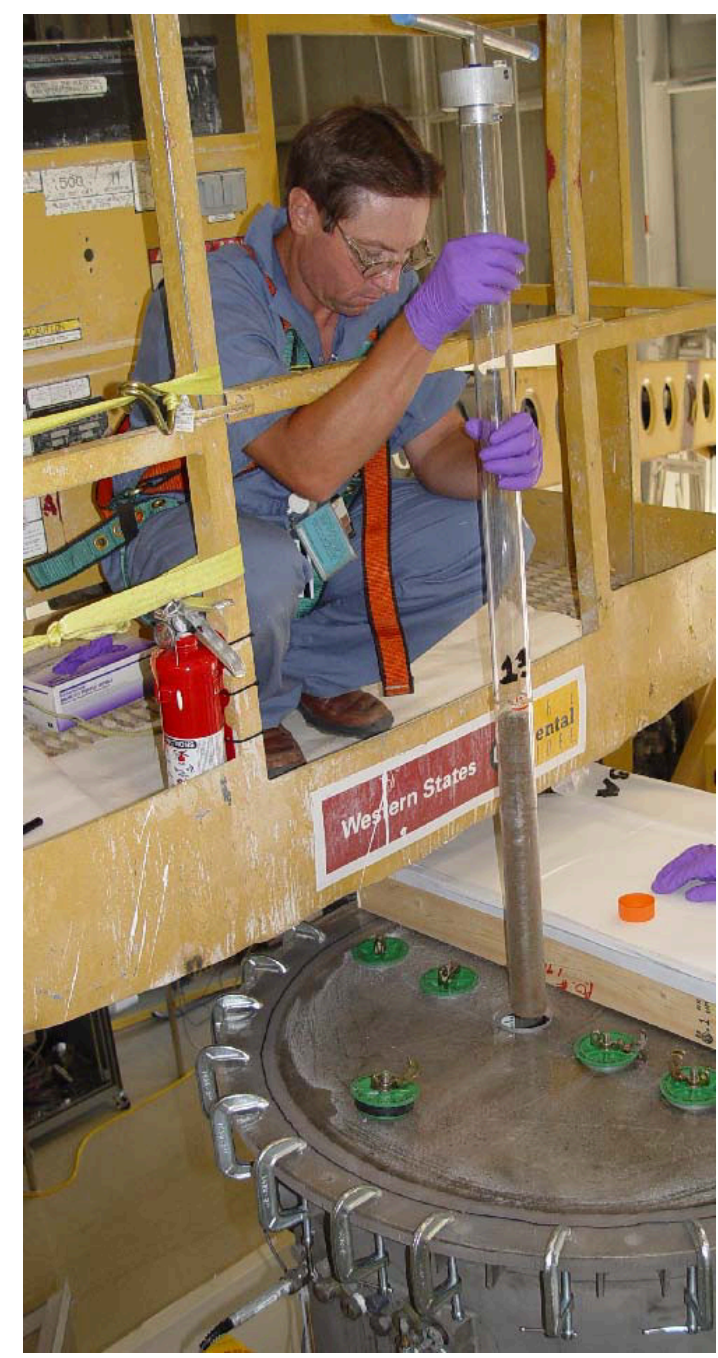

Figure 10. Column coring for gravimetric water content and solid phase ${ }^{14} \mathrm{C}$ activity determinations.

3.3.3.2 Mass Balance Water Content Determination. Water content by mass balance was calculated as the difference in total inflow and total outflow plus a packing water content of $10 \%$. (The packing water content was established through evaluation of reflectometry water content measurements). Total inflow included the surrogate vadose zone water and tracer solutions. Total outflow included 
column effluent, sample extractions, and headspace evaporative loss. While injected and extracted waters were easily tracked by direct measurements, determination of headspace evaporative loss required monitoring the relative humidity, temperature, and headspace ventilation rate. The relative humidity of laboratory air and headspace gas was monitored using MET-One relative humidity sensors. ${ }^{\mathrm{s}}$ The headspace temperature was assumed equal to the laboratory air temperature. The headspace ventilation rate was monitored via the mass flow controller's digital display.

We determined evaporative water loss by modifying the ideal gas law to calculate the number of water molecules (moles) removed from the headspace. Because this calculation involves vapor-phase water, a functional relationship describing water-vapor pressure as a function of temperature was developed from published vapor-pressure values over a 0 to $35^{\circ} \mathrm{C}$ temperature range (Olmsted and Williams 1994). This functional relationship was combined with the difference in supply air and headspace humidity to modify the ideal gas law for moles of water removed as a function of temperature and humidity (Equation (4)). The mass removal rate is obtained using the headspace ventilation rate and the molecular weight of water (Equation (5)). Under steady state conditions, the change in headspace volume is proportional to the change in water vapor concentration; therefore, residence time may be ignored and the unit volume drops out of the expression.

$n_{\text {Removed }}(t, R H)=\left[\frac{V\left(V P_{\mathrm{H}_{2} \mathrm{O}}(t)\left(\frac{\Delta R H}{100 \%}\right)\right)}{R T}\right]$

$\mathrm{H}_{2} \mathrm{O}_{\text {Removed }}(t, R H)=Q\left(n_{\text {Removed }} * M W_{\mathrm{H}_{2} \mathrm{O}}\right)$

where

$\begin{array}{lll}n_{\text {Removed }}(t, R H) & = & \begin{array}{l}\text { moles of water removed from headspace as a function of } \\ \text { temperature and relative humidity, }{ }^{\circ} \mathrm{C} \text { and } \%\end{array} \\ \mathrm{~V} & = & \text { unit volume of gas, } \mathrm{L} \\ V P_{\mathrm{H}_{2} \mathrm{O}}(t) & = & \text { water-vapor pressure as a function of temperature }=0.0063 \mathrm{e}^{0.0634^{*} \mathrm{t}}, \\ \mathrm{t} & = & \text { atm } \\ \Delta \mathrm{RH} & = & \text { difference of supply air and headspace relative humidity, } \% \\ \mathrm{R} & = & \text { the gas constant }=0.08206 \mathrm{~L} \text { atm mol }{ }^{-1} \mathrm{~K}^{-1} \\ \mathrm{~T} & \text { gas temperature }={ }^{\circ} \mathrm{C}+272.15, \mathrm{~K} \\ \mathrm{H}_{2} \mathrm{O}_{\mathrm{Removed}}(t, R H) & = & \text { water removal rate, } \mathrm{g} \text { day }{ }^{-1}\end{array}$

s. Model 083D. 


$$
\begin{array}{lll}
\mathrm{Q} & =\quad \text { volume flow rate of headspace gas, } \mathrm{L} \mathrm{day}^{-1} \\
M W_{\mathrm{H}_{2} \mathrm{O}} & =\quad \text { molecular weight of water }=18.0 \mathrm{~g} \mathrm{~mole}^{-1} .
\end{array}
$$

3.3.3.3 Matric Potential Determinations. Matric potential was recorded using ceramic cup tensiometers ${ }^{t}$ with Honeywell pressure transducers. ${ }^{u}$ The ceramic cups were $5.1-\mathrm{cm}$ long by $2.5-\mathrm{cm}$ diameter with a published -1-bar air entry pressure. The pressure transducers were calibrated at INEEL's Calibration and Standards Laboratory. The calibration expressions used to convert transducer output (millivolt) to water potential (millibar of negative pressure) are given in Table 12.

Prior to taking measurements, water was added to the tensiometers until a hydraulic connection was established between the ceramic cup and surrounding media. Having established the hydraulic connection, the matric potential became increasingly negative as the added water equilibrated with the sediment. Excessive air bubbles resulted in the occasional loss of matric potential readings until the air bubbles were flushed from the tensiometer.

The matric head was calculated by converting matric potential (i.e., -millibar of pressure) to total hydraulic head (i.e., - $\mathrm{cm}$ of $\mathrm{H}_{2} \mathrm{O}$ ), then subtracting the elevation head from each tensiometer level (assuming pore gas and solute heads are negligible). Water content was inferred from matric head using the drainage moisture characteristic curve (MCC) and van Genuchten curve fitting parameters given in Tables 4 and 5, respectively.

Table 12. Tensiometer pressure transducer calibration expressions.

\begin{tabular}{|c|c|}
\hline $\begin{array}{c}\text { Tensiometer } \\
\text { (depth below surface })\end{array}$ & $\begin{array}{c}\text { Conversion Expressions } \\
(\mathrm{mV}=\text { transducer millivolt output })\end{array}$ \\
\hline Level $1(229 \mathrm{~cm})$ & Millibar $=4.8565 \mathrm{mV}+22.96$ \\
\hline Level $5(107 \mathrm{~cm})$ & Millibar $=4.8527 \mathrm{mV}-4.956$ \\
\hline Level $6(76 \mathrm{~cm})$ & Millibar $=4.8954 \mathrm{mV}-15.71$ \\
\hline Level $7(46 \mathrm{~cm})$ & Millibar $=4.8565 \mathrm{mV}-20.12$ \\
\hline
\end{tabular}

3.3.3.4 Water Content Reflectometers. Volumetric water content was determined using water content reflectometers. ${ }^{\mathrm{V}}$ This method is a form of time domain reflectometry (TDR); therefore, we refer to the reflectometers as TDR probes. TDR probes measure the period of an electromagnetic wave as it propagates along the probe's wave guides. Parameters influencing wave propagation are water content, solid/aqueous phase electrical conductivity, media texture/lithology, and temperature. Water content, electrical conductivity, and media texture parameters are incorporated into conversion of probe measurements to water content by calibrating the probes to known water contents in the current sediments. Calibration provides an expression describing water content as a function of wave period. Once converted to water content, probe measurements are corrected for thermal interference.

Prior to installation, the four TDR probes used in this study were calibrated as follows.

1. Water was mixed with SDA sediment in a plastic tub.

t. Soilmoisture Equip. Corp., Model 2710A.

u. Model \#26PCCFA6D.

v. Campbell Scientific Inc. Model CS615. 
2. The four TDR probes were embedded in the tub of moistened sediment.

3. Sediment samples were taken for volumetric water content determination.

4. Probe measurements (wave periods) were recorded.

This process was repeated for three sediment water contents (dry, moistened, and water saturated). The recorded wave periods and corresponding water contents were given to Campbell Scientific Inc. ${ }^{\mathrm{w}}$ for derivation of the expression for water content as a function of wave period, $\tau$, that is given in Equation (6). This equation is derived in part from the expression for bulk electrical conductivity, $\sigma_{\text {bulk }}$, given in Equation (7). Equation (7) incorporates volumetric water content, $\vartheta_{v}$, and a sediment-specific transmission term, $\mathrm{T}$, with the electrical conductivity of both solid, $\sigma_{\text {solid }}$, and aqueous, $\sigma_{\text {aqueous }}$, phases. The sediment-specific transmission term and solid-phase electrical conductivity were not determined in this study. Therefore, bulk electrical conductivity was assumed equivalent to that determined for a sediment-water leachate (i.e., $\sigma_{\text {bulk }}=\sigma_{\text {aqueous }} \vartheta_{v}$ ).

$\vartheta_{v}(\tau)=-0.205+0.232 * \tau+0.069 * \tau^{2}$

$\sigma_{\text {bulk }}=\sigma_{\text {aqueous }} \vartheta_{v} \mathrm{~T}+\sigma_{\text {solid }}$

Sediment temperatures were used for thermal interference corrections. Thermal corrections published by Campbell Scientific are given in Equations (8) and (9). A thermal interference that affects probe measurements more than approximately $\pm 1.6 \%$ cannot be corrected using these equations. Beyond this threshold, the probes are more responsive to changes in temperature than to changes in water content.

$$
\begin{aligned}
& \operatorname{Coef}_{\text {Temperature }}=-3.46 * 10^{-4}+0.019 * \vartheta_{v}(\tau)-0.045 * \vartheta_{v}(\tau)^{2} \\
& \vartheta_{v-\text { Corrected }}=\vartheta_{v}(\tau)-\left[(t-20) * \operatorname{Coef}_{\text {Temperature }}\right]
\end{aligned}
$$

where

$$
\begin{array}{lll}
\operatorname{Coef}_{\text {Temperature }} & = & \text { temperature correction coefficient } \\
\vartheta_{v} & = & \text { volumetric water content, from Equation (6) } \\
\tau & = & \text { TDR probe measurement (i.e., wave period) } \\
\vartheta_{v-\text { Corrected }} & = & \text { volumetric water content corrected for thermal interference } \\
\mathrm{t} & = & \text { temperature of sediment in contact with probe wave guides. }
\end{array}
$$

w. Jim Bilskie, soil physicist, Campbell Scientific Inc., 435-750-9580. 


\subsection{Tracer Preparation, Injection, and Analysis}

Both nonreactive and reactive tracers were used to examine physical and chemical properties of contaminant transport. The nonreactive tracers were sulfur hexafluoride (gaseous $\mathrm{SF}_{6}$ ), bromide (lithium bromide solution), and tritium $\left({ }^{3} \mathrm{H}\right.$ as water); reactive tracers were solutions of radiolabeled sodium carbonate $\left({ }^{14} \mathrm{C}\right)$ and uranium (depleted $\mathrm{U}$ ). Methods of tracer preparation, injection, and analysis are described in this section.

\subsubsection{Sulfur Hexafluoride}

Sulfur hexafluoride $\left(\mathrm{SF}_{6}\right)$ tracer tests were performed at the initial (packing) water content $(\sim 10 \mathrm{vol} \%)$ and again at the experimental water content ( $\sim 30 \mathrm{vol} \%$, the water content for the isotope study). Replicates were performed for each of these two tests, for a total of four tests. The packing water content test was performed 17 weeks prior to start of water application (infiltration) with a replicate 3 weeks later. Between these tests, residual $\mathrm{SF}_{6}$ was evacuated from the column by applying vacuum to the gas ports and drawing atmospheric air from the column surface through the sediment. The experimental water content test was performed in Week 41, with the replicate test 6 weeks later. Residual $\mathrm{SF}_{6}$ was not flushed from the sediment between these tests, but was allowed to naturally attenuate.

For each tracer test, $\sim 10-\mathrm{cm}^{3}$ of a certified $\mathrm{SF}_{6}$ gas standard $(99.995 \% \mathrm{vol})$ was injected through the injection array located $152 \mathrm{~cm}$ below the column surface. This injection depth was selected to maximize the distance over which diffusion was monitored. Five $10-\mathrm{cm}^{3}$ disposable syringes, each containing $\sim 2-\mathrm{cm}^{3} \mathrm{SF}_{6}$, were connected to the Number 4, 6, 7, 16, and 18 injection tubes and simultaneously discharged. The $\mathrm{SF}_{6}$ remaining in the injection tubes was not flushed; therefore, slow diffusion of that $\mathrm{SF}_{6}$ into the column would be expected. We estimated that $\sim 1.8-\mathrm{cm}^{3}$ of $\mathrm{SF}_{6}$ remained in the tubing after each tracer injection (based on an estimated total tube length of $365.76-\mathrm{cm}$ and a $0.0794-\mathrm{cm}$ inside diameter.)

Sediment gas $\mathrm{SF}_{6}$ profiles were monitored using the INNOVA 1312 analyzer. During the experimental water content tests, approximately 4.37-L of gas was removed from the column during each gas profile measurement. Although the gas volume extracted was not determined for the two tests conducted at packing water content, it is probably similar to that for the other tests. For the packing water content tests, 10 gas profile measurements were made in the first $\sim 15 \mathrm{~h}$ of both the primary and replicate tests. Thus, for a measurement volume of 4.37-L per gas profile, 43.7-L would be removed during the first $\sim 15 \mathrm{~h}$ of these tests. For the first experimental water content test, 17 gas profile measurements were made in the first $\sim 15 \mathrm{~h}$. This represents $74.3-\mathrm{L}$ of gas removed during the initial $\sim 15 \mathrm{~h}$. The effect of sample gas extraction on $\mathrm{SF}_{6}$ diffusion was evaluated by decreasing the sampling interval, and thus the total amount of gas removed, during the replicate experimental water content test. For this test, 7 gas profile measurements were made in the first $\sim 15 \mathrm{~h}$. This represents 30.6 - $\mathrm{L}$ of gas removed during the initial $\sim 15 \mathrm{~h}$ of the test. A total pore gas volume of $356 \mathrm{~L}$ is calculated for a $30 \mathrm{vol} \%$ water content.

\subsubsection{Lithium Bromide}

An aqueous lithium bromide ( $\mathrm{LiBr}$ ) tracer was injected into the column on two occasions, at 36 then 94 weeks. The first $\mathrm{LiBr}$ injection was made as steady-state chemical and hydraulic conditions were approached. In comparing transport rates of this $\mathrm{Br}^{-}$test and that of a subsequent tritium tracer test, ${ }^{3} \mathrm{H}$ transport appeared to be significantly retarded. This could be the result of either anion (i.e., $\mathrm{Br}^{-}$) exclusion or tritium sorption. To test which mechanism was the cause, a tritium tracer was included with the second LiBr injection.

The first $\mathrm{LiBr}$ injection used $240-\mathrm{mL}$ of $9.89 \mathrm{mg} \mathrm{Br}^{-1} \mathrm{~mL}^{-1}$ in surrogate vadose zone water; the second used 238-mL of $10.75 \mathrm{mg} \mathrm{Br}^{-} \mathrm{mL}^{-1}$ in equal parts of pore water extracted from Levels 6 and 7. 
These concentrations were calculated to ensure detection after migration to the column bottom. $\mathrm{The} \mathrm{Br}^{-}$ solutions were injected at $60.96 \mathrm{~cm}$ below the column surface. This depth was selected to maximize monitoring distance for downward detection of solutes. To minimize perturbation of local hydraulic potential, the first $\mathrm{Br}^{-}$spike was added under gravitational and capillary force. This was accomplished by placing $\sim 10$-mL aliquots of solution in a bank of 24 syringes (open-ended, $10 \mathrm{~cm}^{3}$ ) mounted $58 \mathrm{~cm}$ above the injection plane and allowing the solution to drain into the column under atmospheric pressure.

Parafilm was used to minimize evaporative losses. This gravity/capillary force injection took $3.7 \mathrm{~h}$. The second $\mathrm{Br}^{-}$spike was injected by force using 24 individual syringes, each containing $\sim 10-\mathrm{mL}$ of injectate. This injection took $1 \mathrm{~h}$.

For the first test, $\mathrm{Br}^{-}$samples were promptly analyzed, without refrigeration, at the IRC. The second test occurred after ${ }^{14} \mathrm{C}$ injection. Those water samples were collected and stored at $4{ }^{\circ} \mathrm{C}$ prior to being shipped to INTEC for analysis.

\subsubsection{Uranium, Carbon-14, and Tritium Injection}

An aqueous cocktail of uranium, ${ }^{14} \mathrm{C}$, and tritium was prepared. Uranium was in the form of an inductively coupled plasma (ICP) analyzer depleted $\mathrm{U}$ standard, ${ }^{14} \mathrm{C}$ as radiolabeled sodium carbonate, and tritium $\left({ }^{3} \mathrm{H}\right)$ as water. The ${ }^{14} \mathrm{C}$ and ${ }^{3} \mathrm{H}$ activities were selected to comply with facility isotope limits while providing activities above analytic detection limits. The mass of uranium was selected, through rigorous geochemical solubility calculations, to prevent uranium precipitation upon injection while providing concentrations above detection limits.

Maintaining uranium solubility in the tracer cocktail required a $\sim 3-\mathrm{L}$ injection volume. However, injecting this volume would create severe chemical and hydraulic perturbations. To minimize these perturbations, water was extracted from the column, mixed with the tracers, and injected back into the column. Although this process was performed as rapidly as possible, it took 11 days. Injectate water extraction began at $\sim 55$ weeks. This water was extracted from sampling lysimeters located 15.2-cm above and below the injection plane (i.e., Levels 6 and 7). The extracted water was combined daily and stored at $-10^{\circ} \mathrm{C}$ in a $5-\mathrm{L}$ polypropylene container with an airtight lid. The total mass of water extracted and stored was 3,070.95-g.

To prepare for tracer injection, $\sim 2.0 \mathrm{~mL}$ of 1 -microCi ${ }^{14} \mathrm{C} \mathrm{g}^{-1}$ and $\sim 0.9 \mathrm{~mL}$ of 1 -microCi ${ }^{3} \mathrm{H} \mathrm{g}^{-1}$ were combined with $50 \mathrm{~mL}$ of pore water in a $100-\mathrm{mL}$ volumetric flask with a glass stopper. This solution was stored at $4{ }^{\circ} \mathrm{C}$ until sufficient water was extracted. On the day of injection, the ${ }^{14} \mathrm{C}$ and ${ }^{3} \mathrm{H}$ solution was added to the extracted pore water. Then, a 5.3333-g $( \pm 0.0001)$ aliquot of a $1-\mathrm{g} \mathrm{U} \mathrm{L}^{-1} \mathrm{ICP}$ standard was added to the mixture. The cocktail was allowed to equilibrate to room temperature, then mixed. Its $\mathrm{pH}$ was measured ( 8.0) and a 220.88-g sample was taken for ${ }^{14} \mathrm{C},{ }^{3} \mathrm{H}$, and $\mathrm{U}$ analysis.

The isotope cocktail was injected via the array located $60.96-\mathrm{cm}$ below the column surface in Week 57. One 125-mL Pyrex syringe was used to inject cocktail into each of the 24 injection tubes, Figure 11. The amount injected through each tube was determined by weighing the syringe before and after each injection; 2,849.97 g was injected into the column or $\sim 119 \mathrm{~g}$ per injection point. To push the cocktail from the injection tube into the column, each injection was followed by an injection $\sim 3 \mathrm{~cm}^{3}$ of air. Nevertheless, some cocktail is expected to have remained in the stainless steel injection array and polyvinyl chloride manifold tubing.

As described in the section on lithium bromide, a combined ${ }^{3} \mathrm{H}$ and $\mathrm{Br}^{-}$injection was made because the first ${ }^{3} \mathrm{H}$ and $\mathrm{Br}^{-}$tracer tests, initiated $\sim 20$ weeks apart, indicated significant retardation of ${ }^{3} \mathrm{H}$ movement relative to $\mathrm{Br}^{-}$movement. A simultaneous injection was made in Week 94 to evaluate anion exclusion (i.e., accelerated $\mathrm{Br}^{-}$movement) as the cause of apparent ${ }^{3} \mathrm{H}$ retardation. For this injection, 


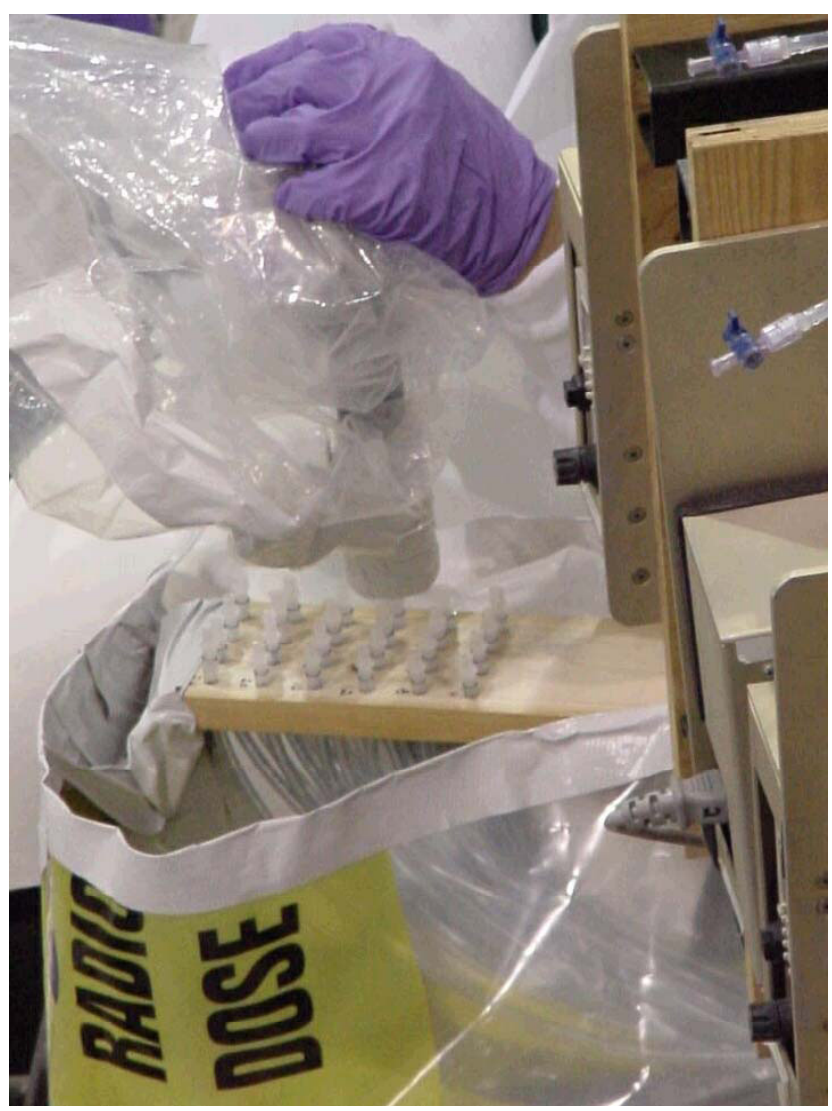

Figure 11. Injection of the ${ }^{14} \mathrm{C}$, tritium, and uranium cocktail solution. The injection syringe, polyvinyl chloride tubing, and Luer fittings are shown. To contain water vapor and prevent the spread of radiological contamination, the syringe was enclosed in a plastic bag.

approximately $0.9 \mathrm{~mL}$ of a $1.0-$ microC ${ }^{3} \mathrm{H} \mathrm{g}^{-1}$ solution and 2.78-g of $\mathrm{LiBr}$ were added to $\sim 251 \mathrm{~g}$ of pore water extracted from Levels 6 and 7. A 16-g aliquot was taken for ${ }^{3} \mathrm{H}$ and $\mathrm{Br}^{-}$analysis and 238.44-g was injected using the array $60.96-\mathrm{cm}$ below the surface $(\sim 9.9-\mathrm{g}$ per injection point). To push the cocktail from the injection tube into the column, each injection was followed by an injection $\sim 3 \mathrm{~cm}^{3}$ of air.

3.4.3.1 Uranium Analysis. Lysimeter water samples were used to monitor uranium (U) movement. $\mathrm{U}$ analyses were performed using a Chemcheck ${ }^{\mathrm{x}}$ automated laser-induced kinetic phosphorescence analyzer (KPA) with Uraplex ${ }^{\mathrm{y}}$ scintillating cocktail. This method reports uranium as total $\mathrm{U}$ with a minimum detection limit of $0.5 \mu \mathrm{g} \mathrm{\textrm {L } ^ { - 1 }}$. The KPA was calibrated using solutions prepared by serial dilution of an inductively coupled plasma (ICP) analyzer depleted U standard. KPA results were verified by analysis of sample splits using a Thermo Electron ${ }^{z}$ inductively coupled plasma mass spectrometer at INEEL's Test Reactor Area ICP-MS laboratory.

Approximately one year after U injection (i.e., 50 weeks), water samples collected from Level 6, $15-\mathrm{cm}$ below the injection plane, did not show uranium migration. At this time $(\sim 107$ weeks after start of infiltration), the column was cored, as described in Section 3.3.3.1, Gravimetric Water Content

\footnotetext{
x. Model KPA-L.

y. Chemcheck Industries.

z. Series X ICP-MS.
} 
Determinations. Vertical cores were taken that represent the sediment profile from the column surface through six of the cocktail delivery points to Level 6 . At the time of this report, the extent of $U$ movement is being evaluated by acid slurry extraction of $U$ from core subsamples. The extent of $U$ movement and the uranium sorption coefficient will be the focus of a later report.

3.4.3.2 Carbon-14 and Tritium Analysis. ${ }^{14} \mathrm{C}$ and ${ }^{3} \mathrm{H}$ activities were measured using a Beckman $^{\text {aa }}$ liquid scintillation counter (LSC) at the IRC, following procedures given in Appendix B. Two separate scintillation cocktails were used to accommodate alkaline and acid sample matrices-Ultima-flo $\mathrm{AF}^{\mathrm{bb}}$ with alkaline samples and Ecolum ${ }^{\mathrm{cc}}$ with acidified samples.

Pore water samples were collected from lysimeters for ${ }^{3} \mathrm{H}$ and ${ }^{14} \mathrm{C}$ activity analysis. In mixed isotope samples, ${ }^{14} \mathrm{C}$ interferes in ${ }^{3} \mathrm{H}$ counting. We minimized this interference by lowering the sample $\mathrm{pH}$ to $\sim 2$. At low $\mathrm{pH},{ }^{14} \mathrm{C}$ may defuse from solution as radiolabeled $\mathrm{CO}_{2}$ gas $\left({ }^{14} \mathrm{CO}_{2}\right)$. However, $\mathrm{CO}_{2}$ gas is highly soluble in water; therefore, ${ }^{14} \mathrm{C}$ activity was not completely eliminated. Nevertheless, this method worked well for ${ }^{3} \mathrm{H}$ counting at observed activities. Relatively low ${ }^{3} \mathrm{H}$ energy allowed ${ }^{14} \mathrm{C}$ counting without effort to reduce ${ }^{3} \mathrm{H}$ background. We made alkaline dilutions of ${ }^{14} \mathrm{C}$ water samples to prevent gas phase partitioning and loss of ${ }^{14} \mathrm{CO}_{2}$.

Pore gas samples were collected for ${ }^{14} \mathrm{CO}_{2}$ activity analysis using a 1-L gas syringe. The automated gas sampling system was disconnected and gas samples (each $200 \mathrm{~mL}$ ) were taken from the stainless steel sampling tubes. Immediately following extraction, each gas sample was injected into a 1-L Tedlar bag containing a known mass of $\mathrm{CO}_{2}$ trap solution [0.5M sodium hydroxide $\left.(\mathrm{NaOH})\right]$ and shaken vigorously to trap the ${ }^{14} \mathrm{CO}_{2}$ gas. Aliquots of the $\mathrm{CO}_{2}$ trap solutions were weighed for ${ }^{14} \mathrm{C}$ analysis.

${ }^{14} \mathrm{C}$ flux at the column surface was monitored by LSC analysis of headspace ${ }^{14} \mathrm{CO}_{2}$ samples. A split of the total headspace flow was bubbled through a 2 molar $\mathrm{NaOH}$ trap solution $(\sim 1300 \mathrm{~mL})$ to collect $\mathrm{CO}_{2}$ samples. Though the headspace ventilation system provided a constant total gas flow, accurate measurement of both the total and trap flow rates is critical to ${ }^{14} \mathrm{C}$ surface flux calculations. During $\mathrm{CO}_{2}$ sample collection periods, headspace exhaust and $\mathrm{CO}_{2}$ trap flow rates were occasionally measured using a Gilibrator primary flow calibrator. ${ }^{\mathrm{dd}} \mathrm{CO}_{2}$ trap efficiency was calculated using INNOVA 1312 analyses of headspace gas entering and exiting the $\mathrm{CO}_{2}$ trap. A sample collection period of approximately seven days found an average trap efficiency of $96 \%( \pm 1.4 \%)$. At the end of each collection period, the trap volume was recorded, sample aliquots were taken, and the trap solution was replaced with new solution. ${ }^{14} \mathrm{C}$ surface flux is calculated from the average activity of three separate aliquot determinations. Aliquot mass and isotope disintegration counts were combined to calculate aliquot activity (Equation (10)).

Equation (10) is combined with $\mathrm{CO}_{2}$ trap efficiency, gas flow rates, and total trap mass to calculate ${ }^{14} \mathrm{C}$ activity flux (Equation (11)). Total ${ }^{14} \mathrm{C}$ activity released by surface flux is determined by plotting Equation (11) over time and integrating the area under the curve.

$$
\text { Act }_{\text {Sample }}=\frac{\mathrm{C} * \mathrm{DPM}}{\mathrm{m}_{\text {Sample }}}
$$

aa. Model LS 6000LL.

bb. PerkinElmer Analytical

cc. ICN Biomedical.

dd. INEEL Calibration Lab. \#714817. 


$$
\mathrm{F}_{14 \mathrm{c}}=\frac{\operatorname{Act}_{\text {Sample }} * \mathrm{Q}_{\text {Total }} * \mathrm{~m}_{\text {Trap }}}{\Delta \mathrm{t}^{*} \mathrm{Q}_{\text {Trap }} *\left(\frac{\mathrm{EFF}}{100 \%}\right)}
$$

where

$$
\begin{array}{ll}
\text { Act }_{\text {Sample }} & =\text { activity per gram of aliquot, microCi } \mathrm{g}^{-1} \\
\mathrm{C} & =\text { conversion factor, } 4.5 \mathrm{E}-7 \text { microCi disintegration }{ }^{-1} \mathrm{~min}^{-1} \\
\mathrm{DPM} & =\text { disintegration's per minute (liquid scintillation counts) } \\
\mathrm{m}_{\text {Sample }} & ={ }^{14} \mathrm{C} \text { flux, microCi day }{ }^{-1} \\
F_{14 C} & =\text { total mass of } \mathrm{CO}_{2} \text { trap solution, } \mathrm{g} \\
\mathrm{m}_{\text {Trap }} & =\text { total headspace flow (ventilation), liters min }^{-1} \\
\mathrm{Q}_{\mathrm{Total}} & =\mathrm{CO}_{2} \text { trap flow (split of total headspace flow), liters } \mathrm{min}^{-1} \\
\mathrm{Q}_{\text {Trap }} & =\mathrm{period}_{\mathrm{CO}} \mathrm{CO}_{2} \text { trapping, days. } \\
\Delta \mathrm{t} & =\mathrm{CO}_{2} \text { trap efficiency, } \% . \\
\mathrm{EFF} &
\end{array}
$$

Solid phase ${ }^{14} \mathrm{C}$ activity at Levels $8,7,6,3,2$, and the column surface were determined from vertical core and bulk sediment samples described in Section 3.3.3.1, Gravimetric Water Content Determinations. Surface activity was measured for $\sim 0.3$-cm thick samples of the vertical cores taken at the sediment/atmosphere interface. At the time of vertical coring, the column surface had a significant community of photosynthesizing organisms. We expect solid phase ${ }^{14} \mathrm{C}$ activity to be associated primarily with inorganic species; therefore, biological uptake is not included in our determination of solid phase ${ }^{14} \mathrm{C}$. Solid phase ${ }^{14} \mathrm{C}$ was extracted by acidification of sediment aliquots and capture of liberated ${ }^{14} \mathrm{CO}_{2}$ gas using a sodium hydroxide trap solution. Trap solution activity was measured by LSC. These measurements represent an aggregate solid, liquid, and gas phase ${ }^{14} \mathrm{C}$ activity. Liquid and gas phase ${ }^{14} \mathrm{C}$ activity profiles, determined five days prior to coring, were used with aliquot water contents, determined from sample splits, and aliquot mass $(\sim 5-\mathrm{g})$ to subtract liquid and gas phase activity from trap solution measurements. The resulting solid phase activities were divided by dry aliquot mass, calculated from sample split water contents, to produce an average vertical solid phase activity distribution (i.e., ${ }^{14} \mathrm{C}$ activity per gram of dry sediment) from the six core and two bulk samples.

${ }^{14} \mathrm{C}$ activity, partitioned in solid, aqueous, and gas phases, was used to calculate the aqueous/gas $\left(K_{a g}\right)$ and aqueous/solid $\left(K_{d}\right){ }^{14} \mathrm{C}$ partition ratios at the time of vertical coring (approximately one year following the isotope injection). The total residual solid phase activity was calculated by plotting the average activity distribution over dry sediment mass then integrating the area under the curve. The average lift density given in Table $1\left(1.31 \mathrm{~g} \mathrm{~cm}^{-3}\right)$ was used with measurements of vertical core and bulk sediment water contents (Section 3.3.3.1, Gravimetric Water Content Determinations) to calculate dry sediment mass. Total aqueous and gas phase activities, on the day of coring, were calculated by plotting 
their activity profiles over respective water content and gas-filled pore volume profiles, then integrating the area under the curves. Residual (retained) ${ }^{14} \mathrm{C}$ activity partitioned in solid, aqueous, and gas phases was combined with the activity removed by sampling, effluent water, and surface flux to calculate a ${ }^{14} \mathrm{C}$ activity mass balance (percent of injected activity). 


\section{RESULTS AND DISCUSSION}

This chapter is divided into three sections, hydro-chemical characterization, biological assays, and tracer and ${ }^{14} \mathrm{C}$ transport. In Section 4.1, measurements of water content, bulk density, chemistry, and sediment-gas concentrations are presented to establish hydraulic and chemical state in relation to the ${ }^{14} \mathrm{C}$ transport study. Preliminary bioassay results are discussed in Section 4.2. Results of the tracer, ${ }^{14} \mathrm{C}$, and uranium transport tests are presented in Section 4.3. Errors associated with these measurements are discussed in Appendix A.

\subsection{Hydro-Chemical Characterization}

In this study, hydraulic steady state is defined as an extended period during which hydraulic flux and volumetric water content do not change with time. The hydraulic state was monitored using four independent methods: gravimetric, mass balance, matric potential, and TDR probes. These methods indicate that relatively constant hydraulic flux $\left(\sim 1.0 \mathrm{~L} \mathrm{day}^{-1}\right)$ and volumetric water content $(\sim 28 \%)$ were maintained during the transport study. Below, water content measurements and the interpretation of data sets are discussed for each method. We present a summary of water content determinations, relative to ${ }^{14} \mathrm{C}$ and the first $\mathrm{Br}^{-}$injections in Table 13.

Table 13. Summary of water content determination by four independent methods.

\begin{tabular}{|c|c|c|c|c|c|c|}
\hline $\begin{array}{l}\text { Method of Water } \\
\text { Content } \\
\text { Determination }\end{array}$ & $\begin{array}{c}\text { Column } \\
\text { Level }\end{array}$ & $\begin{array}{c}\text { Water } \\
\text { Content at } \\
\text { Time of } \mathrm{Br}^{-} \\
\text {Injection \#1 } \\
\text { (vol\%) }\end{array}$ & $\begin{array}{l}\text { Water } \\
\text { Content } \\
\text { at Time } \\
\text { of } \mathrm{SF}_{6} \\
\text { Test \#2 } \\
\left(\mathrm{vol}^{\circ} \%\right)\end{array}$ & $\begin{array}{c}\text { Water } \\
\text { Content at } \\
\text { Time of }{ }^{14} \mathrm{C}, \\
{ }^{3} \mathrm{H} \text {, and } \mathrm{U} \\
\text { Injection } \\
\text { (vol\%) }\end{array}$ & $\begin{array}{l}\text { Water Content } \\
26 \text { Weeks } \\
\text { After }{ }^{14} \mathrm{C},{ }^{3} \mathrm{H}, \\
\text { and } \mathrm{U} \\
\text { Injection } \\
\text { (vol\%) }\end{array}$ & $\begin{array}{c}\text { Water } \\
\text { Content } \\
50 \text { Weeks } \\
\text { After }{ }^{14} \mathrm{C} \text {, } \\
{ }^{3} \mathrm{H} \text {, and U } \\
\text { Injection } \\
\text { (vol\%) }\end{array}$ \\
\hline $\begin{array}{l}\text { Weeks after start } \\
\text { of infiltration } \\
\text { (approximate) }\end{array}$ & & 35 & 41 & 57 & 83 & 107 \\
\hline \multirow{6}{*}{$\begin{array}{l}\text { Core and porthole } \\
\text { gravimetric } \\
\text { determinations } \\
\text { (average values) }\end{array}$} & 8 & 24.0 & & & & 25.3 \\
\hline & 7 & & & & & 26.1 \\
\hline & 6 & & & & & 25.7 \\
\hline & 3 & & & & & 24.2 \\
\hline & 2 & 27.2 & & & & 24.6 \\
\hline & Average & 25.6 & & & & 25.2 \\
\hline Mass balance & Average & 29.8 & 29.9 & 29.7 & 30.1 & 29.3 \\
\hline \multirow{5}{*}{$\begin{array}{l}\text { Tensiometer/ } \\
\text { matric potential } \\
\text { estimation }\end{array}$} & 7 & $\sim 29$ & $\sim 29$ & $\sim 29$ & $\sim 29$ & $\sim 29$ \\
\hline & 6 & $\sim 29$ & $\sim 29$ & $\sim 29$ & $\sim 29$ & $\sim 29$ \\
\hline & 5 & $\sim 29$ & $\sim 29$ & $\sim 29$ & $\sim 29$ & $\sim 29$ \\
\hline & 1 & $\sim 29$ & $\sim 29$ & $\sim 29$ & $\sim 29$ & $\sim 29$ \\
\hline & Average & $\sim 29$ & $\sim 29$ & $\sim 29$ & $\sim 29$ & $\sim 29$ \\
\hline \multirow[t]{5}{*}{ TDR probes } & 7 & 27.7 & 27.3 & 26.2 & 27.6 & 27.7 \\
\hline & 5 & 27.9 & 27.7 & 26.1 & 27.6 & 28.1 \\
\hline & 4 & 29.2 & 28.1 & 25.8 & 30.6 & 28.4 \\
\hline & 1(excluded) & & & & & \\
\hline & Average & 28.3 & 27.7 & 26.0 & 28.6 & 28.1 \\
\hline
\end{tabular}




\subsubsection{Water Content and Bulk Density}

The general consistency of the four independent approaches (i.e., gravimetric, mass balance, tensiometer, and TDR probe) and the reliability of the mass-balance method, suggest a volumetric water content of $30 \%( \pm 1 \%)$ during the transport experiments. This water content value will be compared to those estimated by fitting analytical solutions to $\mathrm{Br}^{-}$and $\mathrm{SF}_{6}$ tracer breakthrough curves in Section 4.3.

4.1.1 Gravimetric Water Content Determination. Results of three gravimetric water content determinations are given in Table 14. The first determinations were made, for Level 8 and 2 portholes, in Week 35 (23 weeks before ${ }^{14} \mathrm{C}$ injection) when influent and effluent water flow rates indicated approach of hydraulic steady state. We extracted the second set of Level 8 and 2 porthole samples in Week 89, 32 weeks after the ${ }^{14} \mathrm{C}$ injection when radiological hazards associated with handling sediment samples diminished. A third set of water content determinations were made from the six vertical cores extracted 107 weeks after the start for inflow or 50 weeks after the cocktail injection. The six cores, consisting of two sections each, were extracted at six sampling locations and extended from the column surface to a depth of $\sim 76 \mathrm{~cm}$. Due to air voids resulting from excessive compaction, water contents were not determined for some core subsamples (e.g., Levels 8 through 6 at Point 9). These voids are believed to be sufficient to reduce sediment water content through vapor phase loss. Water contents were determined for the remaining vertical cores. Measurements are reported as volumetric water contents by converting gravimetric measurements to volumetric equivalences, assuming a pore water density of $0.998 \mathrm{~g} \mathrm{~cm}^{-3}$ at $20^{\circ} \mathrm{C}$.

Between the first and second determinations, the water content increased by $3.9 \%$ (from 24.0 to 27.9 vol\%) at Level 8 and by $4.1 \%$ (from 27.2 to 31.3 vol\%) at Level 2 (Table 14). These apparent increases represent a relatively small change occurring over a relatively long period, 55 weeks. The third determinations show the water contents to be virtually identical at Levels 3 and 2 (24.2 and 24.6 vol\%, respectively). This consistency of Level 3 and 2 water contents suggests lower column vertical

Table 14. Water content determinations of porthole and core samples, vol $\%$.

\begin{tabular}{|c|c|c|c|c|c|}
\hline Elapse Time and Sample Type & Level 8 & Level 7 & Level 6 & Level 3 & Level 2 \\
\hline Week 35 & & & & & \\
\hline Porthole Samples & 24.0 & & & & 27.2 \\
\hline Week 89 & & & & & \\
\hline Porthole Samples & 27.9 & & & & 31.3 \\
\hline Week 107 & & & & & \\
\hline Point 1 Core & 23.9 & 25.8 & 25.6 & & \\
\hline Point 5 Core & 26.3 & 26.6 & 25.7 & & \\
\hline Point 9 Core & & & & & \\
\hline Point 13 Core & 25.2 & 24.2 & 24.0 & & \\
\hline Point 17 Core & 25.6 & 26.6 & 28.2 & & \\
\hline Point 21 Core & & 27.2 & 25.2 & & \\
\hline Porthole Samples & & & & 24.2 & 24.6 \\
\hline Core Averages (n) & $25.3(4)$ & $26.1(5)$ & $25.7(5)$ & & \\
\hline
\end{tabular}


homogeneity. However, slight horizontal heterogeneity of the upper column is suggested by the variation observed in vertical-core water contents. The greatest variation is observed at Level 7, where an average $26.1 \pm 3.3 \%$ water content is measured (Table 14). Between the second and third porthole determinations (i.e., in the last 18 weeks of the ${ }^{14} \mathrm{C}$ study), the Level 2 water content declined by $6.7 \%$. This decline is consistent with determinations made for the Level 8 porthole and its nearest vertical core subsample (i.e., Level 8 of core taken at Point 17), which indicates an upper column decline of $2.3 \%$ (from 27.9 to $25.6 \mathrm{vol} \%$ ). Results of gravimetric determinations indicate that average water content increased $\sim 4 \%$ (i.e., from $\sim 26$ to $\sim 30$ vol\%) during the 23 weeks before and 32 weeks after the ${ }^{14} \mathrm{C}$ injection. The water content during these weeks is of most significance, because of the rapid discharge of ${ }^{14} \mathrm{C}$ following the injection. Results of gravimetric determinations indicate that the average volumetric water content during this time was $\sim 28 \mathrm{vol} \%$. During the last 18 weeks of the study, the water content returned to a range consistent with that determined before the cocktail injection (i.e., between 24 and $27 \mathrm{vol} \%$ ).

4.1.1.2 Bulk Density Determinations. Results of bulk density determinations are given in Table 15. The bulk densities of vertical cores from Points 9 and 21 were not calculated due to uncertainty of core volumes resulting from incomplete core recovery. Settling was not apparent during the study; therefore, density differences observed between the two coring dates are believed due to coring location (i.e., porthole versus center of column) rather than column settling. The horizontal cores were extracted from portholes where control of packing density was less easily achieved. Therefore, densities of vertical cores are assumed more representative of the column at the time of the tracer studies. Upper and lower core average densities (Table 15) are consistent with densities recorded for these levels (i.e., surface-toLevel 7 and Level 7-to- Level 6) during column packing (Table 1). Results of post-study bulk density determinations, by coring, are generally consistent with the average bulk density $\left(1.31 \pm 0.05 \mathrm{~g} \mathrm{~cm}^{-3}\right)$ calculated during column packing.

4.1.1.3 Mass Balance. An approach based on mass balance is, perhaps, the most reliable way to determine water content. Using this approach, a $0.4 \%$ increase in water content (i.e., from 29.7 to $30.1 \mathrm{vol} \%$ ) is calculated for the 26 weeks following ${ }^{14} \mathrm{C}$ injection (Table 13). This increase is due to the average $0.27 \mathrm{~L} \mathrm{day}^{-1}$ greater influent than effluent flow observed during this period. Influent and

Table 15. Core sample bulk density determinations.

\begin{tabular}{|c|c|c|c|c|}
\hline \multirow{2}{*}{} & \multicolumn{2}{|c|}{$\begin{array}{c}\text { Upper Core Samples } \\
\text { (Surface to Level 7) }\end{array}$} & \multicolumn{2}{c|}{$\begin{array}{c}\text { Lower Core Samples } \\
\text { (Level 7 to Level 6) }\end{array}$} \\
\cline { 2 - 5 } Elapse Time and Sample Type & $\begin{array}{c}\text { Dry Bulk } \\
\text { Density } \\
\left(\mathrm{g} \mathrm{cm}^{-3}\right)\end{array}$ & $\begin{array}{c}\text { Wet Bulk } \\
\text { Density } \\
\left(\mathrm{g} \mathrm{cm}^{-3}\right)\end{array}$ & $\begin{array}{c}\text { Dry Bulk } \\
\text { Density } \\
\left(\mathrm{g} \mathrm{cm}^{-3}\right)\end{array}$ & $\begin{array}{c}\text { Wet Bulk } \\
\text { Density } \\
\left(\mathrm{g} \mathrm{cm}^{-3}\right)\end{array}$ \\
\hline Week 35 & & & & \\
\hline Level 8 porthole core & 1.05 & 1.29 & 1.19 & 1.46 \\
\hline Level 2 porthole core & & & & \\
\hline Week 107 & 1.28 & 1.52 & 1.35 & 1.60 \\
\hline Point 1 vertical core & 1.37 & 1.63 & 1.44 & 1.69 \\
\hline Point 5 vertical core & 1.37 & 1.62 & 1.34 & 1.58 \\
\hline Point 13 vertical core & 1.32 & 1.56 & 1.50 & 1.78 \\
\hline Point 17 vertical core & 1.34 & 1.58 & 1.41 & 1.66 \\
\hline Average of vertical cores $(\mathrm{n}=4)$ & & & & \\
\hline
\end{tabular}


effluent flow rate time series are presented, with applied effluent lysimeter head, in Figure 12. Although lysimeter suction was held relatively constant, slight variation of effluent flow is observed. The effluent flow rate gradually converges with the influent rate after ${ }^{14} \mathrm{C}$ injection (Figure 12). This change of effluent flow is believed due to long term changes in the hydraulic potential gradient and/or lysimeter permeability. A decline in water content of $0.8 \%$ (i.e., from 30.1 to $29.3 \mathrm{vol} \%$ ) is calculated for the last 24 weeks of the study (Table 13). This decline results in a water content that is within $0.4 \%$ of that calculated for the ${ }^{14} \mathrm{C}$ injection date. Given the reliability of the cumulative mass balance approach and this relatively small water content fluctuation, water content is believed to have remained effectively constant during the transport study (Figure 13) at $30 \mathrm{vol} \%$ ( $\pm 1 \mathrm{vol} \%)$.

4.1.1.4 Matric Potential. The moisture characteristic curve (MCC) and tensiometer total hydraulic head are given in Figure 14a and $\mathrm{b}$. To aid interpretation, applied effluent lysimeter head is included in the tensiometer plot. Initially, a brief period of upper column (Levels 5, 6, and 7) drainage and Level 1 wetting was observed (Figure 14b). This may be due in part to either slight drainage of upper levels, following reduction of the hydraulic flux from $\sim 5$ to $\sim 1 \mathrm{~L}^{\text {day }}{ }^{-1}$, and the wetting of the column bottom or to tensiometer conditioning. Variations in the hydraulic gradient due to changes in lysimeter suction are most pronounced at Level 1. With relatively constant suction, the hydraulic head at Level 1 approached values comparable to those of Level 5, 6, and 7 immediately before ${ }^{14} \mathrm{C}$ injection at Week 57.

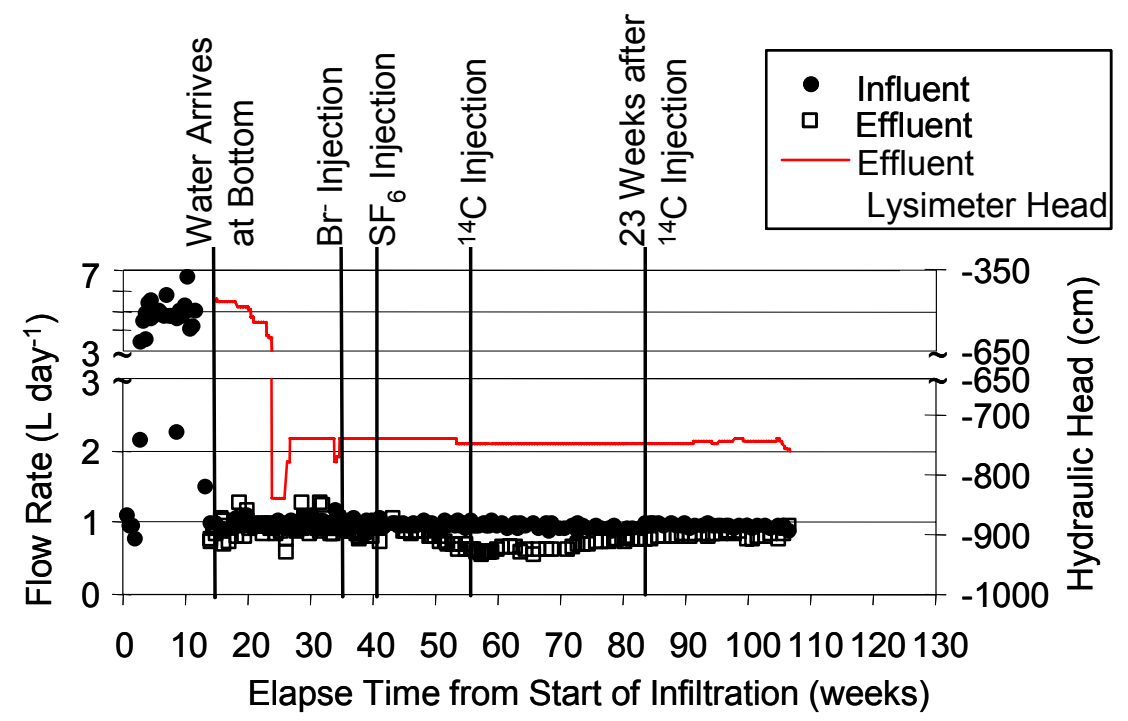

Figure 12. Influent and effluent flow rates with effluent lysimeter head.

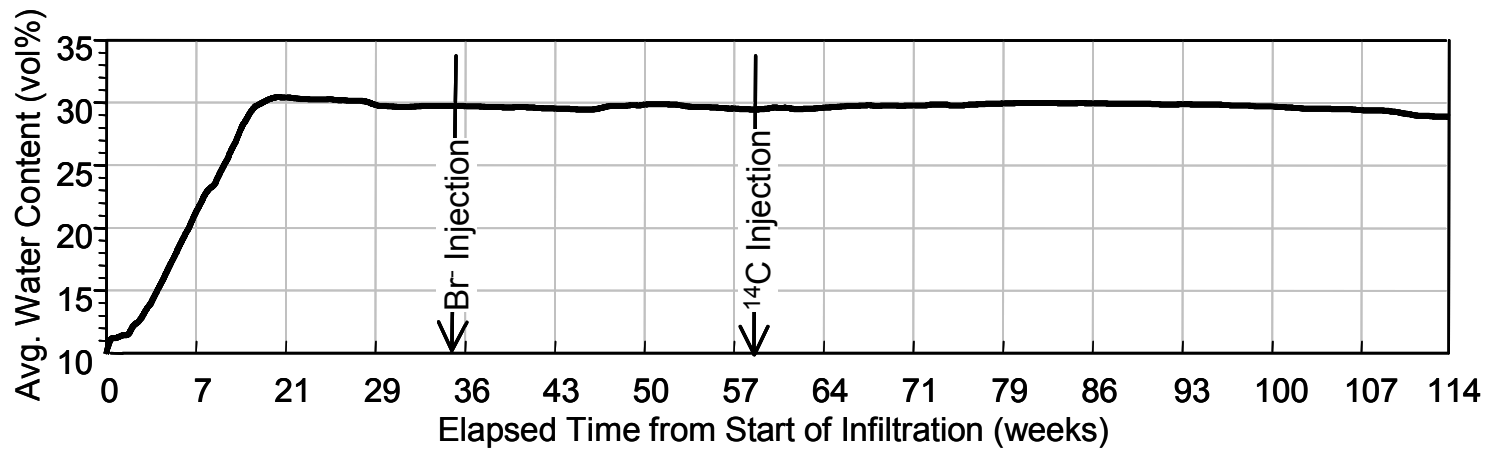

Figure 13. Mass balance based cumulative volumetric water content. 
a)
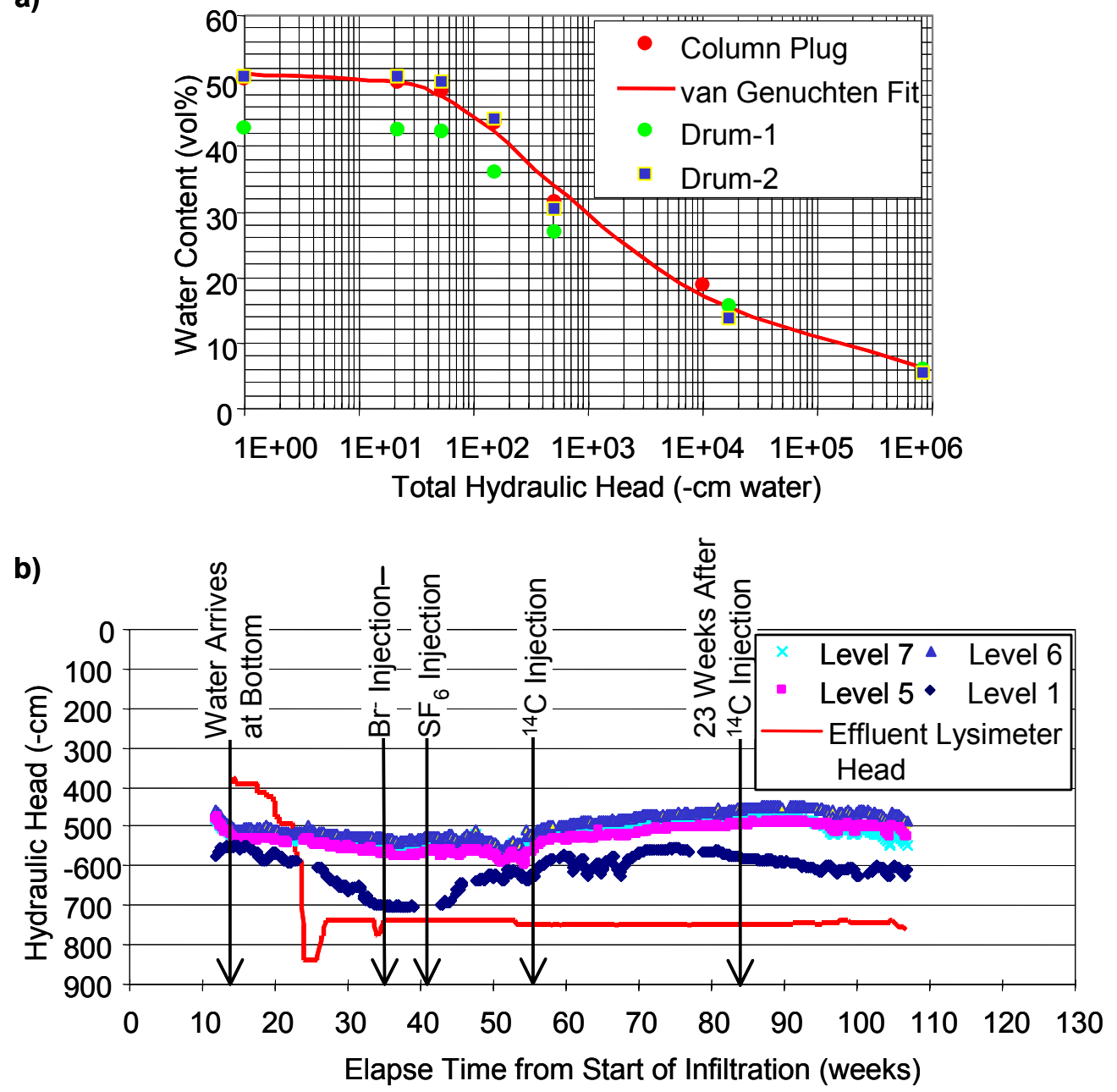

Figure 14. Moisture characteristic curve (a) and tensiometer and effluent lysimeter hydraulic heads (b).

Extracting water to make the isotope injectate lowered the hydraulic head during the 10 days prior to ${ }^{14} \mathrm{C}$ injection (Figure 14b). Following injection, the effluent flow rate was supplemented by extracting water from the sampling lysimeters at Level 0 on three occasions. The extraction cycles appear as three successive peaks and valleys at Level 1 between 60 and 70 weeks (Figure 14b). While these hydraulic head fluctuations were not observed above Level 1, we stopped supplemental water extractions to prevent potential changes of upper level seepage velocity that might affect the aqueous phase transport rate. The supply of influent and extraction of effluent were both paused while column was cored; the response of the hydraulic gradient was observed in tensiometer readings at Week 107 (Figure 14b). If we ignore the MCC provided by the van Genuchten fit and consider the drum and plug sample values (Figure 14a), tensiometer measurements yield a $\sim 27$ to $\sim 31 \mathrm{vol} \%$ water content ( $29 \mathrm{vol} \%$ average) for the mean hydraulic head $(-540-\mathrm{cm})$ at the time of ${ }^{14} \mathrm{C}$ injection. The lack of sensitivity in tensiometer-MCC-based approaches produces a similar range of water contents for the mean hydraulic head $(-546-\mathrm{cm})$ recorded 50 weeks after the cocktail injection. This lack of sensitivity produces a consistent water content estimate of 29 vol\% during the entire transport study (Table 13). While tensiometer-based estimates are generally consistent with gravimetric and mass balance approaches, fluctuations of water content are not observed due to the lack of sensitivity. For this reason, the tensiometer data is most useful as an indicator of relative hydraulic potential rather than water content. 
4.1.1.5 Reflectometry. TDR water content data are plotted in Figure 15a. These measurements have been corrected for pore water electrical conductivity and thermal interference using Equation (9). A $10 \%$ volumetric water content was recorded by TDR probes prior to application of water. This is the only measure of initial (packing) water content. (The sediment had been stored approximately 2 years.) A $10 \%$ packing water content is reasonable, given the measured $\sim 14$ to $\sim 16 \%$ range at the time of column packing. With initiation of water flow, four probe responses were noted in the TDR time series. First, the probes respond to changing pore water conductivity with passage of the infiltration front. Second, the Level 1 probe consistently produces questionably high readings. Third, all probes respond to thermal interference in excess of the probe's correction limit. Fourth, the readings of all probes instantaneously increase then gradually return to near initial values. The apparent cause of each of these responses is next discussed.

The probes respond to changing pore water conductivity as the infiltration front moves. This response produced artificial rises and declines in water contents (Weeks 5 through 20, Figure 15a). Highly soluble solids leach from sediment surfaces as water infiltrates. As the water percolates down, dissolved solids are transported and concentrated along the infiltration (wetting) front, causing a spike of relatively high ionic strength pore water. Because the TDR probes were calibrated to record changes of water content at a constant and relatively low aqueous ionic strength, breakthrough curves were observed for each probe with passage of the ion spike. As the spike eluted, relatively constant conductivity, representative of probe calibration conditions, was established by the slow and steady leaching of soluble solids and the probes began to respond to changes of conductivity due to water content. The TDR probe time series is expanded in Figure $15 \mathrm{~b}$ to show the ion spike breakthrough curves. Water sampling began as the wetting front approached the bottom of the column. Thus, conductivity breakthrough curves were only recorded at levels below 2 . The ion spike's arrival and elution is observed in pore water conductivity measurements at Levels 1,0C, and $0 \mathrm{G}$ (Figure 15c). TDR readings cannot be corrected for the ion spike without knowing the water content of the spike.

Following passage of the ion spike, the Level 1 TDR probe consistently recorded water contents that were considerably greater than those recorded by probes at upper levels (Figure 15a). The Level 1 TDR probe is located $\sim 15-\mathrm{cm}$ above the west effluent lysimeter pair (Figures 5 and 6 ). Elevated water content near this probe could be due to the use of a common effluent lysimeter suction source and water collection manifold. Applying a uniform suction at all lysimeters could limit water extraction and increase solute residence time near lysimeters having relatively low hydraulic conductivity. However, the consistency of Level $0 \mathrm{C}$ and $0 \mathrm{G}$ conductivity breakthrough curves (Figure 15c) suggests similarity of residence times for both lysimeter pairs. Therefore, it is believed that the Level 1 TDR probe readings are erroneous. This response, or malfunction, may be due, at least in part, to improper pre-emplacement calibration or accidental alteration of the waveguide separation distance during emplacement.

All probes indicated a rise and decline of water content during the summer months (approximately Weeks 50 and 100, Figure 15a). This is due to thermal interference that approached the correction limit (1.6\%); see Section 3.3.3.4, Water Content Reflectometers, for more detail. Because this thermal interference is minimal at Levels 4, 5, and 7, and the TDR measurements during cool weather periods of laboratory thermal stability are believed to represent those during the spike, additional thermal correction is unnecessary. (The pronounced response of the Level 1 probe to this thermal interference, compared to the Level 4, 5, and 7 probes, is further evidence of its malfunction.)

The fourth notable response - that the readings of all probes instantaneously increase then gradually return to near initial values - involves two step-changes recorded by probes at Levels 4, 5, and 7 between Weeks 60 and 80, Figure 15a. This response is believed to be due to a hardware connection fault. It is followed by a gradual return to values near those recorded prior to these step changes. 
a)

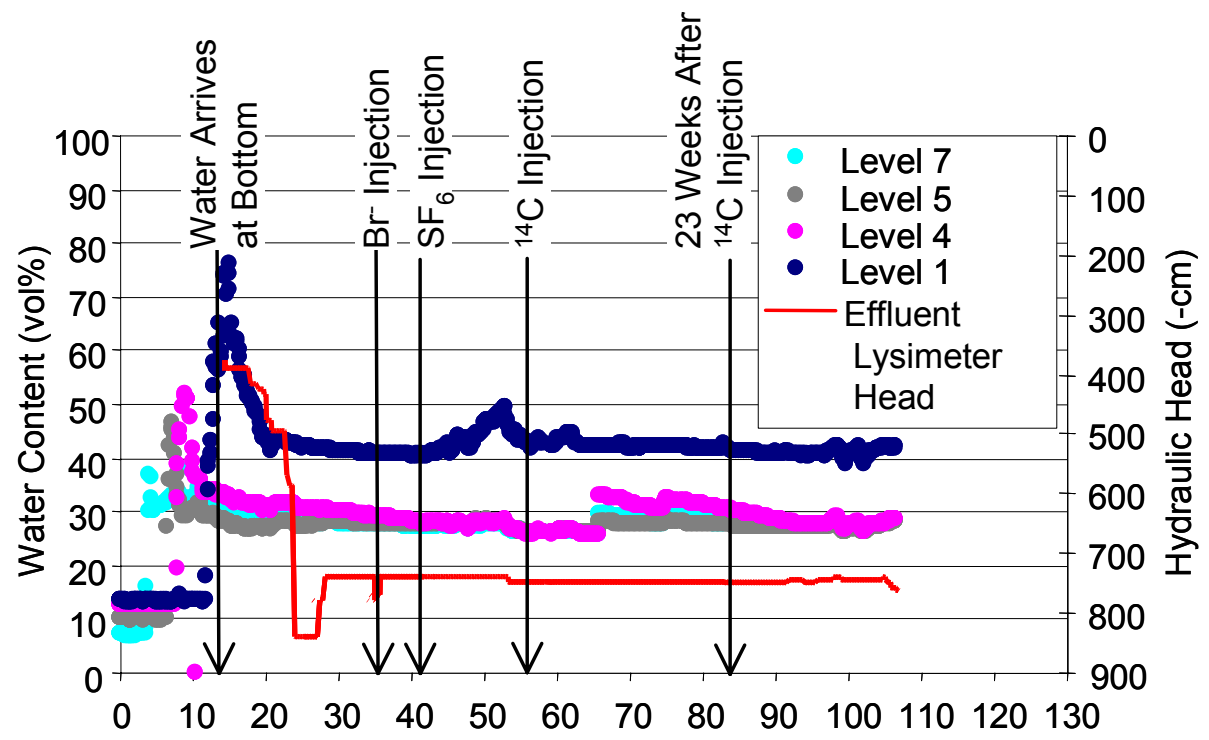

b)

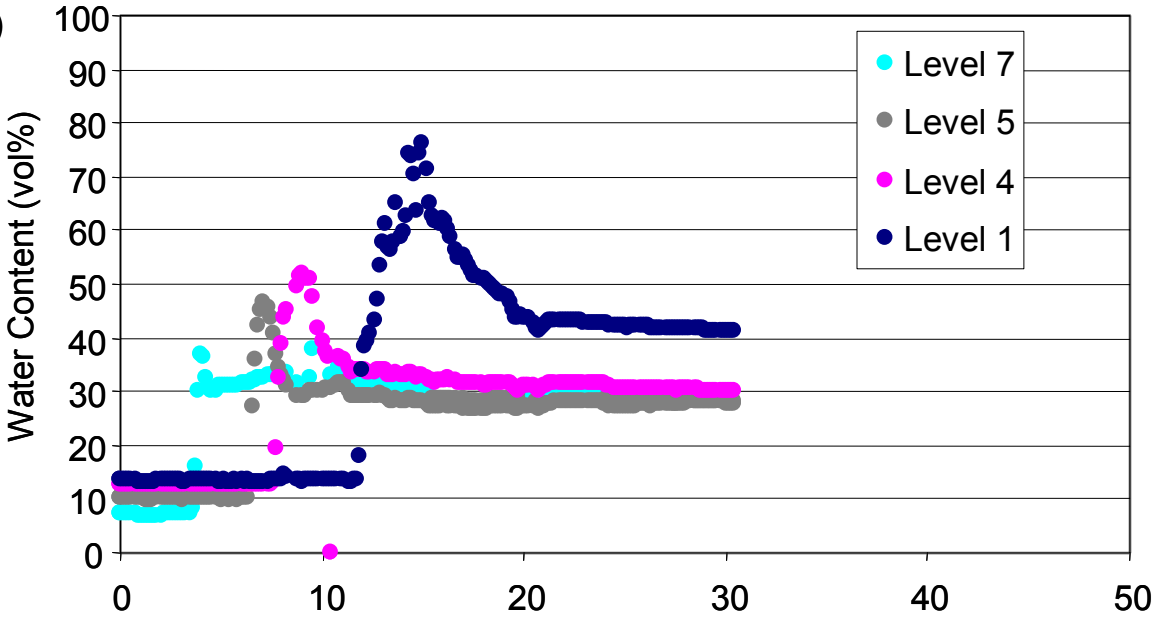

c)

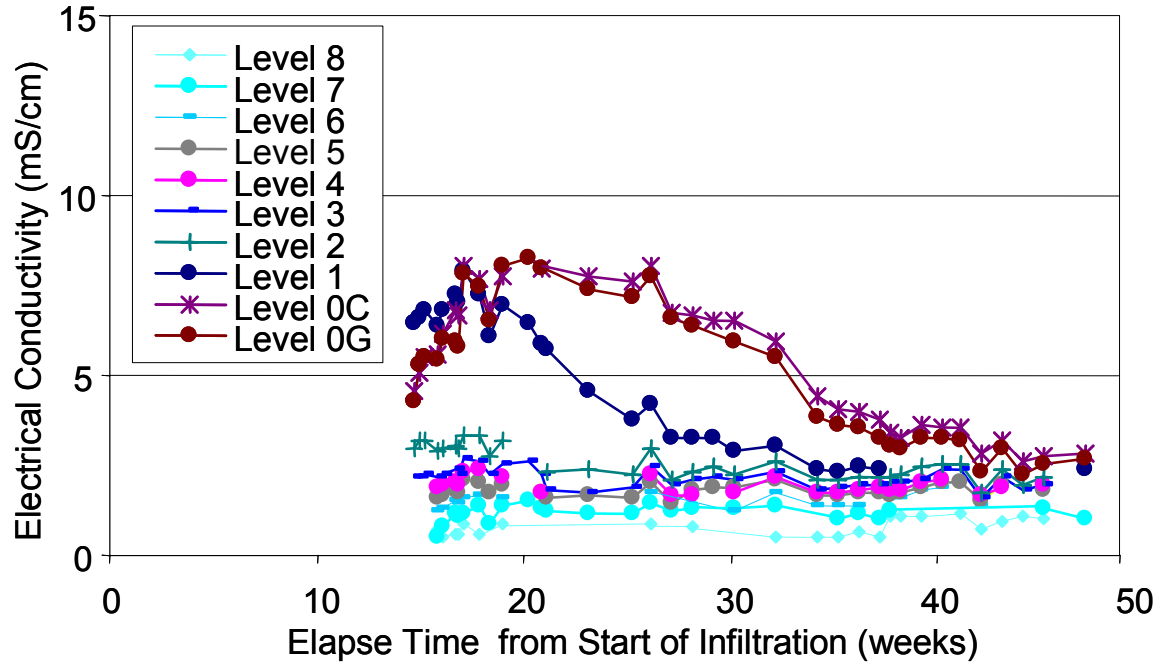

Figure 15. Reflectometer (TDR probe) data. (a) volumetric water content and effluent-lysimeter hydraulic head, (b) wetting/dissolved-salts front breakthrough curves recorded by TDR probes, and (c) electrical conductivity time series. 
The Level 4, 5, and 7 TDR probes yield an average $26.0 \%$ volumetric water content on the day of ${ }^{14} \mathrm{C}$ injection. While measurements following the assumed hardware fault are somewhat questionable, probe readings return to an average $28.4 \%( \pm 2 \%)$ following those events. With the exception of transient pore-water conductivity, thermal, and hardware fault events that produce errant readings, TDR water content measurements are generally consistent with those made using gravimetric, tensiometer, and mass balance methods.

\subsubsection{Water Chemistry}

For this study, chemical steady state is defined to be an extended period over which water chemistry at each column level is constant. Slow leaching of dissolved species and thermally induced fluctuations of microbially generated $\mathrm{CO}_{2}$ affect maintenance of steady-state conditions. However, $\mathrm{pH}$, electrical conductivity, and alkalinity measurements indicated near steady-state conditions for three months before the ${ }^{14} \mathrm{C}$, uranium, and tritium cocktail was injected. Linear fits of $\mathrm{pH}$, electrical conductivity, and alkalinity measurements during these three months produce respective slopes of $-4 \times 10^{-4},-3 \times 10^{-4}$, and $1 \times 10^{-2}$. Water chemistry is given, relative to bromide and ${ }^{14} \mathrm{C}$ injections, in Table 16. The electro neutrality (\% error) in Table 16 is calculated as

$\left(\sum\right.$ Cations $-\sum$ Anions $) /\left(\sum\right.$ Cations $+\sum$ Anions $) * 100$

where Anions and Cations are in units of milliequivalence. While observed fluctuations of ionic species are relatively insignificant to the ${ }^{14} \mathrm{C}$ transport study, changes in $\mathrm{CO}_{2 \text { (gas) }}$ will affect aqueous/gas partitioning of ${ }^{14} \mathrm{C}$. However, we were unable to fully constrain microbial $\mathrm{CO}_{2}$ production due, largely, to fluctuations of sediment temperature. Table 17 gives $\mathrm{pH}$, bicarbonate alkalinity, and $\mathrm{CO}_{2 \text { (gas) }}$ concentrations measured six days before the isotope injection to establish the initial chemical state for the transport study. Average $\mathrm{pH}$, bicarbonate alkalinity, $\mathrm{CO}_{2}$, and $\mathrm{O}_{2}$ measurements recorded during the 50 -week transport study are given in Table 18. A discussion of water chemistry and aqueous species analyses follows.

Measurement of $\mathrm{pH}$, electrical conductivity, and alkalinity began as the wetting front approached the bottom of the column. Therefore, the chemistry of the passing front was not recorded at upper levels. The most notable aspect of these data is for column wet up. An initial increase in conductivity occurred as highly soluble solids accumulated along, and traveled with, the wetting front. This effect is pronounced in conductivity measurements for Levels 1 and 0 (Figure 15c). At the column's bottom, solute residence time increases because excess dissolved salts are extracted via nonuniform flow paths converging at effluent lysimeters located $\sim 15-\mathrm{cm}$ above the bottom. The increased residence time is evident in the relatively persistent tail of the Level 0 (i.e., the effluent lysimeter level) conductivity breakthrough curve (Figure 15c). As the excess dissolved salts elute, the slow and steady leaching of soluble solids established relatively constant conductivity for the duration of the transport study.

The elimination of excess dissolved solids is apparent in a comparison of ionic species over time. Aqueous chemistry and $\mathrm{CO}_{2}$ sediment gas concentration profiles are given for 26, 34, 51, 79, and 106 weeks after start of water infiltration in Figure 16. From these profiles, excess dissolved salts are shown to be eliminated and relatively constant ion concentrations established prior to and after the ${ }^{14} \mathrm{C}$ injection. We found relatively high nitrate $\left(\mathrm{NO}_{3}{ }^{-}\right)$concentrations among the ionic species eliminated. Elevated $\mathrm{NO}_{3}{ }^{-}$concentrations are not uncommon in desert vadose zone sediments (Hartsough et al. 2001, Walvoord et al. 2003).

Results of dissolved carbon analysis show organic carbon, at Level 0 , to be reduced by a factor of 10.8 over the 90 -week sampling interval (Table 19). This reduction is believed due to both microbial metabolism and elution by effluent water. 


\begin{tabular}{|c|c|c|c|c|c|c|c|c|c|c|c|c|c|c|c|c|c|c|c|c|c|}
\hline 苂 & $\begin{array}{l}\overparen{ఠ} \\
\stackrel{\Xi}{\Xi} \\
\Xi\end{array}$ & $\begin{array}{l}0 \\
\infty \\
0 \\
0\end{array}$ & $\stackrel{n}{\stackrel{n}{+}}$ & $\stackrel{\circ}{\stackrel{2}{-}}$ & $\begin{array}{l}8 \\
\stackrel{0}{ } \\
i\end{array}$ & $\underset{ָ}{ָ}$ & 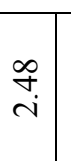 & $\begin{array}{l} \pm \\
\text { i }\end{array}$ & $\vec{\sim}$ & $\begin{array}{l}0 \\
\infty \\
\infty\end{array}$ & $\stackrel{n}{r}$ & 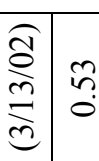 & \begin{tabular}{c|c}
$\hat{n}$ & $\grave{\sigma}$ \\
$\hat{\sigma}$ &
\end{tabular} & ?. & $\underline{\sigma}$ & $\stackrel{\Re}{=}$ & $\begin{array}{l}\circ \\
\infty \\
-\end{array}$ & 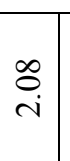 & $\stackrel{m}{\sim}$ & $\begin{array}{l}\stackrel{\circ}{\circ} \\
\dot{+}\end{array}$ & $\begin{array}{l}8 \\
\dot{r} \\
\dot{n}\end{array}$ \\
\hline Oঠ & $\begin{array}{l}\overparen{ఠ} \\
\stackrel{\delta}{\Xi} \\
ٍ\end{array}$ & $\vec{Z}$ & $\begin{array}{l}\vec{b} \\
i n\end{array}$ & $\stackrel{m}{r}$ & $\frac{n}{\infty}$ & $\begin{array}{l}\infty \\
\stackrel{\sigma}{a}\end{array}$ & $\begin{array}{l}0 \\
\vdots \\
0\end{array}$ & $\begin{array}{l}\vec{\infty} \\
\Xi \\
=\end{array}$ & $\begin{array}{l}8 \\
\stackrel{2}{ }\end{array}$ & & & 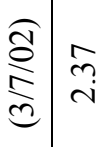 & \begin{tabular}{c|c}
$\hat{n}$ & $\tilde{\infty}$ \\
0
\end{tabular} & $\begin{array}{l}0 \\
0 \\
a\end{array}$ & $\begin{array}{l}n \\
\beth \\
=\end{array}$ & $\begin{array}{l}\mathbb{J} \\
\stackrel{i}{J}\end{array}$ & $\vec{\sim}$ & $\begin{array}{l}\mathbb{J} \\
\dot{J}\end{array}$ & $\begin{array}{l}\hat{b} \\
\dot{v}\end{array}$ & & \\
\hline$\vec{T}$ & 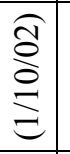 & 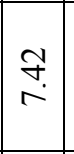 & 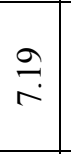 & $\frac{0}{\pi}$ & $\stackrel{ }{ }$ & $\underset{r}{\stackrel{D}{r}}$ & $\underset{\sim}{\sigma}$ & $\stackrel{\infty}{\sigma}$ & જ઼ & $\underset{0}{\infty}$ & \begin{tabular}{l|l}
$\infty$ & \\
0 & \\
0 & \\
\end{tabular} & 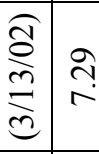 & 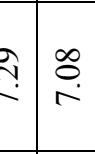 & $r$ & 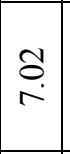 & $r$ & જ̆ & $\begin{array}{l}\infty \\
\stackrel{0}{o}\end{array}$ & જ̆ & $\begin{array}{l}0 \\
0 \\
0 \\
0\end{array}$ & $\hat{\sigma}$ \\
\hline 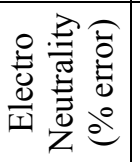 & & ठ․ & $\exists$ & $\stackrel{\simeq}{\leftrightarrows}$ & $\begin{array}{l}\mathfrak{D} \\
\infty \\
0\end{array}$ & $\stackrel{\hat{\sigma}}{0}$ & $\begin{array}{l}n \\
\mathfrak{0} \\
0\end{array}$ & $\begin{array}{l}\mathbb{J} \\
\dot{0} \\
0\end{array}$ & مै & \begin{tabular}{l}
\multirow{2}{*}{} \\
$\stackrel{i}{i}$
\end{tabular} & $\begin{array}{l}0 \\
0 \\
\dot{1}\end{array}$ & & 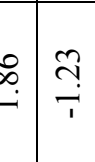 & $\begin{array}{l}\tilde{T} \\
\tilde{m} \\
0 \\
1\end{array}$ & 吕 & $\stackrel{m}{=}$ & $\vec{I}$ & $\stackrel{\infty}{\infty}$ & $\underset{\sim}{\Delta}$ & $\begin{array}{l}0 \\
0 \\
\dot{1}\end{array}$ & $\begin{array}{l}0 \\
0 \\
\dot{\varphi}\end{array}$ \\
\hline 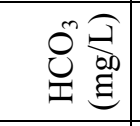 & & 足 & त్ర & $\underset{⿱}{\stackrel{D}{~}}$ & $\underset{⿱}{ \pm}$ & $\frac{n}{a}$ & $\widehat{\widehat{\sigma}}$ & $\tilde{\alpha}$ & I & $\underset{⿱}{I}$ & 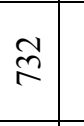 & $\hat{\text { mे }}$ & $\frac{n}{n}$ & $\stackrel{\infty}{\curvearrowright}$ & 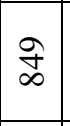 & $\widehat{\widehat{a}}$ & $\tilde{n}$ & a & $\stackrel{\infty}{\alpha}$ & $\stackrel{n}{\infty}$ & $\stackrel{+}{\Delta}$ \\
\hline O) & & $\begin{array}{l}n \\
n \\
n\end{array}$ & $\begin{array}{l}\stackrel{P}{+} \\
\infty \\
\infty \\
\stackrel{d}{0}\end{array}$ & $\begin{array}{l}\vec{n} \\
\grave{n}\end{array}$ & $\begin{array}{c}\text { లె. } \\
\text { లె }\end{array}$ & $\begin{array}{l}\stackrel{ \pm}{~} \\
\dot{\sim} \\
n\end{array}$ & $\frac{n}{a}$ & $\stackrel{ }{i}$ & 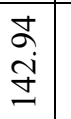 & 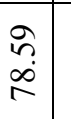 & $\begin{array}{l}\stackrel{0}{\infty} \\
\stackrel{\infty}{\infty}\end{array}$ & & 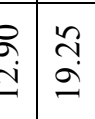 & $\begin{array}{l}\infty \\
\stackrel{i}{i} \\
\dot{i}\end{array}$ & $\frac{\infty}{\Delta}$ & 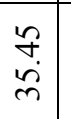 & $\begin{array}{l}\infty \\
\infty \\
i \\
n\end{array}$ & $\begin{array}{l}\vec{n} \\
\tilde{\Xi}\end{array}$ & 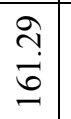 & $\begin{array}{l}0 \\
\stackrel{\infty}{\Xi} \\
\Xi \\
=\end{array}$ & $\begin{array}{l}\stackrel{\vartheta}{f} \\
\stackrel{J}{\Xi}\end{array}$ \\
\hline そ) & & 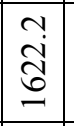 & $\begin{array}{l}\vec{i} \\
\stackrel{0}{0} \\
\end{array}$ & $\hat{\stackrel{2}{0}}$ & 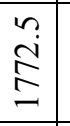 & $\begin{array}{l}n \\
\stackrel{+}{+} \\
\infty \\
-\end{array}$ & $\begin{array}{l}\stackrel{+}{+} \\
\stackrel{\infty}{-} \\
\end{array}$ & 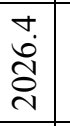 & $\begin{array}{l}n \\
\stackrel{n}{N} \\
\end{array}$ & $\begin{array}{l}n \\
n \\
\infty \\
o \\
\sigma \\
\end{array}$ & $\begin{array}{l}\dot{v} \\
\dot{q} \\
\dot{J} \\
\end{array}$ & & \begin{tabular}{l|l}
+ \\
\end{tabular}$\stackrel{?}{\stackrel{n}{n}}$ & iे. & \begin{tabular}{|l|} 
\\
$\infty$ \\
$\infty$ \\
$\sim$ \\
$\tilde{N}$ \\
\end{tabular} & $\frac{N}{n}$ & $\begin{array}{l}+\dot{+} \\
\dot{\sim} \\
m \\
\end{array}$ & $\begin{array}{c}\tilde{Z} \\
\tilde{\sigma} \\
\tilde{\sigma}\end{array}$ & $\begin{array}{l}a \\
\infty \\
0 \\
n\end{array}$ & $\begin{array}{l}\stackrel{0}{\dot{ \pm}} \\
\stackrel{\vec{\sim}}{ } \\
\end{array}$ & $\begin{array}{l}n \\
\infty \\
\infty \\
=\end{array}$ \\
\hline 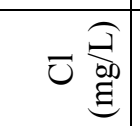 & & $\stackrel{9}{9}$ & $\underset{\text { iे }}{i}$ & $\overrightarrow{\mathrm{i}}$ & $\begin{array}{l}0 \\
\stackrel{1}{i}\end{array}$ & $\stackrel{n}{i}$ & $\overrightarrow{\vec{i}}$ & $\begin{array}{l}\vec{\infty} \\
i\end{array}$ & 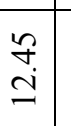 & $\begin{array}{c}\stackrel{ \pm}{~} \\
\stackrel{\infty}{+}\end{array}$ & $\underset{\substack{\infty \\
\dot{+}}}{\infty}$ & & ڤू & $\stackrel{n}{6}$ & $\stackrel{\infty}{\infty}$ & $\stackrel{\infty}{n}$ & $\stackrel{\sim}{n}$ & $\stackrel{\infty}{\infty}$ & $\stackrel{n}{m}$ & 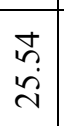 & $\begin{array}{l}\stackrel{\Xi}{\sim} \\
\underset{\sim}{\Delta}\end{array}$ \\
\hline 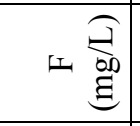 & & & & & & & & & & & & & & & & & & & & & \\
\hline 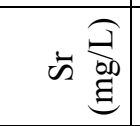 & & $\tilde{n}$ & $\begin{array}{l}\infty \\
\infty \\
0\end{array}$ & 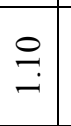 & શે & $\underset{+}{\stackrel{+}{*}}$ & $\stackrel{n}{n}$ & $\stackrel{ \pm}{-}$ & $\begin{array}{l}\underset{\infty}{\infty} \\
\stackrel{i}{i}\end{array}$ & $\begin{array}{l}\dot{0} \\
\dot{+} \\
\dot{n}\end{array}$ & $\begin{array}{l}\text { \&े } \\
\text { in }\end{array}$ & "n & $\begin{array}{l}t \\
\qquad \\
\end{array}$ & $\stackrel{\varrho}{\rightrightarrows}$ & $\begin{array}{c}\infty \\
\stackrel{n}{-}\end{array}$ & $\stackrel{n}{n}$ & 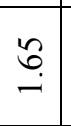 & $\underline{\sigma}$ & $\underset{\dot{C}}{i}$ & $\begin{array}{l}\stackrel{n}{n} \\
\dot{n}\end{array}$ & $\stackrel{\vec{m}}{m}$ \\
\hline 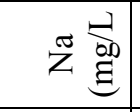 & & $\hat{\infty}$ & $\begin{array}{l}0 \\
\stackrel{0}{0} \\
9\end{array}$ & $\begin{array}{l}\vec{n} \\
\ddot{n}\end{array}$ & 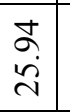 & $\begin{array}{l} \\
\stackrel{2}{0} \\
\text { i }\end{array}$ & $\begin{array}{l}\text { I } \\
\stackrel{0}{0} \\
\text { en }\end{array}$ & $\begin{array}{l}\circ \\
\infty \\
i \\
\infty\end{array}$ & $\frac{\partial}{\dot{\theta}}$ & $\begin{array}{l}\text { ڤे } \\
\text { ஸे }\end{array}$ & กิ & $\stackrel{\text { ㄱ}}{r}$ & 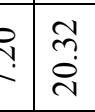 & 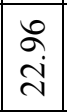 & 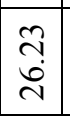 & $\begin{array}{l}8 \\
\stackrel{1}{N}\end{array}$ & 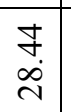 & $\underset{m}{\dot{m}}$ & $\begin{array}{l}\widetilde{\alpha} \\
\stackrel{j}{n}\end{array}$ & $\begin{array}{l}\vec{N} \\
\stackrel{f}{f}\end{array}$ & $\begin{array}{l}\stackrel{\partial}{\circ} \\
\dot{f}\end{array}$ \\
\hline 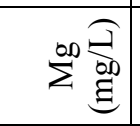 & & $\begin{array}{l}\dot{8} \\
\dot{0} \\
\end{array}$ & $\stackrel{n}{n}$ & $\begin{array}{l}8 \\
\dot{n} \\
n\end{array}$ & $\begin{array}{l}\infty \\
\dot{0} \\
\dot{b}\end{array}$ & 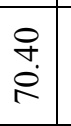 & 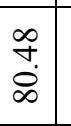 & $\begin{array}{l}\text { ํ. } \\
\text { Һ̊ }\end{array}$ & $\begin{array}{l}\stackrel{0}{\oplus} \\
\stackrel{m}{\emptyset}\end{array}$ & 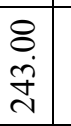 & $\begin{array}{l}8 \\
n \\
0 \\
n \\
n\end{array}$ & ๗ิ & 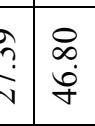 & $\begin{array}{l}\dot{m} \\
m \\
\infty \\
n\end{array}$ & $\overrightarrow{\tilde{n}}$ & 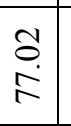 & $\begin{array}{l}\tilde{v} \\
\dot{0} \\
\infty\end{array}$ & $\begin{array}{l}\infty \\
0 \\
\circ\end{array}$ & $\begin{array}{l}\stackrel{P}{+} \\
\stackrel{0}{\Xi} \\
=\end{array}$ & 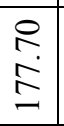 & $\begin{array}{l}8 \\
8 \\
8 \\
\end{array}$ \\
\hline ت & & $\begin{array}{l}\infty \\
8 \\
8 \\
0 \\
\end{array}$ & $\begin{array}{l} \\
\\
0 \\
0 \\
0\end{array}$ & 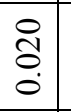 & $\begin{array}{l}\stackrel{J}{\Delta} \\
0 \\
0\end{array}$ & 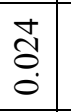 & 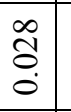 & $\begin{array}{l} \\
\\
0 \\
0 \\
0\end{array}$ & 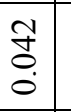 & \begin{tabular}{l|} 
\\
$\dot{0}$ \\
$\vdots$ \\
0
\end{tabular} & $\begin{array}{l}0 \\
8 \\
0 \\
0\end{array}$ & $\begin{array}{l}\text { O } \\
0 \\
0\end{array}$ & 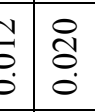 & \begin{tabular}{|l|} 
\\
\\
0 \\
0 \\
0
\end{tabular} & \begin{tabular}{|l|} 
\\
\\
0 \\
0 \\
\end{tabular} & $\begin{array}{l}0 \\
0 \\
0 \\
0 \\
0\end{array}$ & $\begin{array}{l} \\
\\
0 \\
0 \\
\end{array}$ & 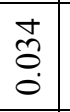 & 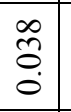 & $\begin{array}{l}\infty \\
0 \\
0 \\
0 \\
0\end{array}$ & \begin{tabular}{l}
\multirow{2}{*}{} \\
\multirow{2}{0}{} \\
0
\end{tabular} \\
\hline 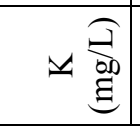 & & $\stackrel{i}{i}$ & बे & $\begin{array}{l}\underset{+}{+} \\
\dot{*}\end{array}$ & $\stackrel{n}{n}$ & $\underset{⿱ ㇒}{ \pm}$ & $=$ & సู่ & $\frac{m}{\infty}$ & $\begin{array}{l}\stackrel{q}{+} \\
=\end{array}$ & $\begin{array}{l}\hat{6} \\
=\end{array}$ & $\stackrel{n}{n}$ & \begin{tabular}{c|c}
$G$ & $\vec{J}$ \\
& $\stackrel{+}{+}$
\end{tabular} & ֶָ. & $\begin{array}{l}\infty \\
\infty \\
i \\
\dot{n}\end{array}$ & बे. & 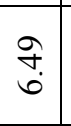 & o. & $\stackrel{\circ}{\circ}$ & $\begin{array}{l}0 \\
\stackrel{n}{0} \\
\stackrel{n}{n}\end{array}$ & $\frac{1}{0}$ \\
\hline 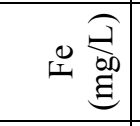 & & $\begin{array}{l}\text { तิ } \\
0 \\
0\end{array}$ & 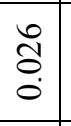 & 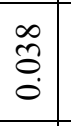 & $\begin{array}{l}\stackrel{0}{0} \\
0 \\
0\end{array}$ & 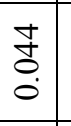 & \begin{tabular}{l}
\multirow{2}{*}{} \\
0 \\
0
\end{tabular} & $\begin{array}{l}0 \\
\stackrel{2}{0} \\
0\end{array}$ & 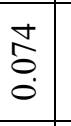 & $\begin{array}{l} \pm \\
\\
\end{array}$ & 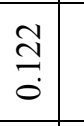 & $\begin{array}{l}\text { ¿े } \\
\text { Oे. } \\
0\end{array}$ & 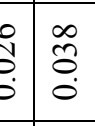 & 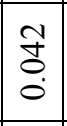 & $\begin{array}{l}\dot{H} \\
0 \\
0 \\
0\end{array}$ & $\begin{array}{l}0 \\
0 \\
0 \\
0\end{array}$ & $\begin{array}{l}8 \\
0 \\
0 \\
0\end{array}$ & $\begin{array}{l}\text { ț } \\
\stackrel{0}{0} \\
0\end{array}$ & $\begin{array}{l}\stackrel{0}{0} \\
\stackrel{0}{0}\end{array}$ & \begin{tabular}{l}
8 \\
\hdashline \\
\end{tabular} & $\begin{array}{l}\dot{J} \\
\stackrel{2}{\circ} \\
\stackrel{0}{0}\end{array}$ \\
\hline 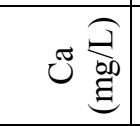 & & $\overrightarrow{8}$ & $\hat{\sim}$ & $\begin{array}{l}\infty \\
\infty \\
\infty \\
-\end{array}$ & $\begin{array}{l}\infty \\
\dot{0} \\
\stackrel{N}{N}\end{array}$ & $\begin{array}{l}0 \\
\dot{\infty} \\
\stackrel{+}{\sim}\end{array}$ & $\begin{array}{l}\sim \\
\infty \\
\infty \\
\sim\end{array}$ & $\begin{array}{c}\stackrel{9}{+} \\
\dot{+}\end{array}$ & $\begin{array}{l}\infty \\
\infty \\
\dot{\sigma}\end{array}$ & $\begin{array}{l}\infty \\
\ddot{n} \\
\alpha\end{array}$ & $\begin{array}{l}0 \\
\tilde{n} \\
\hat{0}\end{array}$ & ?̊ & 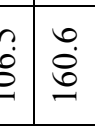 & $\begin{array}{l}0 \\
\ddot{i} \\
\dot{\imath}\end{array}$ & $\begin{array}{l}\infty \\
\\
\\
\sim \\
\end{array}$ & $\begin{array}{l}0 \\
\stackrel{1}{N} \\
\end{array}$ & \begin{tabular}{|l|} 
\\
\\
\\
\end{tabular} & $\stackrel{\sim}{\tilde{m}}$ & $\begin{array}{l}\infty \\
\dot{\infty} \\
\infty \\
m\end{array}$ & $\begin{array}{l}\hat{i} \\
\dot{0}\end{array}$ & $\begin{array}{l}n \\
2 \\
0\end{array}$ \\
\hline $\begin{array}{l}\overline{0} \\
\overrightarrow{0} \\
\\
\end{array}$ & & $\infty$ & $r$ & 0 & $n$ & $\nabla$ & $m$ & $\sim$ & - & 0 & ర & $\infty$ & $\infty \sim$ & 0 & $n$ & $\nabla$ & $m$ & $\sim$ & - & 0 & ర్ \\
\hline & & \multicolumn{10}{|c|}{ 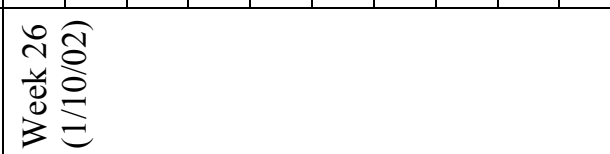 } & \multicolumn{10}{|l|}{ 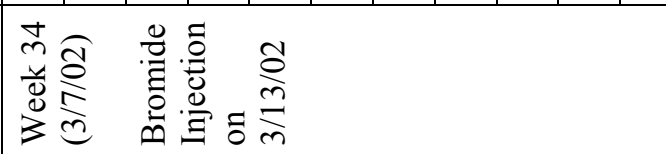 } \\
\hline
\end{tabular}




\begin{tabular}{|c|c|c|c|c|c|c|c|c|c|c|c|c|c|c|c|c|c|c|c|c|c|c|}
\hline 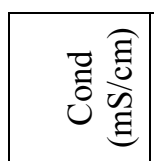 & 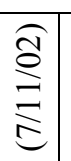 & $\stackrel{\bullet}{\circ}$ & 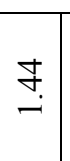 & $\stackrel{ \pm}{I}$ & $\stackrel{\infty}{\Im}$ & $\begin{array}{c}\stackrel{m}{\sim} \\
\vec{i}\end{array}$ & 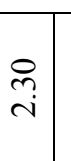 & $\begin{array}{l}\infty \\
\tilde{i} \\
i\end{array}$ & $\begin{array}{l}n \\
\infty \\
\stackrel{\infty}{+} \\
i\end{array}$ & $\begin{array}{l}\hat{b} \\
i\end{array}$ & în & 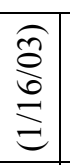 & $\mid \begin{array}{l}n \\
n \\
o\end{array}$ & @ & $\vec{\sim}$ & $\stackrel{+}{n}$ & 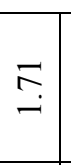 & $\stackrel{8}{\circ}$ & $\stackrel{\text { aे }}{\text { in }}$ & $\stackrel{\widetilde{n}}{\sim}$ & $\begin{array}{l}\tilde{b} \\
i \\
i\end{array}$ & $\begin{array}{l}\hat{b} \\
\dot{1}\end{array}$ \\
\hline$\stackrel{0}{0} \frac{\partial}{\partial}$ & 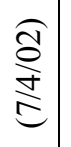 & $\underset{\dot{m}}{ \pm}$ & $\stackrel{\infty}{\sim}$ & $\begin{array}{l}\tilde{n} \\
\tilde{n}\end{array}$ & $\begin{array}{l}\infty \\
\mathfrak{n} \\
i n\end{array}$ & $\stackrel{n}{n}$ & $\begin{array}{l}2 \\
\hat{\infty} \\
\infty\end{array}$ & $\begin{array}{l}\stackrel{\circ}{\varrho} \\
\stackrel{a}{=}\end{array}$ & $\begin{array}{l}\stackrel{\imath}{\hat{i}} \\
\dot{v}\end{array}$ & & & $\begin{array}{l}\overparen{\approx} \\
\stackrel{0}{0} \\
\stackrel{\Xi}{\Xi}\end{array}$ & \begin{tabular}{l}
$\stackrel{0}{8}$ \\
\hdashline \\
$-i$
\end{tabular} & $\begin{array}{l}\stackrel{n}{+} \\
+\end{array}$ & ñ & 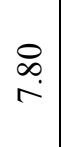 & $\begin{array}{l}\infty \\
\infty \\
\infty\end{array}$ & $\frac{尺}{a}$ & \begin{tabular}{l}
$\stackrel{n}{?}$ \\
\hdashline
\end{tabular} & $\stackrel{\overbrace{}}{=}$ & & \\
\hline$\vec{z}$ & $\frac{\widehat{\Xi}}{\stackrel{2}{\Xi}}$ & $\begin{array}{l}\infty \\
\stackrel{\infty}{r} \\
\end{array}$ & O̦. & $\underset{N}{\sim}$ & 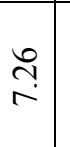 & $\underset{\sigma}{\stackrel{D}{r}}$ & $\stackrel{m}{\pi}$ & $\hat{\sigma}$ & $\vec{r}$ & $\underset{r}{\sigma}$ & 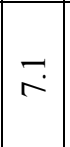 & 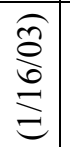 & $\mid \begin{array}{l}\infty \\
\\
\sim\end{array}$ & $\hat{0}$ & $\stackrel{8}{\circ}$ & $\overrightarrow{0}$ & $\begin{array}{l}\infty \\
\text { ğ }\end{array}$ & જ. & హे & $\bar{\sigma}$ & $\begin{array}{l}n \\
\infty \\
0 \\
0\end{array}$ & જૂ \\
\hline 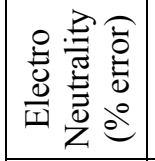 & & $\begin{array}{l}0 \\
n \\
n \\
m\end{array}$ & $\overrightarrow{0}$ & $\begin{array}{l}0 \\
\\
i\end{array}$ & $\stackrel{8}{\stackrel{+}{+}}$ & $\begin{array}{l}\vec{\infty} \\
\dot{1}\end{array}$ & $\begin{array}{l}\stackrel{D}{1} \\
\stackrel{n}{n}\end{array}$ & 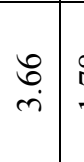 & $\stackrel{\infty}{\stackrel{\infty}{-}}$ & $\begin{array}{l}8 \\
\dot{n}\end{array}$ & $\begin{array}{c}\bar{\sigma} \\
\dot{m}\end{array}$ & & 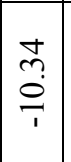 & $\begin{array}{l}8 \\
\dot{0} \\
i \\
i\end{array} \mid$ & $\stackrel{n}{q}$ & $\begin{array}{l}\tilde{n} \\
\dot{n}\end{array}$ & $\stackrel{\infty}{\underset{T}{T}}$ & $\begin{array}{l}0 \\
\infty \\
i\end{array}$ & $\begin{array}{l}\stackrel{0}{0} \\
\text { ì }\end{array}$ & ஸ़ & $\begin{array}{l}8 \\
i \\
i\end{array}$ & $\vec{i}$ \\
\hline 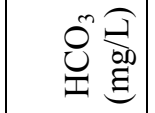 & & 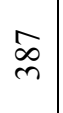 & हे & $\stackrel{?}{\sim}$ & 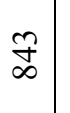 & $\frac{0}{a}$ & ஜ & ำ & ఠิ & $\stackrel{\tilde{\theta}}{0}$ & $\stackrel{0}{\infty}$ & & $\vec{n}$ & $\frac{\pi}{n}$ & $\begin{array}{l}\infty \\
8 \\
8\end{array}$ & 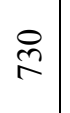 & $\stackrel{ }{\underset{N}{*}}$ & 앙 & $\stackrel{\infty}{\curvearrowright}$ & $\stackrel{2}{\approx}$ & $\frac{N}{\infty}$ & $\hat{\infty}$ \\
\hline O) & & $\begin{array}{l}\hat{n} \\
\hat{n}\end{array}$ & $\begin{array}{l}\hat{b} \\
\underline{-}\end{array}$ & $\begin{array}{c}n \\
\tilde{n}\end{array}$ & $\begin{array}{l}\infty \\
0 \\
\dot{d}\end{array}$ & 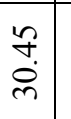 & $\begin{array}{l}\stackrel{g}{+} \\
\dot{b}\end{array}$ & 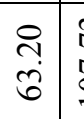 & 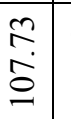 & $\begin{array}{l}\hat{\sigma} \\
\dot{v} \\
\dot{J}\end{array}$ & $\begin{array}{l} \\
\vdots \\
0 \\
n \\
n\end{array}$ & & $\stackrel{9}{\Xi}$ & $\ddot{\sigma}$ & $\frac{0}{\grave{\lambda}}$ & $\stackrel{\dot{\rho}}{\dot{n}}$ & $\stackrel{\sim}{\stackrel{\sim}{m}}$ & $\stackrel{m}{m}$ & $\vec{r}$ & $\ddot{g}$ & $\hat{\theta}$ & $\overline{\check{I}}$ \\
\hline 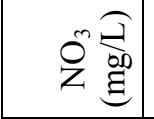 & & $\stackrel{\ddot{i}}{i}$ & \begin{tabular}{l|}
$\dot{J}$ \\
\end{tabular} & ๙े & $\stackrel{n}{\dddot{n}}$ & $\begin{array}{l}\overrightarrow{8} \\
\text { ळे }\end{array}$ & 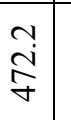 & \begin{tabular}{l|l}
$\sim$ \\
\\
\end{tabular} & $\begin{array}{l}0 \\
\dot{0} \\
\dot{0} \\
\text { in }\end{array}$ & $\begin{array}{l}0 \\
\infty \\
0 \\
0 \\
0\end{array}$ & $\begin{array}{l}0 \\
i \\
\sigma \\
\end{array}$ & & $\frac{n}{\dot{\gamma}}$ & 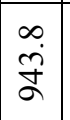 & $\begin{array}{l}\dot{\sigma} \\
\stackrel{a}{\sigma}\end{array}$ & $\begin{array}{l}\mathfrak{c} \\
\infty \\
\end{array}$ & $\frac{m}{n}$ & 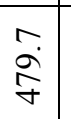 & $\begin{array}{l}n \\
\tilde{n} \\
\tilde{n}\end{array}$ & సิ & $\hat{\mathscr{o}}$ & $\begin{array}{l}n \\
n \\
n\end{array}$ \\
\hline 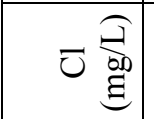 & & $\underset{-}{\sigma}$ & $\begin{array}{l}\infty \\
\infty \\
0\end{array}$ & $\begin{array}{c}\infty \\
0 \\
0\end{array}$ & $\underset{\text { aे }}{\text { in }}$ & $\stackrel{\varrho}{-}$ & $\stackrel{\infty}{\infty}$ & $\begin{array}{l}\tilde{\sigma} \\
\text { i } \\
\end{array}$ & $\stackrel{\hat{c}}{i}$ & $\stackrel{\sim}{\sim}$ & $\mid \begin{array}{l} \pm \\
\infty \\
\sim \\
\dot{n}\end{array}$ & & $\begin{array}{l}n \\
0 \\
-1\end{array}$ & $\begin{array}{l}n \\
0 \\
- \\
-\end{array}$ & o. & $\stackrel{?}{\stackrel{n}{+}}$ & $\stackrel{\overbrace{}}{-}$ & $\stackrel{\infty}{\stackrel{\infty}{-}}$ & 占 & $\overrightarrow{\mathrm{n}}$ & $\begin{array}{l}\mathfrak{S} \\
\mathrm{i}\end{array}$ & ñ \\
\hline 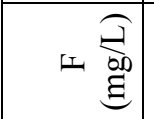 & & & & & & & & & & & & & $\bar{n}$ & $\tilde{n}$ & 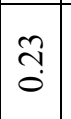 & $\stackrel{\simeq}{\underset{0}{0}}$ & $\hat{0}$ & $\vec{ก}$ & $\stackrel{0}{\circ}$ & 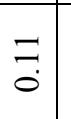 & $\stackrel{n}{0}$ & $\stackrel{2}{\stackrel{0}{0}}$ \\
\hline 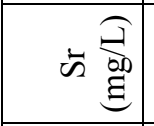 & & $\hat{n}$ & סِ & $\begin{array}{l}0 \\
= \\
=\end{array}$ & $\stackrel{?}{n}$ & $\underset{-}{\sigma}$ & $\begin{array}{l}\infty \\
\infty \\
-\end{array}$ & $\vec{\sigma}$ & $\begin{array}{c}\stackrel{n}{i} \\
\vec{i}\end{array}$ & $\stackrel{\infty}{m}$ & 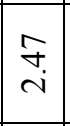 & & f & $\mid \begin{array}{l}0 \\
0\end{array}$ & $\underset{\text { ¿ }}{0}$ & $\stackrel{\cong}{\leftrightarrows}$ & $\stackrel{n}{?}$ & $\stackrel{n}{n}$ & $\stackrel{+}{\stackrel{ }{Z}}$ & $\widehat{\Omega}$ & $\begin{array}{c}0 \\
\stackrel{1}{i}\end{array}$ & $\stackrel{\tilde{n}}{i}$ \\
\hline Z & & $\underset{\hat{\sigma}}{\stackrel{2}{0}}$ & $\begin{array}{l}\infty \\
0 \\
0 \\
0\end{array}$ & $\begin{array}{l}\vec{\sigma} \\
\dot{\sim}\end{array}$ & $\stackrel{n}{\stackrel{n}{\delta}}$ & $\begin{array}{l}\text { กे } \\
\text { ลे }\end{array}$ & $\begin{array}{l}0 \\
\tilde{n} \\
0 \\
n \\
n\end{array}$ & $\begin{array}{ll}n \\
i \\
i\end{array}$ & $\begin{array}{l}\vec{\sim} \\
\dot{m} \\
\dot{m}\end{array}$ & $\begin{array}{l}+ \\
\infty \\
\infty \\
\infty\end{array}$ & $\frac{n}{m}$ & & $\begin{array}{l}n \\
\tilde{n} \\
0 \\
\end{array}$ & $\vec{f}$ & 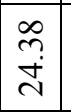 & $\vec{~}$ & $\begin{array}{l}\text { ஸे } \\
\stackrel{\text { nे }}{ }\end{array}$ & $\begin{array}{l}m \\
\stackrel{m}{m}\end{array}$ & $\begin{array}{l}\vec{\infty} \\
\dot{j}\end{array}$ & $\begin{array}{l}\stackrel{n}{n} \\
\dot{m}\end{array}$ & $\begin{array}{l}\tilde{b} \\
\dot{f}\end{array}$ & $\begin{array}{l}\infty \\
n \\
i \\
f\end{array}$ \\
\hline 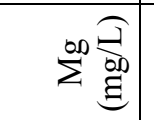 & & $\begin{array}{l}\hat{N} \\
\infty \\
i\end{array}$ & $\begin{array}{l}\infty \\
\stackrel{2}{+} \\
\dot{f}\end{array}$ & $\begin{array}{l}\hat{b} \\
\ddot{n} \\
i n\end{array}$ & $\begin{array}{l}\vec{b} \\
\stackrel{0}{0}\end{array}$ & $\begin{array}{l}\infty \\
n \\
2\end{array}$ & $\begin{array}{l}\tilde{1} \\
\infty \\
\infty \\
\infty\end{array}$ & 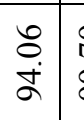 & $\begin{array}{l}2 \\
\stackrel{2}{a}\end{array}$ & 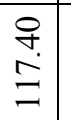 & $\begin{array}{l}\dot{8} \\
\dot{\theta} \\
=\end{array}$ & & $\begin{array}{l}\infty \\
\infty \\
\infty \\
-\end{array}$ & $\begin{array}{l}m \\
\tilde{n} \\
n\end{array}$ & $\begin{array}{l}\dot{y} \\
m \\
i \\
y\end{array}$ & $\begin{array}{l}\stackrel{a}{1} \\
\dot{n}\end{array}$ & $\begin{array}{l}8 \\
0 \\
i \\
i\end{array}$ & $\stackrel{\overbrace{}}{\pi}$ & 함 & 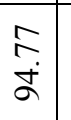 & $\begin{array}{l}\hat{N} \\
\infty \\
0 \\
0\end{array}$ & $\bar{\sigma}$ \\
\hline 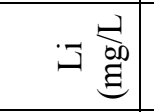 & & $\begin{array}{l} \\
\\
\\
\end{array}$ & 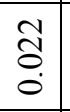 & 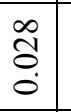 & 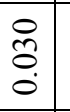 & $\begin{array}{l}0 \\
0 \\
0 \\
0\end{array}$ & \begin{tabular}{l|} 
\\
$\tilde{O}$ \\
0 \\
0
\end{tabular} & 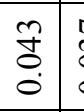 & $\begin{array}{l}\hat{\sigma} \\
\hat{0} \\
0\end{array}$ & 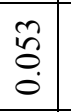 & $\begin{array}{l} \\
\\
0 \\
0 \\
\end{array}$ & & \begin{tabular}{|l|} 
\\
\\
0 \\
0 \\
\end{tabular} & \begin{tabular}{|l|} 
\\
\\
0 \\
0
\end{tabular} & $\begin{array}{l}m \\
0 \\
0 \\
0\end{array}$ & $\begin{array}{l} \\
0 \\
0 \\
0 \\
\end{array}$ & $\begin{array}{l} \\
\\
0 \\
0 \\
0\end{array}$ & 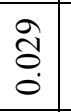 & 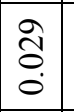 & 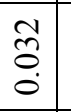 & 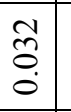 & $\begin{array}{l}2 \\
\tilde{\sigma} \\
0 \\
\end{array}$ \\
\hline 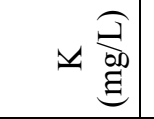 & & $\begin{array}{l}\infty \\
\infty \\
\dot{n}\end{array}$ & $\begin{array}{l}\tilde{N} \\
\text { in }\end{array}$ & $\frac{n}{6}$ & 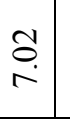 & 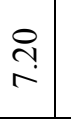 & $\begin{array}{l}\tilde{\infty} \\
0 \\
0\end{array}$ & \begin{tabular}{l|l}
0 & 0 \\
$\infty$ & \\
$\infty$ & 1
\end{tabular} & $\stackrel{\infty}{\stackrel{\infty}{\sim}}$ & $\stackrel{\overbrace{}}{a}$ & $\begin{array}{l}\widehat{\sigma} \\
\infty \\
\infty\end{array}$ & & $\stackrel{+}{\stackrel{+}{-}}$ & $\hat{\hat{i}}$ & \begin{tabular}{|c|}
$\infty$ \\
0 \\
$\dot{m}$ \\
$\dot{n}$
\end{tabular} & $\stackrel{\sim}{\tilde{r}}$ & $\stackrel{\tilde{r}}{+}$ & $\begin{array}{l}\infty \\
\dot{\forall}\end{array}$ & $\begin{array}{l}\overrightarrow{\dot{n}} \\
\dot{n}\end{array}$ & $\begin{array}{l}+ \\
\infty \\
i\end{array}$ & గี & 帝 \\
\hline 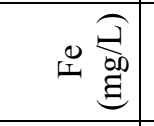 & & $\begin{array}{c}0 \\
0 \\
0\end{array}$ & $\begin{array}{l}\text { Iิ } \\
\text {. }\end{array}$ & ڤె & $\begin{array}{l}\stackrel{+}{0} \\
0 \\
0\end{array}$ & $\begin{array}{l}\vec{J} \\
\stackrel{0}{0}\end{array}$ & $\stackrel{n}{\stackrel{n}{0}}$ & \begin{tabular}{l}
0 \\
\multirow{0}{0}{} \\
0
\end{tabular} & $\begin{array}{l}\infty \\
0 \\
0\end{array}$ & $\begin{array}{l}\hat{0} \\
0 \\
0\end{array}$ & $\begin{array}{l}n \\
\tilde{o} \\
\dot{0}\end{array}$ & & $\begin{array}{l}\overline{8} \\
0 \\
0\end{array}$ & $\begin{array}{l}\overrightarrow{8} \\
0 \\
0\end{array}$ & 官 & 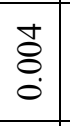 & ڤ̊̊̊ & $\begin{array}{l}0 \\
8 \\
0\end{array}$ & $\begin{array}{l}\text { Oे } \\
8 \\
0 \\
0\end{array}$ & \begin{tabular}{l}
\multirow{8}{0}{} \\
$\stackrel{0}{0}$
\end{tabular} & $\begin{array}{l}0 \\
8 \\
0\end{array}$ & $\begin{array}{l}2 \\
0 \\
0 \\
0\end{array}$ \\
\hline 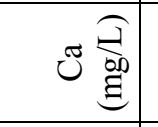 & & $\begin{array}{l}\vec{a} \\
=\end{array}$ & $\stackrel{\sim}{i}$ & $\begin{array}{l}\infty \\
\stackrel{\infty}{\sim}\end{array}$ & $\begin{array}{l}\stackrel{0}{0} \\
\stackrel{0}{0}\end{array}$ & ָ̀. & $\begin{array}{l}\dot{\nabla} \\
\underset{\sim}{2}\end{array}$ & \begin{tabular}{|l|l}
\multirow{T}{*}{} \\
$\stackrel{+}{+}$
\end{tabular} & $\begin{array}{l}0 \\
\stackrel{0}{0} \\
\stackrel{n}{n}\end{array}$ & $\begin{array}{l}\vec{v} \\
\ddot{b} \\
\ddot{v}\end{array}$ & $\begin{array}{c}\stackrel{0}{\sim} \\
\stackrel{F}{f} \\
\end{array}$ & & $\stackrel{n}{n}$ & \begin{tabular}{l|} 
\\
$\dot{0}$ \\
\\
\end{tabular} & 品 & $\stackrel{m}{a}$ & $\stackrel{n}{\sim}$ & $\begin{array}{l}\infty \\
\stackrel{+}{\sim} \\
\end{array}$ & $\stackrel{+}{\stackrel{0}{~}}$ & $\stackrel{+}{\dot{\vec{d}}}$ & $\begin{array}{l}\hat{b} \\
\text { లn } \\
\end{array}$ & $\underset{n}{N}$ \\
\hline$\vec{\circlearrowright}$ & & $\infty$ & $r$ & 6 & $n$ & $\nabla$ & $m$ & $N$ & - & ర & ర) & & $\infty$ & $r$ & 6 & $n$ & $\nabla$ & $m$ & $\sim$ & - & 8 & ర) \\
\hline & \multicolumn{11}{|c|}{ 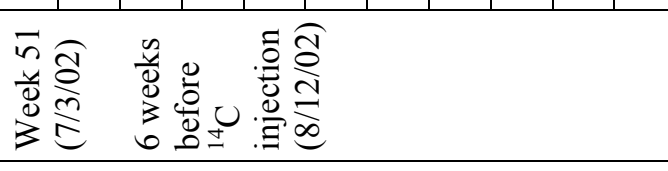 } & \multicolumn{11}{|c|}{ 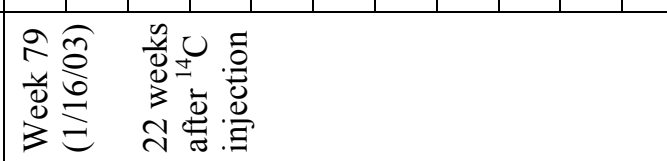 } \\
\hline
\end{tabular}




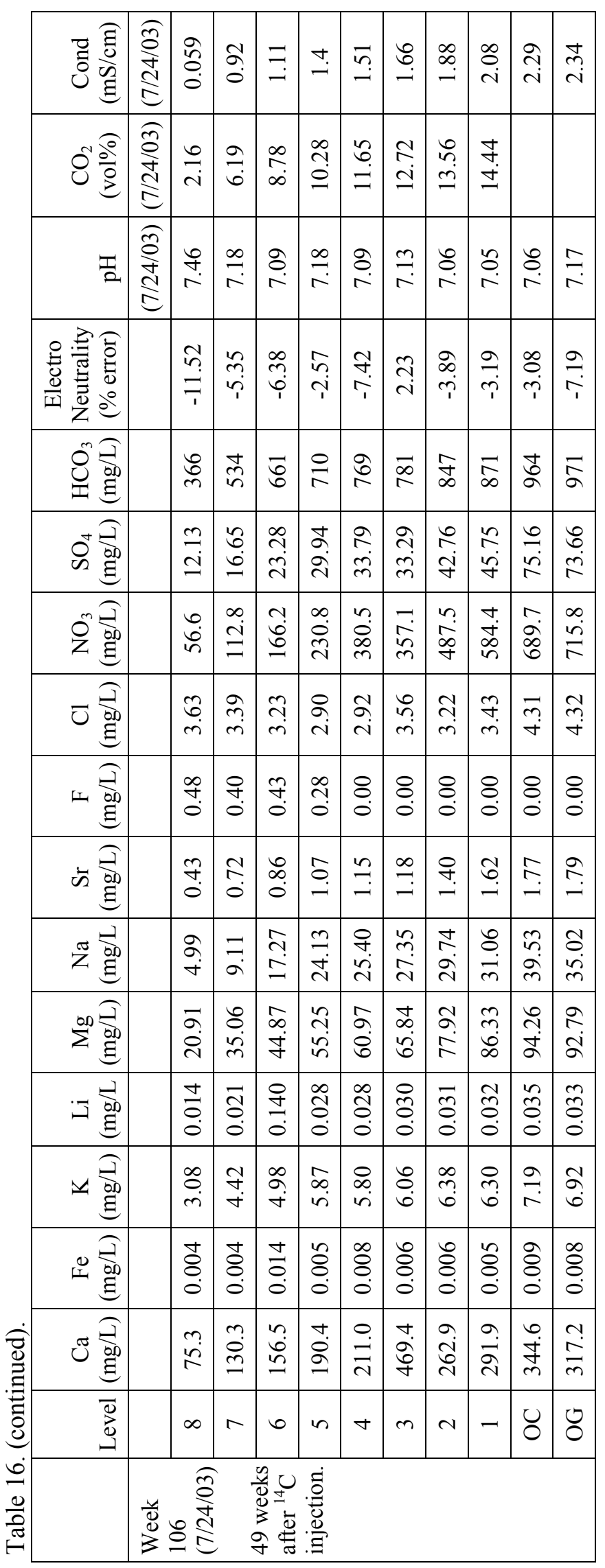


Table 17. $\mathrm{pH}$, bicarbonate alkalinity, and $\mathrm{CO}_{2}$ six days prior to ${ }^{14} \mathrm{C}$ injection.

\begin{tabular}{|l|c|c|c|c|c|c|c|c|}
\hline & \multicolumn{8}{|c|}{ Column Level } \\
\hline & 1 & 2 & 3 & 4 & 5 & 6 & 7 & 8 \\
\hline $\mathrm{pH}( \pm 0.3 \%)$ & 6.91 & 6.94 & 6.99 & 7.00 & 7.03 & 6.97 & 7.09 & 7.36 \\
\hline $\mathrm{HCO}_{3}, \mathrm{mg} \mathrm{L}^{-1}\left( \pm 10 \mathrm{mg} \mathrm{L}^{-1}\right)$ & 998 & 964 & 911 & 834 & 886 & 809 & 627 & 399 \\
\hline $\mathrm{CO}_{2}, \mathrm{vol} \%( \pm 1 \%)$ & 16.21 & 15.13 & 14.03 & 12.78 & 11.18 & 9.33 & 6.42 & 2.16 \\
\hline
\end{tabular}

Table 18. Average $\mathrm{pH}, \mathrm{CO}_{2}, \mathrm{O}_{2}$, and bicarbonate profiles during transport study (Weeks 56 through 106 of water infiltration).

\begin{tabular}{|c|c|c|c|c|c|}
\hline $\begin{array}{c}\text { Column } \\
\text { Level }\end{array}$ & $\begin{array}{c}\text { Depth from Surface } \\
(\mathrm{cm})\end{array}$ & $\begin{array}{c}\mathrm{pH} \\
( \pm 0.3 \%)\end{array}$ & $\begin{array}{c}\mathrm{CO}_{2} \\
( \pm 2 \mathrm{vol} \%)\end{array}$ & $\begin{array}{c}\mathrm{O}_{2} \\
( \pm 1 \mathrm{vol} \%)\end{array}$ & $\begin{array}{c}\mathrm{HCO}_{3} \\
\left( \pm 10 \mathrm{mg} \mathrm{L}^{-1}\right)\end{array}$ \\
\hline 8 & 15.2 & 7.39 & 1.73 & 19.25 & 361 \\
\hline 7 & 45.7 & 7.16 & 4.99 & 15.94 & 552 \\
\hline 6 & 76.2 & 7.08 & 7.12 & 13.72 & 676 \\
\hline 5 & 106.7 & 7.07 & 8.36 & 12.59 & 745 \\
\hline 4 & 137.2 & 7.03 & 9.53 & 11.47 & 773 \\
\hline 3 & 167.6 & 7.03 & 10.44 & 10.55 & 798 \\
\hline 2 & 198.1 & 6.99 & 11.25 & 9.72 & 831 \\
\hline 1 & 228.6 & 6.98 & 12.08 & 8.78 & 880 \\
\hline OC & 243.8 & 6.94 & - & - & 901 \\
\hline OG & 243.8 & 6.97 & - & - & 892 \\
\hline
\end{tabular}



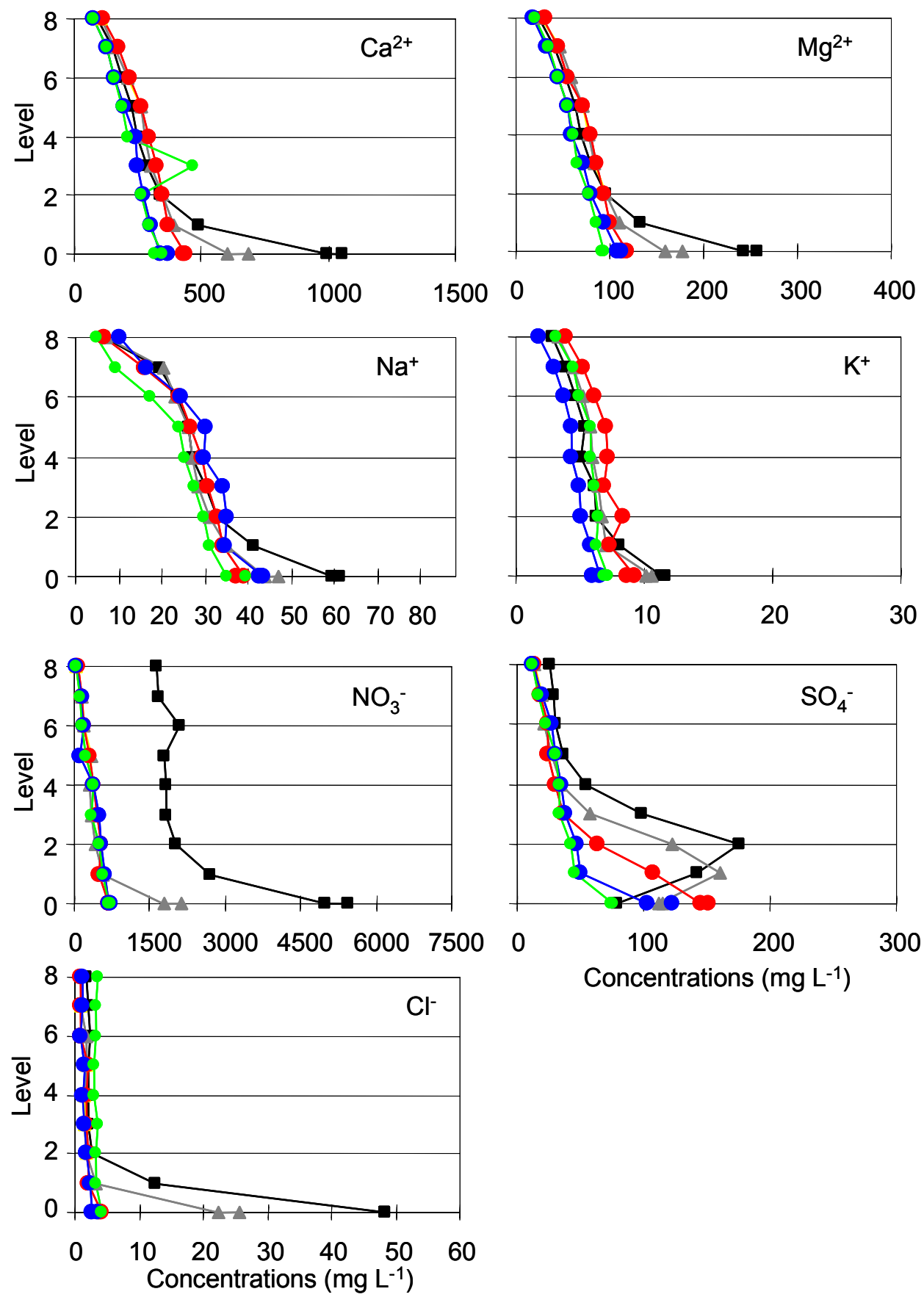

Figure 16. Aqueous chemistry and sediment $\mathrm{CO}_{2}$ gas profiles (legend on next page). 

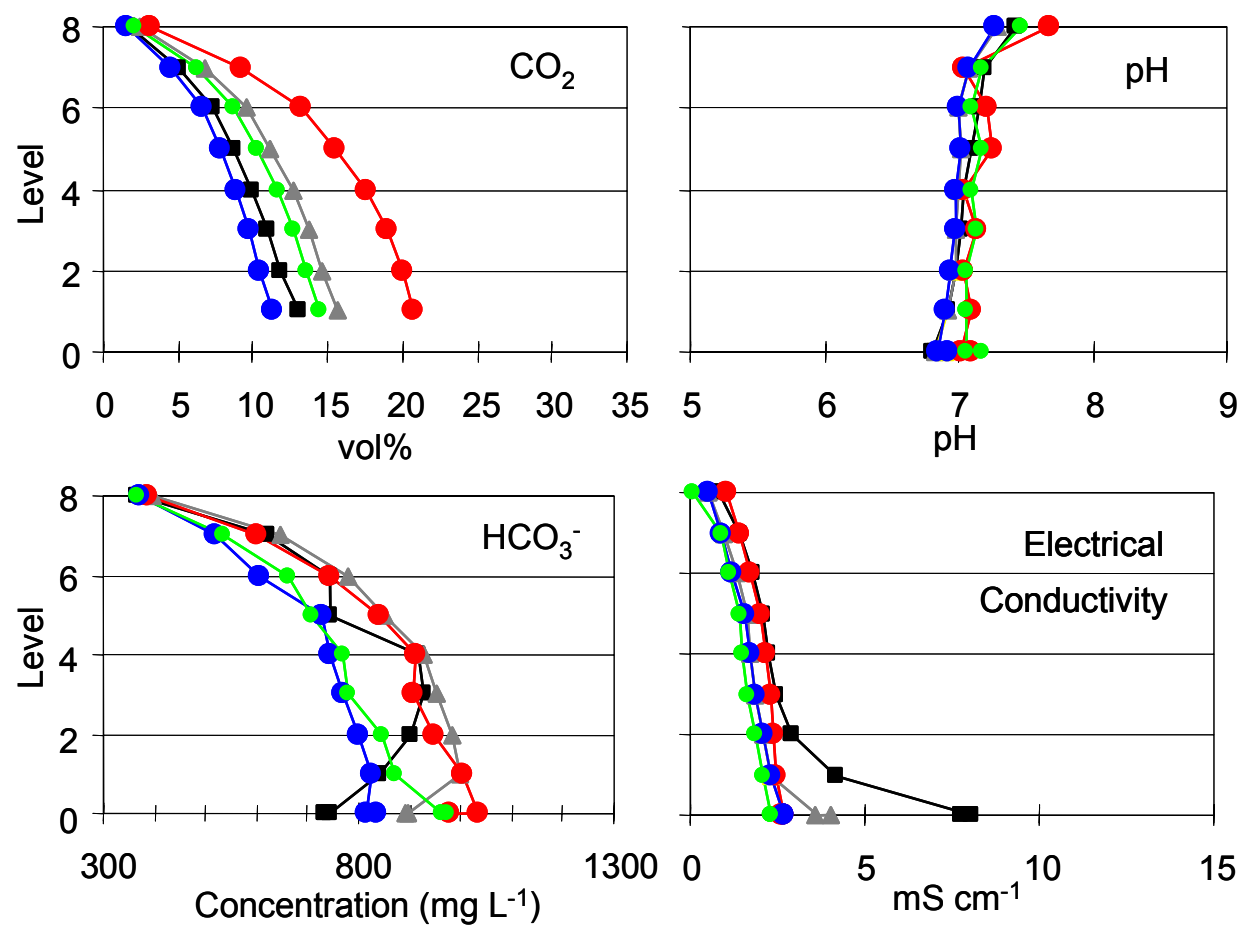

$$
\begin{aligned}
& \longrightarrow-26 \text { weeks after start of infiltration (12 week after water reached bottom) } \\
& -34 \text { weeks after start of infiltration ( } 1 \text { week before } \mathrm{Br} \text { injection \#1) } \\
& -51 \text { weeks after start of infiltration ( } 6 \text { weeks before }{ }^{14} \mathrm{C} \text { injection) } \\
& -79 \text { weeks after start of infiltration ( } 22 \text { weeks after }{ }^{14} \mathrm{C} \text { injection) } \\
& -106 \text { weeks after start of infiltration (49 weeks after }{ }^{14} \mathrm{C} \text { injection) }
\end{aligned}
$$

Figure 16. (continued).

Table 19. Dissolved carbon results.

\begin{tabular}{|l|c|c|c|c|}
\hline \multicolumn{1}{|c|}{ Elapse Time } & Level & $\begin{array}{c}\text { Total Carbon } \\
\left(\mathrm{mg} \mathrm{L}^{-1}\right)\end{array}$ & $\begin{array}{c}\text { Inorganic Carbon } \\
\left(\mathrm{mg} \mathrm{L}^{-1}\right)\end{array}$ & $\begin{array}{c}\text { Organic Carbon } \\
\left(\mathrm{mg} \mathrm{L}^{-1}\right)\end{array}$ \\
\hline $\begin{array}{l}\text { Week 16 (11/1/01) or 41 weeks } \\
\text { before }{ }^{14} \text { C injection }\end{array}$ & $0 \mathrm{C}-0 \mathrm{G}$ & 326 & 143 & 183 \\
\hline $\begin{array}{l}\text { Week 106 (7/24/03) or 49 weeks } \\
\text { after 14C injection }\end{array}$ & $0 \mathrm{C}$ & 168 & 151 & 17 \\
\cline { 2 - 5 } & $0 \mathrm{G}$ & 195 & 178 & 17 \\
\cline { 2 - 5 } & 1 & 164 & 151 & 13 \\
\cline { 2 - 5 } & 2 & 167 & 155 & 12 \\
\cline { 2 - 5 } & 3 & 155 & 143 & 9 \\
\cline { 2 - 5 } & 4 & 152 & 143 & 9 \\
\cline { 2 - 5 } & 5 & 146 & 137 & 5 \\
\cline { 2 - 5 } & 6 & 130 & 125 & 4 \\
\cline { 2 - 5 } & 7 & 113 & 109 & 4 \\
\cline { 2 - 5 } & 8 & 71 & 67 & 9 \\
\hline
\end{tabular}




\subsection{3 $\mathrm{CO}_{2}$ and $\mathrm{O}_{2}$ Gas Concentration Monitoring}

In the vadose zone, aqueous/gas partitioning of carbonate species is primarily controlled by microbially-generated $\mathrm{CO}_{2}$. At the SDA, microbial metabolism of organic debris produces sediment gas $\mathrm{CO}_{2}$ concentrations as high as $10 \mathrm{vol} \%$ (Hull and Bishop 2003). Similar $\mathrm{CO}_{2}$ concentrations were observed during the 12-month transport study (Figure 17). $\mathrm{CO}_{2}$ and $\mathrm{O}_{2}$ concentration time series from the start of water application is given in Figure 18. Variations of pore gas $\mathrm{CO}_{2}$ and $\mathrm{O}_{2}$ concentrations are primarily due to sediment temperature fluctuations (Figure 19). A narrative about the $\mathrm{CO}_{2}$ and $\mathrm{O}_{2}$ concentration time series in Figure 18 is provided next to aid interpretation of these data.

The first notable event affecting the data in Figure 18 was an equipment failure that resulted in the loss of data from Weeks 5 to 11 and 35 to 37. Early in the study, pore gas concentrations were disrupted when excessive suction was applied to the effluent lysimeters and atmospheric air was drawn down through the column from the surface. These disruptions, and resulting rebounds of gas concentration, are observed from Weeks 12 to 16 and 26 to 29.

Temperature fluctuations significantly affected pore gas concentrations. Rising temperatures during summer months stimulated microbial $\mathrm{O}_{2}$ consumption and $\mathrm{CO}_{2}$ production. Increased microbial metabolism produced the two relatively large $\mathrm{CO}_{2}$ peaks and $\mathrm{O}_{2}$ valleys observed between Weeks 45 and 60 and again at Week 107 (Figure 18). Given the dynamic nature of the sediment temperature and pore gas relationship, and the fact that the laboratory is heated but not cooled, an autumn date was selected for ${ }^{14} \mathrm{C}$ injection to allow ${ }^{14} \mathrm{C}$ migration to be monitored over the longest possible period of temperature stability. The ${ }^{14} \mathrm{C}$, uranium, and tritium cocktail was injected on August 12, 2002 as declining autumn temperatures allowed pore gas $\mathrm{CO}_{2}$ to approach pre-summer concentrations. Following the injection, a steady decline in $\mathrm{CO}_{2}$ and increase in $\mathrm{O}_{2}$ concentration was observed (Figure 18). The relatively stable sediment temperature and water content (Figures 19 and 13, respectively) over this period of steadily declining $\mathrm{CO}_{2}$ surface flux (Weeks 65 through 95, Figure 19) suggests the steady depletion of easily metabolized carbon. This depletion is further suggested by the dissolved carbon analysis (Table 19).

Control and measurement of the column's headspace ventilation rate was critical to bulk $\mathrm{CO}_{2}$ and ${ }^{14} \mathrm{CO}_{2}$ surface flux calculations. Control of the ventilation rate was hampered by internal condensation in

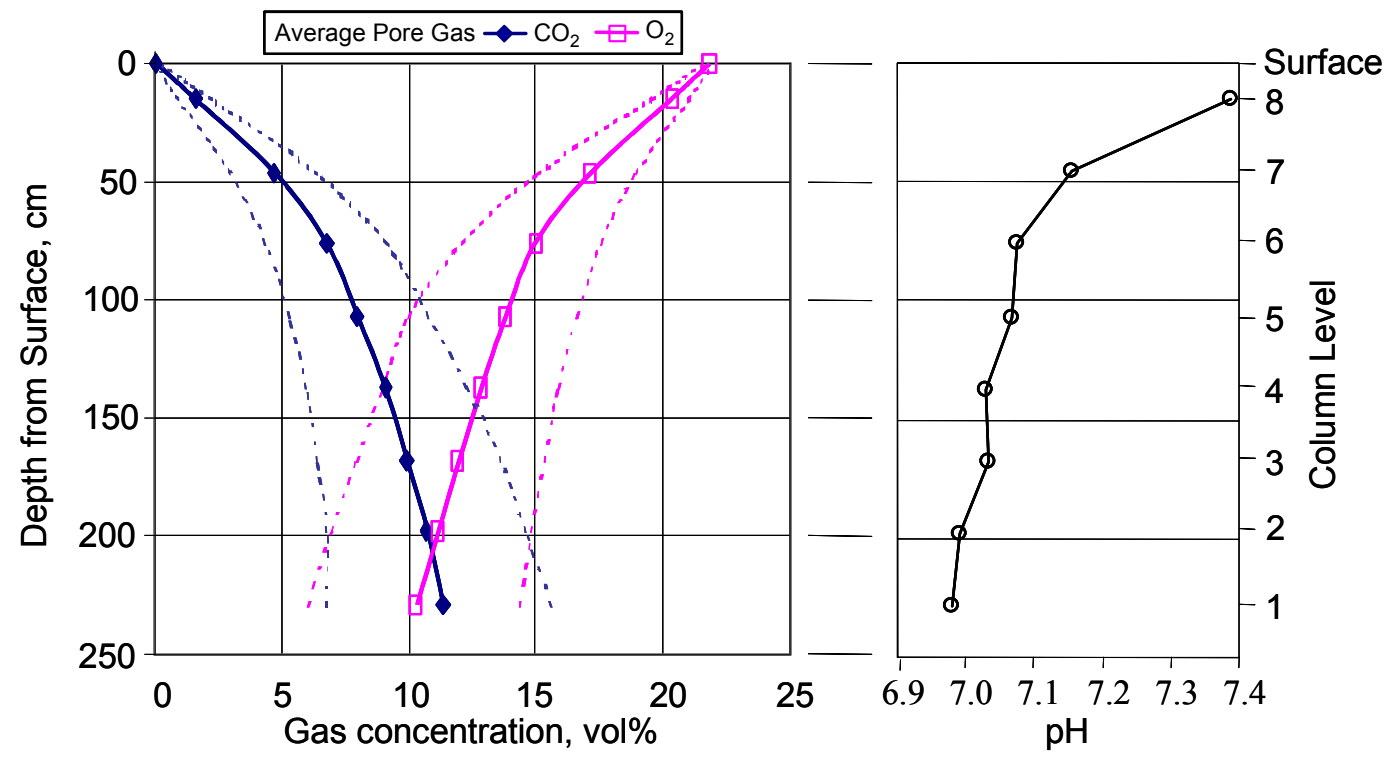

Figure 17. Average $\mathrm{CO}_{2}, \mathrm{O}_{2}$, and $\mathrm{pH}$ profiles during ${ }^{14} \mathrm{C}$ transport study (dotted lines represent gas concentration ranges during the $\sim 107$ week study). 


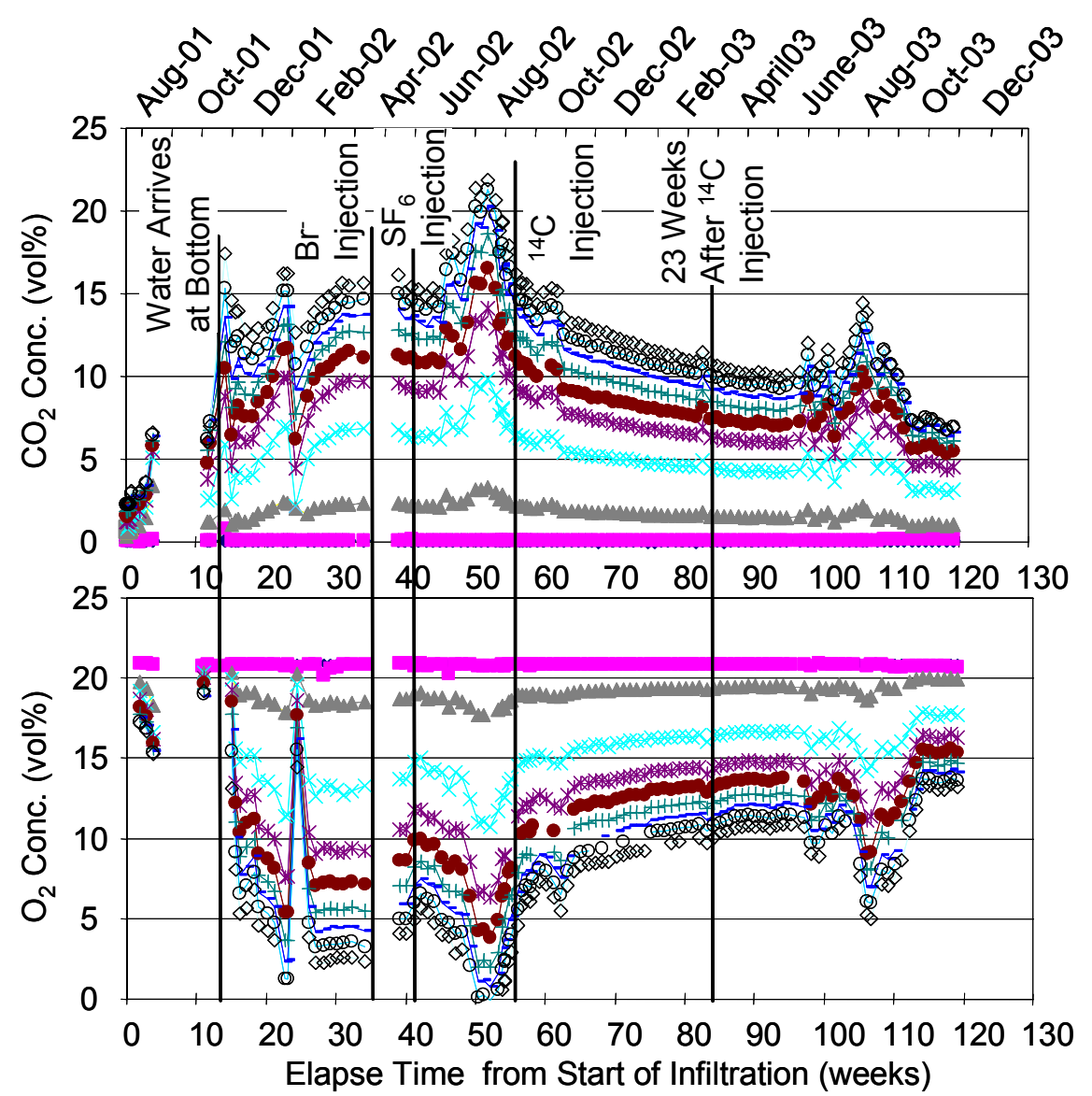

\begin{tabular}{|lllll|}
\hline - Background & - Level 8 & + Level 4 & $*$ Level 6 & - -Level 2 \\
- Head_Space & $*$ Level 7 & - - Level 3 & - -Level 5 & $\diamond$ Level 1 \\
\hline
\end{tabular}

Figure 18. Sediment gas $\mathrm{CO}_{2}$ and $\mathrm{O}_{2}$ concentration time series at each column level.

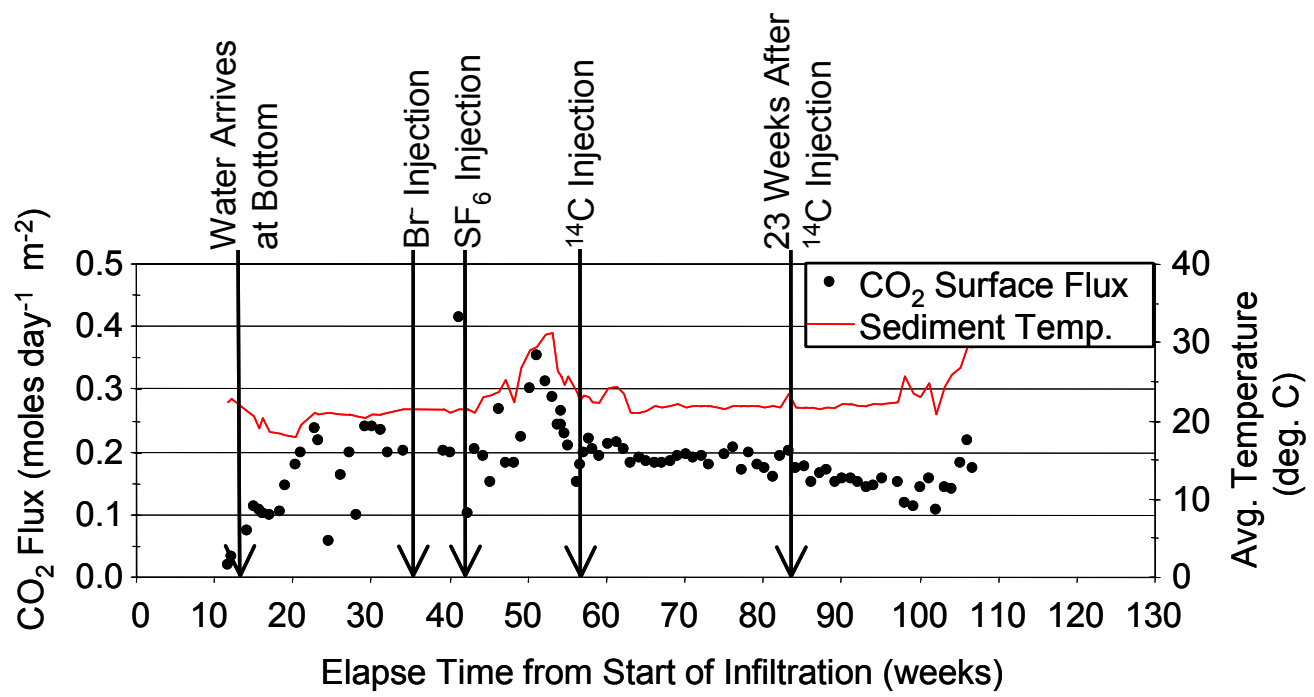

Figure 19. Bulk $\mathrm{CO}_{2}$ surface flux. 
the mass flow controller due to the high relative humidity of headspace gases. Using heat tape to keep controller and tubing surfaces at an elevated temperature was largely effective, but the flow controller did experience condensation and lose control during the later portion of the study. Though the condensation event caused undefined deviation of the headspace ventilation rate, the rate indicated by the controller was consistent with the desired set point value $\left(\sim 7 \mathrm{~L} \mathrm{~min}^{-1}\right)$. Therefore, calculation of $\mathrm{CO}_{2}$ surface flux using the flow rate indicated by the controller produces the fluctuations observed between Weeks 75 and 85 (Figure 19). The condensation event may have been due to an inadvertent lowering of controller and tubing surface temperatures, from $\sim 35^{\circ}$ to $\sim 25^{\circ} \mathrm{C}$. Following this event, water was removed from the controller, surface temperatures were increased, and flow control was reestablished. The electronic controller did not indicate loss of control, which demonstrates the need for independent flow control and measurement validation.

\subsection{Biological Assays}

The sediment's biological community was not characterized prior to initiation of the transport study. Sediment samples taken in Week 36 from column Levels 2, 3, and 8, are currently undergoing analysis to identify microbial communities. Complete results are not yet available; however, preliminary results indicate a diverse community that changes in structure with depth. Change in community may be due to shifts in $\mathrm{CO}_{2}$ and $\mathrm{O}_{2}$ concentration with depth. Upon completion of the transport study, in January of 2004, additional sediment samples were taken from all column levels for biological assay. These samples are currently undergoing analysis and will be discussed in a future report.

\subsection{Tracer, Carbon-14, and Uranium Transport}

To examine the movement of water, gas, and conservative solute through the sediment, we injected a highly insoluble gas, sulfur hexafluoride, both before and during the water infiltration period, and conservative liquid tracers, lithium bromide and tritium, after reaching a quasi steady-state flow conditions. Data from these experiments is used to estimate characteristics of the unsaturated flow system that affect transport of ${ }^{14} \mathrm{C}$, including average linear seepage velocity, dispersivity and flow path tortuosity.

To examine reactive transport of uranium $(\mathrm{U})$ and ${ }^{14} \mathrm{C}$ through the sediment, we injected an aqueous cocktail of $\mathrm{U}$ and ${ }^{14} \mathrm{C}$, with the conservative tritium tracer. At the end of the ${ }^{14} \mathrm{C}$ transport study (50 weeks after $U$ injection), uranium had not been detected at the sampling lysimeter located $15.2-\mathrm{cm}$ below the injection plane, suggesting a $\mathrm{K}_{d}$ greater than $2.5 \mathrm{~L} \mathrm{~kg}^{-1}$. Uranium migration results will be discussed in a subsequent report on the analysis of sediment core subsamples.

\subsubsection{Gas Tracer-Sulfur Hexafluoride}

The breakthrough curves for the sulfur hexafluoride $\left(\mathrm{SF}_{6}\right)$ tracer tests are shown in Figure 20 . The similarity of the primary and replicate test curves indicates good reproducibility. During the tests at experimental water content, we evaluated the effect of sampling on $\mathrm{SF}_{6}$ movement by extracting $\sim 41 \%$ more sample gas during the first $\sim 15 \mathrm{~h}$ of the primary test than was extracted during the same period of the replicate test. Given this difference in sample gas removal and the consistency of the primary and replicate breakthrough curves ( $\sim 30 \%$ test in Figure 20$)$, gas sampling is believed to have had an insignificant effect on $\mathrm{SF}_{6}$ movement.

The diffusivity of gas in unsaturated sediments is dependent upon water saturation, which controls tortuosity of the pore space available for gas movement. The $\sim 10$ and $\sim 30 \%$ volumetric water content tests were performed to collect data needed to estimate the relationship between water content and tortuosity. Comparing the breakthrough curves of the primary tests in Figure 21, the effect of water content is evident. Though virtually identical $\mathrm{SF}_{6}$ concentrations were used, higher concentration peaks 


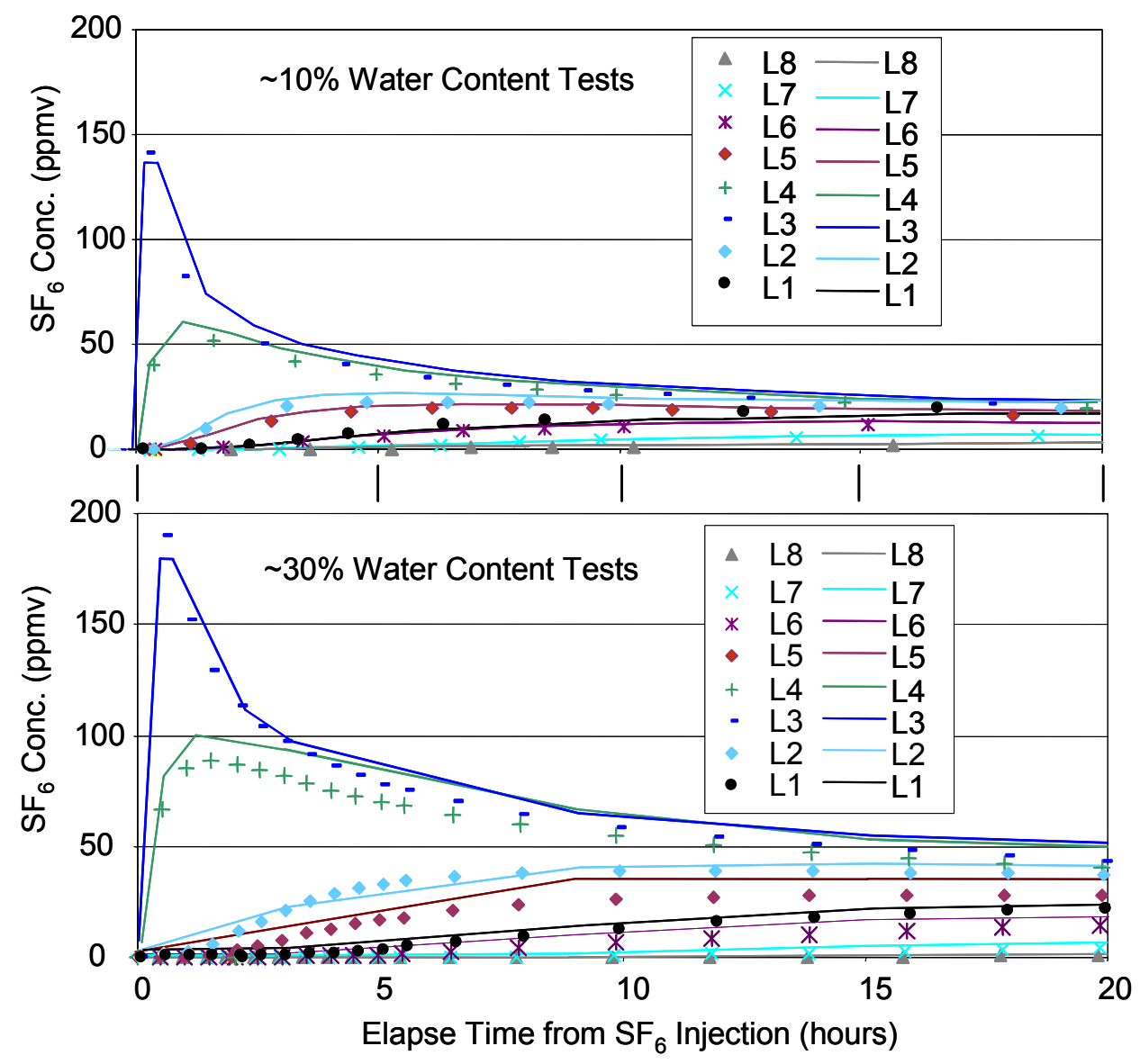

Figure $20 . \mathrm{SF}_{6}$ concentration in primary and replicate tests at packing $(\sim 10 \%)$ and experimental $(\sim 30 \%)$ water contents. $($ characters $=$ primary tests, lines $=$ replicate tests, $\mathrm{L}=$ column level. $)$

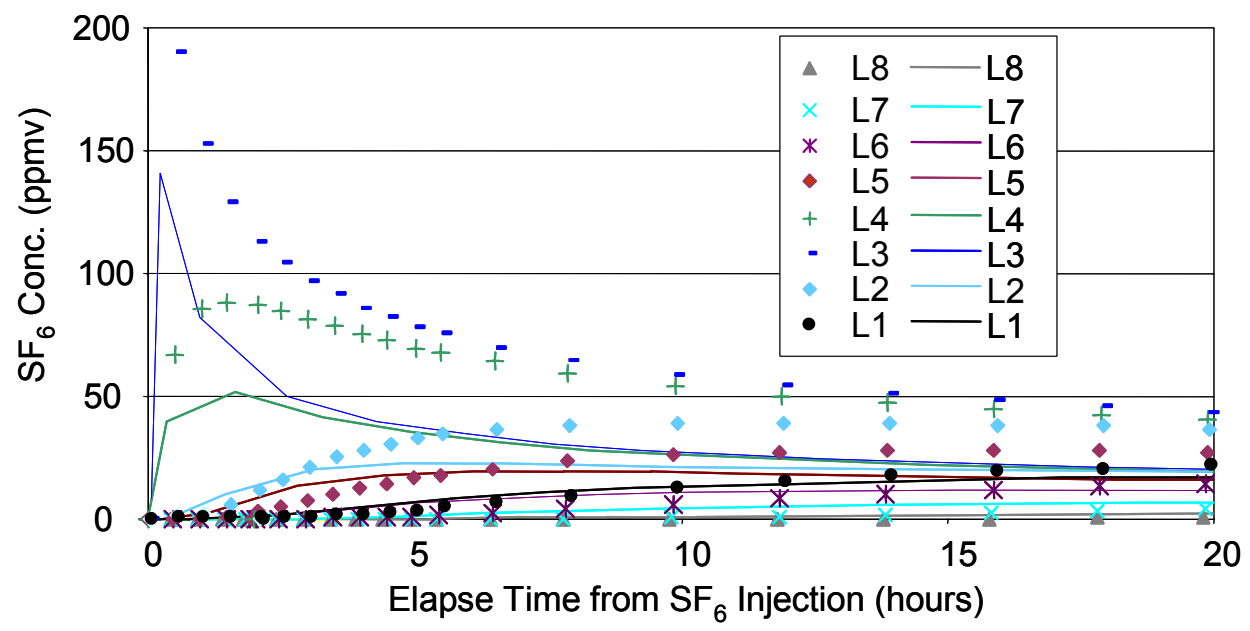

Figure 21. Comparison of primary $\mathrm{SF}_{6}$ tests at packing $(\sim 10 \%)$ and experimental $(\sim 30 \%)$ volumetric water content. (characters $=\sim 30 \%$ test; lines $=\sim 10 \%$ test). 
are observed for the test at $\sim 30 \%$ than for the one at $\sim 10 \%$. This is due to minimization of tortuosity at relatively low water content, which allows gas to diffuse from the column faster. However, $\mathrm{SF}_{6}$ migrated rapidly throughout the column during both tests, with concentration peaks arriving at the nearest levels (Levels 4 and 3) within 0.5 to $2 \mathrm{~h}$ of the injections.

The effective gas-phase diffusion coefficient in a porous medium is less than the free-air diffusion coefficient because of the tortuosity of the diffusion paths in the pores. As pores fill with water, the air space available for diffusion decreases, and the tortuosity of the diffusion paths increases. This phenomenon is described by a tortuosity parameter defined by Millington (1959) as:

$$
\tau=\frac{\phi_{T}^{2}}{\phi_{g}^{m}}
$$

where

$$
\begin{array}{lll}
\tau & = & \text { tortuosity parameter (dimensionless) } \\
\phi_{\mathrm{T}} & = & \text { total porosity }\left(\mathrm{cm}^{3} / \mathrm{cm}^{3}\right) \\
\phi_{\mathrm{g}} & = & \text { volumetric gas content }\left(\mathrm{cm}^{3} / \mathrm{cm}^{3}\right) \\
\mathrm{m} & =\quad \text { empirical parameter for exponential dependence of diffusion on gas-filled porosity. }
\end{array}
$$

Millington (1959) proposed a value of 2.33 for $m$. Hull and Hohorst (2001) performed gas diffusion experiments in air-dried SDA sediments and obtained an $m$ value of 2.6 by fitting their experimental data.

To obtain estimates of gas-phase diffusion parameters for the meso scale column, we performed a least-squares fit of the analytical solution to the one-dimensional diffusion equation to measured breakthrough curves from the column. Comparisons were made to curves from multiple column levels and for tests conducted at $\sim 10 \%$ and $\sim 30 \%$ water content. The results from fitting the $30 \%$ water content test are shown in Figure 22. Using water content as a fitting parameter, this analysis indicates an initial (packing) water content of $11 \%$ and an experimental water content of $25 \%$, which are generally consistent with values determined using gravimetric, tensiometer, TDR probe, and mass balance methods. The coefficient of determination for these fits was 0.86 using the $m$ value (2.33) recommended by Millington (1959). Additional least-squares analyses of the observed breakthrough curves, using $m$ as the fitting parameter, did not significantly improve the observed breakthrough curve fits. Given the good agreement achieved between the data and the analytical solution, we conclude that the standard Millington equation provides an accurate estimate of $\mathrm{SF}_{6}$ transport and of the relationship between water content and tortuosity in SDA sediments. Furthermore, physical transport parameters determined for $\mathrm{SF}_{6}$ experiments appropriately describe gas phase diffusion in the current system (Table 20).

\subsubsection{Aqueous Tracers-Bromide and Tritium}

Bromide $\left(\mathrm{Br}^{-}\right)$breakthrough curves were fit to an analytical solution to the advection dispersion equation (ADE) for equilibrium transport of a conservative ion slug (CXTFIT2, Toride et al. 1995), Figure 23. A good fit (i.e., a mean $\mathrm{R}^{2}$ of 0.97 and a standard deviation of 0.04 ) was achieved using this approach. Results of curve fitting, at each column level, indicate one-dimensional flow with an average linear seepage velocity range of 0.46 to $0.55 \mathrm{~cm}_{\text {day }}{ }^{-1}$ and a dispersion coefficient ranging from $4.6 \times 10^{-6}$ to $7.9 \times 10^{-6} \mathrm{~cm}^{2} \mathrm{sec}^{-1}$ (Table 21). Calculated hydraulic dispersivities were negligible, ranging from 0 to $7 \mathrm{~mm}$. This is consistent with the results of Hull and Hohorst (2001), who conducted saturated bromide and tritium transport tests with SDA sediment in 31-cm columns and found that dispersivity was on the order of $0.5-\mathrm{mm}$. 


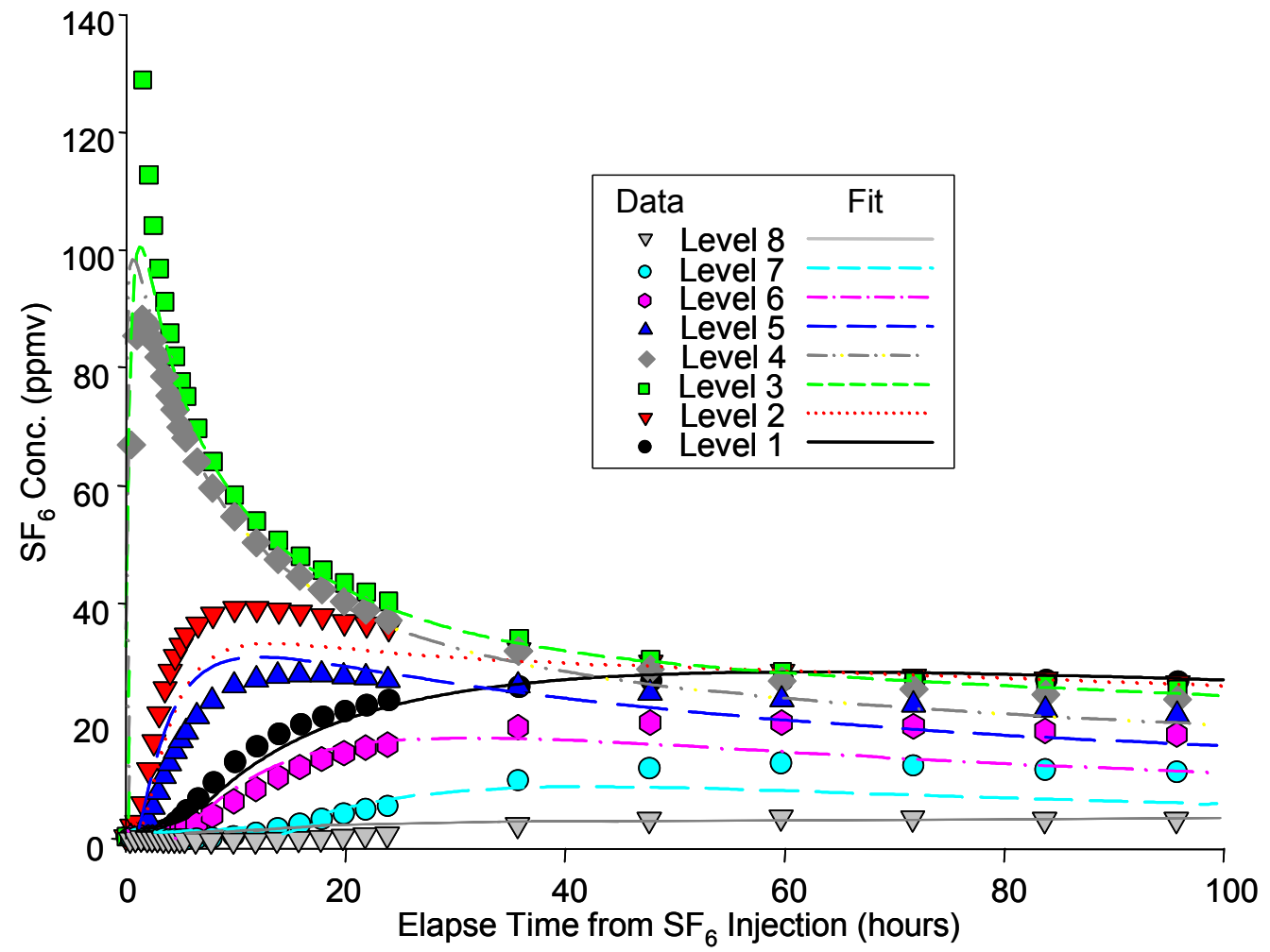

Figure 22. Least-squares fit of $\mathrm{SF}_{6}$ breakthrough curves at $\sim 30 \%$ volumetric water content (i.e., the water content during transport study).

Table 20. Transport parameters used to model $\mathrm{SF}_{6}$ and $\mathrm{Br}^{-}$tracer breakthrough.

\begin{tabular}{|c|c|c|}
\hline Conservative Tracer & Aqueous Diffusion Coefficient & Gaseous Diffusion Coefficient \\
\hline $\mathrm{SF}_{6}$ & - & $1.1 \times 10^{-1} \mathrm{~cm}^{2} \mathrm{sec}^{-1}$ \\
\hline Bromide & $1.8 \times 10^{-5} \mathrm{~cm}^{2} \mathrm{sec}^{-1}$ & - \\
\hline
\end{tabular}




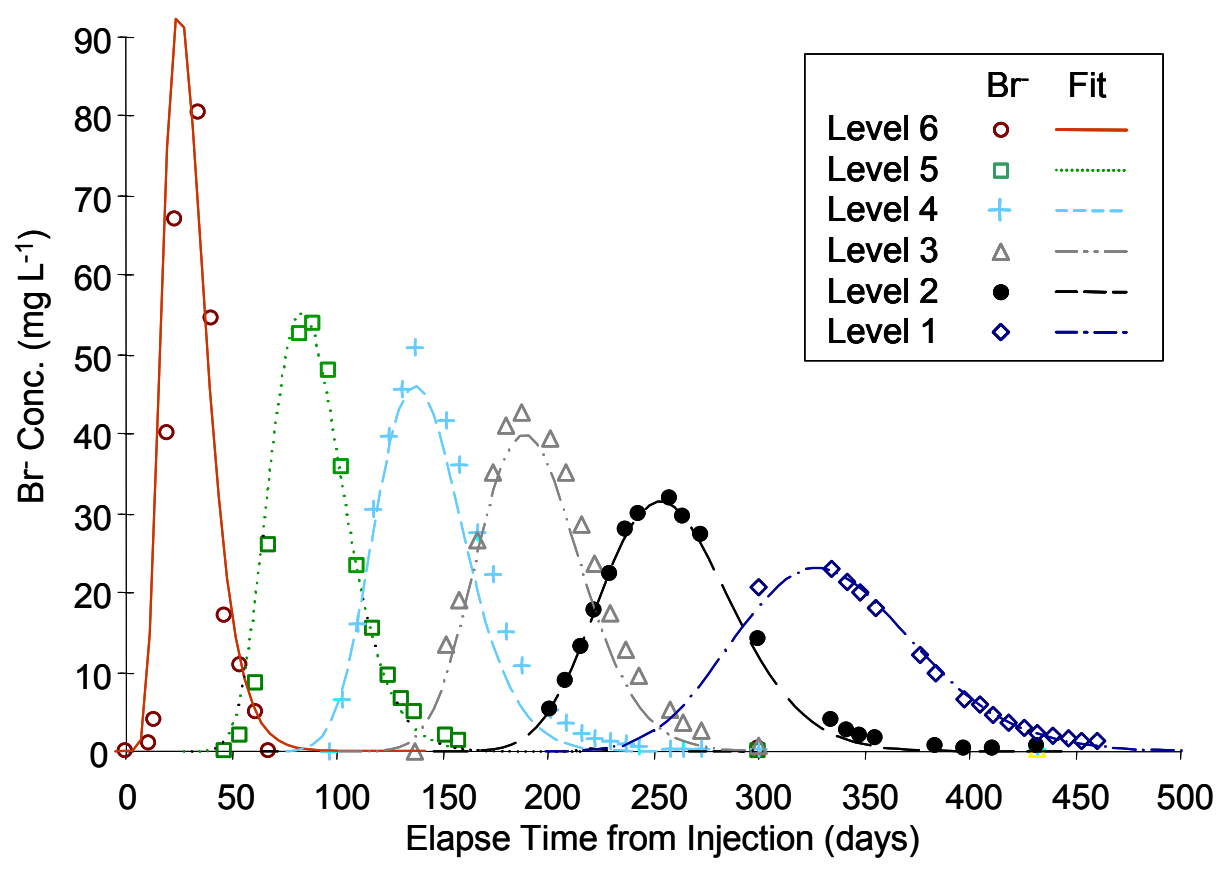

Figure 23. Bromide $\left(\mathrm{Br}^{-}\right)$breakthrough curves and CXTFIT2 fit.

Table 21. Summary of transport parameters determined from CXTFIT2 analysis of conservative tracer tests.

\begin{tabular}{|c|c|c|c|c|}
\hline CXTFIT2 Basis & $\begin{array}{l}\text { Average Linear } \\
\text { Seepage Velocity } \\
\left(\mathrm{cm} \mathrm{day}^{-1}\right)\end{array}$ & $\begin{array}{l}\text { Inferred Volumetric } \\
\text { Water Content }\end{array}$ & $\begin{array}{c}\text { Hydrodynamic } \\
\text { Dispersion Coefficient } \\
\left(\mathrm{cm}^{2} \mathrm{sec}^{-1}\right)\end{array}$ & $\begin{array}{l}\text { Correlation } \\
\text { Coefficient }\end{array}$ \\
\hline Injection to Level 6 & 0.46 & 0.31 & 4.6E-06 & 0.940 \\
\hline Injection to Level 5 & 0.51 & 0.28 & $5.2 \mathrm{E}-06$ & 0.994 \\
\hline Injection to Level 4 & 0.55 & 0.27 & $5.2 \mathrm{E}-06$ & 0.949 \\
\hline Injection to Level 3 & 0.55 & 0.26 & $5.4 \mathrm{E}-06$ & 0.927 \\
\hline Injection to Level 2 & 0.51 & 0.27 & $6.0 \mathrm{E}-06$ & 0.993 \\
\hline Injection to Level 1 & 0.51 & 0.29 & 7.9E-06 & 0.994 \\
\hline Averages & 0.52 & 0.28 & $5.7 \mathrm{E}-06$ & 0.966 \\
\hline
\end{tabular}

Because $\mathrm{Br}^{-}$moves into larger pore-water flow paths by mutual $\mathrm{Br}^{-}$and soil-surface electrostatic repulsion (i.e., anion exclusion), Br- transport is commonly observed to be accelerated, producing a two-region type of breakthrough curve (Bond et al 1982; James and Rubin 1986). We did not observe this anion exclusion effect. However, we evaluated anion exclusion by first fitting a nonequilibrium type transport solution to the ADE. This approach did not significantly improve the $\mathrm{Br}^{-}$breakthrough curve fits. Next, we divided the applied hydraulic flux of $1-\mathrm{L} \mathrm{day}^{-1}$ (or $0.15-\mathrm{cm}^{3} \mathrm{~cm}^{-2} \mathrm{day}^{-1}$ ) by the mean linear $\mathrm{Br}^{-}$seepage velocity $\left(0.52-\mathrm{cm} \mathrm{day}^{-1}\right)$ and estimated a $28 \%( \pm 3 \%)$ average volumetric water content during the ${ }^{14} \mathrm{C}$ transport portion of the study (Table 21). This water content is consistent with TDR, mass balance, and gravimetric determinations. Therefore, we believe $\mathrm{Br}^{-}$acceleration is insignificant in these transport measurements, which validates the use of $\mathrm{Br}^{-}$data in determining physical transport parameters (Table 20). 
We also estimated water content using the tritium $\left({ }^{3} \mathrm{H}\right)$ tracer test data. We divided the applied hydraulic flux $\left(0.15-\mathrm{cm}^{3} \mathrm{~cm}^{-2}\right.$ day $\left.^{-1}\right)$ by the mean linear ${ }^{3} \mathrm{H}$ seepage velocity $\left(0.38-\mathrm{cm} \mathrm{day}^{-1}\right)$ and estimated a $\sim 40 \%$ average volumetric water content. This water content is inconsistent with estimations based on $\mathrm{SF}_{6}$ tracer, $\mathrm{Br}^{-}$tracer, TDR, gravimetric, and mass balance approaches. Therefore, we disregard the $\sim 40 \%$ water content suggested by the ${ }^{3} \mathrm{H}$ data and base our water content estimation on the other approaches. From these independent methods, we selected a most probable volumetric water content of $\sim 28 \%$ during the transport experiments.

In aqueous systems, tritium $\left({ }^{3} \mathrm{H}\right)$ readily partitions into water, as ${ }^{3} \mathrm{H}_{2} \mathrm{O}$. Therefore, the ${ }^{3} \mathrm{H}$ transport velocity is expected to be equivalent to that of water. Comparing the $\mathrm{Br}^{-}$and ${ }^{3} \mathrm{H}$ breakthrough curves in Figure 24 shows that the rate of ${ }^{3} \mathrm{H}$ transport is significantly slower than that of $\mathrm{Br}^{-}$. Validation of the $\mathrm{Br}^{-}$ data suggests that the difference in rate is due to ${ }^{3} \mathrm{H}$ retardation. We conducted a second tracer test to confirm this unexpected retardation of ${ }^{3} \mathrm{H}$, an assumed nonpartitioning conservative tracer. Results of the combination ${ }^{3} \mathrm{H} / \mathrm{Br}^{-}$tracer injection (not presented in this report), initiated in Week 94, confirm the apparent ${ }^{3} \mathrm{H}$ retardation. Inconsistencies of ${ }^{3} \mathrm{H}$ and $\mathrm{Br}^{-}$transport could be explained, at least in part, by tracer losses. However, conservation of ${ }^{3} \mathrm{H}$ and $\mathrm{Br}^{-}$mass was confirmed through fitting the ADE to ${ }^{3} \mathrm{H}$ and $\mathrm{Br}^{-}$breakthrough curves using CXTFIT2. Alternatively, the inconsistencies could be an artifact of residual contamination of sampling lysimeters. However, apparent ${ }^{3} \mathrm{H}$ retardation was confirmed by the combined ${ }^{3} \mathrm{H}$ and $\mathrm{Br}^{-}$tracer test, and residual contamination would be expected to have an equivalent effect on both ${ }^{3} \mathrm{H}$ and $\mathrm{Br}^{-}$samples. The inability to explain apparent ${ }^{3} \mathrm{H}$ retardation by experimental method or design errors led us to conduct a brief literature search. We found that although precipitation and sorption processes are not expected to significantly affect the movement of ${ }^{3} \mathrm{H}$, the potential for fixation of isotopic water on clays and other hydrated soil minerals does exist (Ames and Rai 1978). Further, Thibault et al. (1990) reviewed published studies and reported a ${ }^{3} \mathrm{H}$ sorption coefficient, $K_{d}$, range of 0.04 to $0.1 \mathrm{~mL} \mathrm{~g}^{-1}$ in saturated sandy soils. We calculate a $K_{d}$ of $\sim 0.08-\mathrm{mL} \mathrm{g}^{-1}$ for the current ${ }^{3} \mathrm{H}$ breakthrough curves, which is consistent with that reported by Thibault for saturated sands. Given the unsaturated condition and abundance of clay minerals in the current system, the observed ${ }^{3} \mathrm{H}$ retardation may not be an artifact of method or design error but a true measure of sorption processes.

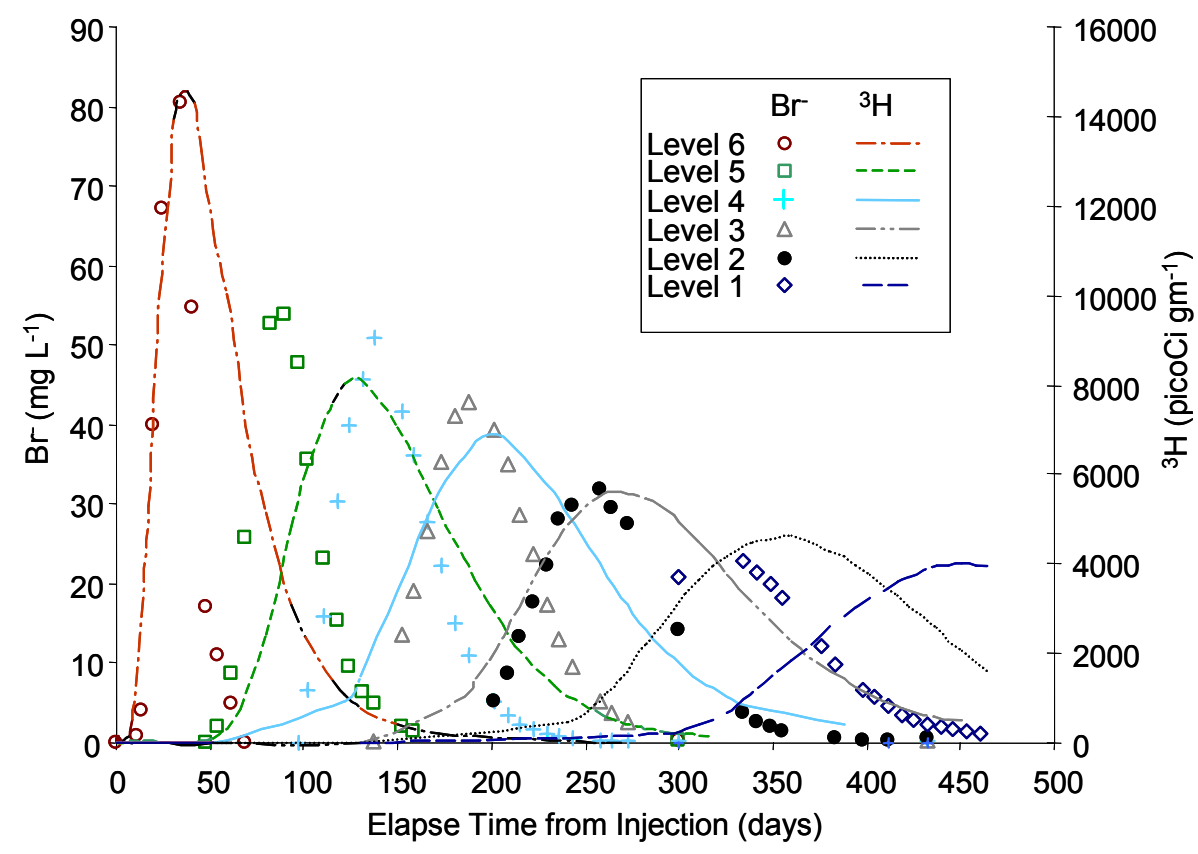

Figure 24. Bromide $\left(\mathrm{Br}^{-}\right)$and tritium $\left({ }^{3} \mathrm{H}\right)$ breakthrough curves. 


\subsubsection{Carbon-14 Transport}

Gas phase carbon-14 $\left({ }^{14} \mathrm{C}\right)$ breakthrough curves (Figure 25) display the same characteristic shape as the $\mathrm{SF}_{6}$ curves (Figure 21) at virtually all levels in the column but lagged, which is consistent with gas-diffusion-dominated transport that is retarded by exchanges with other phases. ${ }^{14} \mathrm{C}$ concentrations at the nearest ports, for example, peaked after approximately one day, as opposed to about an hour for $\mathrm{SF}_{6}$. ${ }^{14} \mathrm{C}$ was detected in both aqueous and gas phases at sampling ports located $\sim 15$-cm above and below the injection plane within $8 \mathrm{~h}$ (0.3 days) of the initial $1610( \pm 16)$ microCi injection (Table 22$).{ }^{14} \mathrm{C}$ was dispersed throughout the column within 7 days (Figure 26), with a maximum ${ }^{14} \mathrm{C}$ surface flux ( 22.37 microCi m$^{-2}$ day $^{-1}$ ) occurring within 25 days of the injection (Table 23 and Figure $27 \mathrm{a}$ ). The surface flux peak was followed by an approximately exponential decline in released activity.

During the initial decline (i.e., from the peak through the steepest portion of the breakthrough curve tail), three reductions and rebounds (fluctuations) of ${ }^{14} \mathrm{C}$ flux were observed (Weeks 59.50, 63.63, and 72.56 in Figure 27). Failure of the mass flow controller to indicate deviation of the headspace ventilation rate resulted in artificial fluctuations of calculated $\mathrm{CO}_{2}$ flux (Weeks 75 to 85 in Figures 19 and 27b). However, during headspace ${ }^{14} \mathrm{C}$ sampling periods, gas flow rates were validated using a method independent of the mass flow controller. Thus, the occasional loss of flow control is believed to be insignificant for ${ }^{14} \mathrm{C}$ flux calculations. This belief is supported by the apparent lack of correlation between ${ }^{14} \mathrm{C}$ and bulk $\mathrm{CO}_{2}$ flux during the period of ventilation rate deviation (Weeks 75 to 85 in Figure 27a and b). Barometric pumping can affect ${ }^{14} \mathrm{C}$ flux, but barometric pumping is not apparent when comparing the ${ }^{14} \mathrm{C}$ flux and barometric pressure time series (Figure 27a and c). Phase partitioning effects can also affect ${ }^{14} \mathrm{C}$ flux; the correlation between reductions of ${ }^{14} \mathrm{C}$ and bulk $\mathrm{CO}_{2}$ flux indicates phase partitioning as the cause of fluctuations in discharged ${ }^{14} \mathrm{C}$ (Table 23 and Figure $27 \mathrm{a}$ and $\mathrm{b}$ ). While gas-phase ${ }^{14} \mathrm{CO}_{2}$ is assumed to diffuse in response to its own concentration gradient, independent of ${ }^{12} \mathrm{CO}_{2}$ and ${ }^{13} \mathrm{CO}_{2}$ partial pressure (Thorstenson et al. 1983), partitioning of ${ }^{14} \mathrm{CO}_{2}$ between aqueous and gas phases is not independent of $\mathrm{CO}_{2}$ partial pressure $\left(\mathrm{pCO}_{2}\right)$. Fluctuations of $\mathrm{pCO}_{2}$, in response to changes of sediment temperature (Figure 27d) and microbial $\mathrm{CO}_{2}$ production, shift aqueous/gas phase ${ }^{14} \mathrm{CO}_{2}$ partitioning and consequently ${ }^{14} \mathrm{C}$ diffusion and discharge. This can be conceptualized by the reaction in Equation (13).

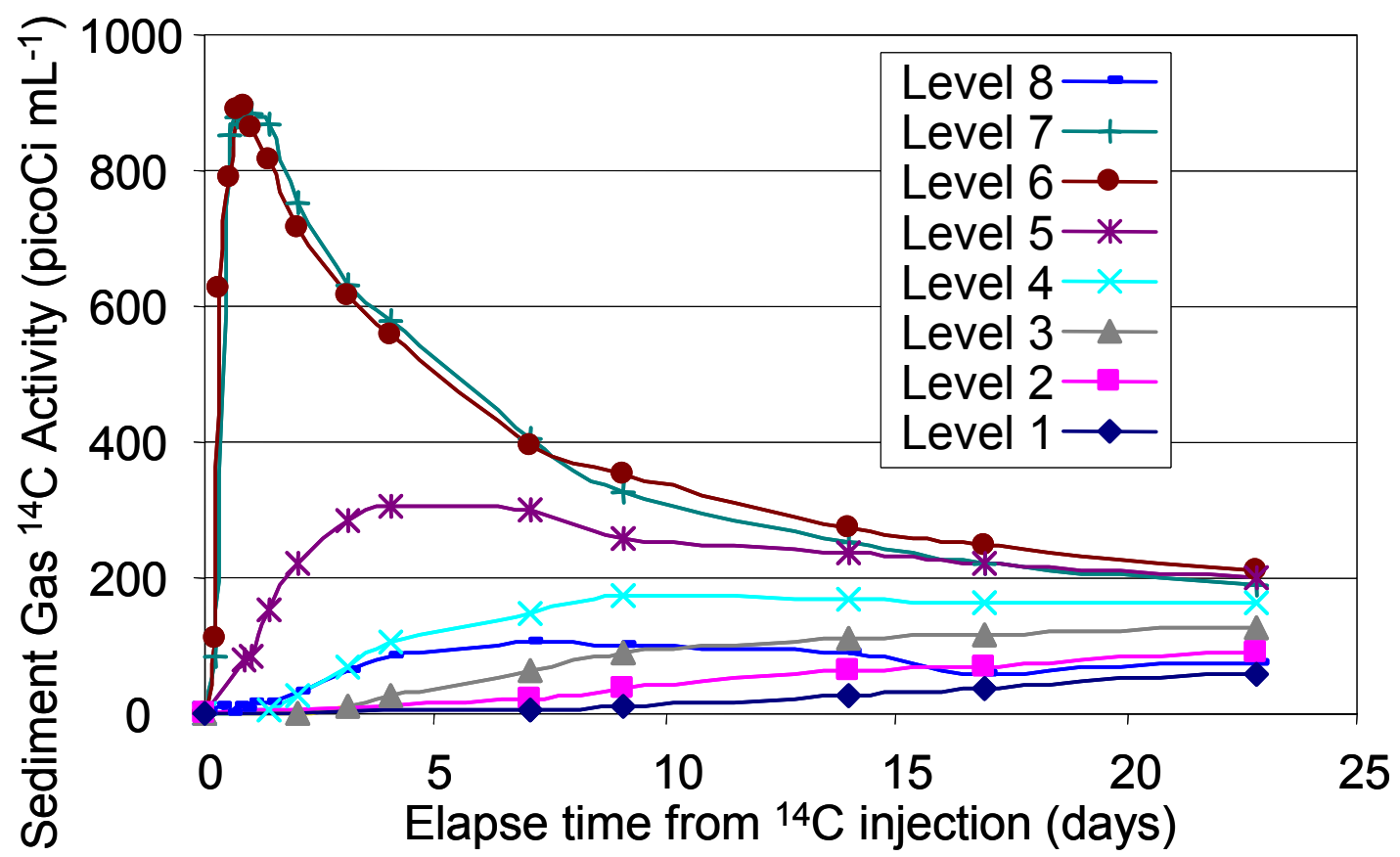

Figure 25. Measured sediment gas ${ }^{14} \mathrm{C}$ breakthrough curves at all eight column levels. 
Table 22. Sediment gas and sediment water ${ }^{14} \mathrm{C}$ activity time series.

\begin{tabular}{|c|c|c|c|c|c|c|c|c|c|c|c|c|c|c|c|c|}
\hline \multirow{3}{*}{$\begin{array}{l}\text { Elapse Time } \\
\text { from }{ }^{14} \mathrm{C} \\
\text { Injection } \\
\text { (days) }\end{array}$} & \multicolumn{8}{|c|}{ Sediment Gas, picoCi ${ }^{14} \mathrm{C} \mathrm{mL}^{-1} \mathrm{Gas}$} & \multicolumn{8}{|c|}{ Sediment Water, picoCi ${ }^{14} \mathrm{C} \mathrm{g}^{-1}$ Water } \\
\hline & \multicolumn{8}{|c|}{ Column Level } & \multicolumn{8}{|c|}{ Column Level } \\
\hline & 1 & 2 & 3 & 4 & 5 & 6 & 7 & 8 & 1 & 2 & 3 & 4 & 5 & 6 & 7 & 8 \\
\hline 0.0 & 0 & 0 & 0 & 0 & 0 & 0 & 0 & 0 & 0 & 0 & 0 & 0 & 0 & 0 & 0 & 0 \\
\hline 0.2 & & & & & & 110 & 85 & & & & & & & & & \\
\hline 0.3 & & & & & & 624 & & 12 & & & & & & 1168 & 3663 & 2 \\
\hline 0.5 & & & & & & 790 & 854 & 1 & & & & & & 2245 & 5076 & 4 \\
\hline 0.7 & & & & & & 888 & 880 & 10 & & & & & & 2937 & 5394 & 8 \\
\hline 0.8 & & & & & 77 & 897 & 866 & 6 & & & & & 102 & 3124 & 5070 & 17 \\
\hline 1.0 & & & & & 84 & 861 & 882 & 16 & & & & & 190 & 3149 & 4922 & 33 \\
\hline 1.4 & & & & 5 & 154 & 813 & 869 & 13 & & & & & 386 & 3029 & 4565 & 124 \\
\hline 2 & & & 2 & 29 & 221 & 718 & 754 & 34 & & & & 79 & 706 & 2833 & 3982 & 281 \\
\hline 3 & & & 10 & 69 & 282 & 618 & 630 & 62 & & & 33 & 224 & 988 & 2581 & 3267 & 554 \\
\hline 4 & & & 25 & 106 & 306 & 557 & 580 & 86 & & & 81 & 361 & 1112 & 2297 & 2818 & 761 \\
\hline 7 & 5 & 20 & 65 & 147 & 299 & 395 & 404 & 104 & 9 & 71 & 244 & 602 & 1194 & 1823 & 2054 & 985 \\
\hline 9 & 10 & 34 & 87 & 174 & 257 & 355 & 329 & 102 & 20 & 122 & 333 & 668 & 1146 & 1596 & 1801 & 976 \\
\hline 14 & 25 & 62 & 112 & 167 & 235 & 274 & 254 & 90 & 72 & 233 & 444 & 719 & 1026 & 1296 & 1390 & 882 \\
\hline 17 & 37 & 71 & 114 & 166 & 219 & 247 & 221 & 87 & 110 & 277 & 470 & 703 & 938 & 1114 & 1228 & 813 \\
\hline 23 & 56 & 90 & 128 & 164 & 198 & 212 & 190 & 74 & 180 & 342 & 502 & 686 & 853 & 1001 & 984 & 661 \\
\hline 52 & 91 & 99 & 105 & 110 & 115 & 107 & 84 & 31 & 352 & 435 & 466 & 511 & 541 & 584 & 507 & 326 \\
\hline 130 & 72 & 70 & 68 & 63 & 59 & 51 & 36 & 13 & 318 & 326 & 326 & 329 & 348 & 279 & 234 & 143 \\
\hline
\end{tabular}

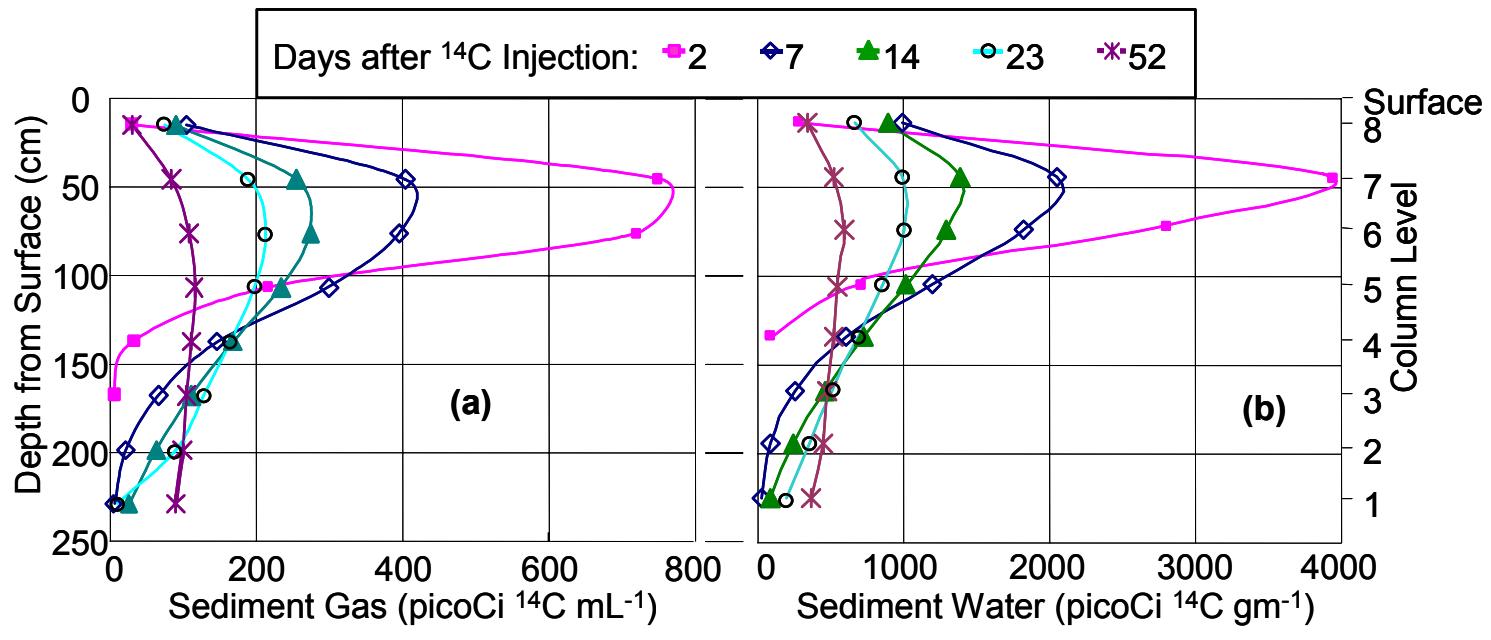

Figure 26. ${ }^{14} \mathrm{C}$ sediment gas (a) and sediment water (b) activity profiles. 
Table 23. ${ }^{14} \mathrm{C}$ and bulk $\mathrm{CO}_{2}$ surface flux data.

\begin{tabular}{|c|c|c|c|c|}
\hline $\begin{array}{l}{ }^{14} \text { C Elapse Time from } \\
\text { Start of Infiltration } \\
\text { (weeks) }\end{array}$ & $\begin{array}{l}\text { Elapse Time from } \\
{ }^{14} \mathrm{C} \text { Injection } \\
\text { (days) }\end{array}$ & $\begin{array}{l}{ }^{14} \mathrm{C} \text { Surface Flux } \\
\left(\text { microCi }{ }^{14} \mathrm{C} \mathrm{m}^{-2} \mathrm{day}^{-1}\right)\end{array}$ & $\begin{array}{l}\mathrm{CO}_{2} \text { Elapse Time from } \\
\text { Start of Infiltration } \\
\text { (weeks) }\end{array}$ & 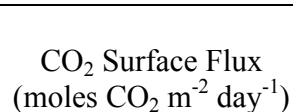 \\
\hline 56.71 & 0.0 & 0.00 & 57.12 & 0.20 \\
\hline 56.77 & 0.4 & 0.08 & $\begin{array}{l}57.69 \\
\end{array}$ & 0.22 \\
\hline 56.80 & 0.6 & 0.06 & 58.13 & 0.21 \\
\hline 56.87 & 1.1 & 0.09 & 59.12 & 0.19 \\
\hline 56.96 & 1.7 & 0.55 & 60.12 & 0.21 \\
\hline 57.07 & 2.5 & 2.66 & 61.26 & 0.21 \\
\hline 57.22 & 3.6 & 7.26 & 62.11 & 0.20 \\
\hline 57.51 & 5.5 & 14.29 & 63.11 & 0.18 \\
\hline 57.86 & 8.0 & 20.10 & 64.11 & 0.19 \\
\hline 58.44 & 12.1 & 22.37 & 65.11 & 0.19 \\
\hline 59.50 & 19.5 & 16.20 & 66.11 & 0.18 \\
\hline 60.41 & 25.9 & 20.11 & 67.11 & 0.18 \\
\hline 60.92 & 29.4 & 17.61 & 68.11 & 0.18 \\
\hline 61.41 & 32.9 & 16.58 & 69.11 & 0.19 \\
\hline 61.91 & 36.4 & 14.36 & 70.11 & 0.20 \\
\hline $\begin{array}{l}62.41 \\
\end{array}$ & 39.9 & 11.66 & 71.11 & 0.19 \\
\hline 62.91 & 43.4 & 10.82 & 72.11 & 0.19 \\
\hline 63.63 & 48.4 & 7.52 & 73.11 & 0.18 \\
\hline 64.63 & 55.4 & 6.74 & 74.11 & 0.15 \\
\hline 65.63 & $\begin{array}{l}62.4 \\
\end{array}$ & 7.67 & 75.11 & 0.20 \\
\hline 66.63 & 69.4 & 7.00 & 76.11 & 0.21 \\
\hline 67.63 & 76.4 & 6.54 & 77.11 & 0.17 \\
\hline 68.63 & 83.4 & 6.37 & 78.11 & 0.20 \\
\hline 69.63 & 90.4 & 5.31 & 79.11 & 0.18 \\
\hline 70.63 & 97.4 & 4.76 & 80.11 & 0.18 \\
\hline 71.56 & 103.9 & 5.14 & 81.11 & 0.16 \\
\hline 72.56 & 110.9 & 3.59 & 82.11 & 0.19 \\
\hline 73.63 & 118.4 & 2.65 & 83.11 & 0.20 \\
\hline 74.65 & 125.5 & 3.31 & 84.12 & 0.17 \\
\hline 78.63 & 153.4 & 2.88 & 85.12 & 0.18 \\
\hline 82.22 & 178.5 & 2.51 & 86.12 & 0.15 \\
\hline 86.64 & 209.5 & 2.08 & 87.12 & 0.16 \\
\hline 94.29 & 263.0 & 1.44 & 88.12 & 0.17 \\
\hline 106.24 & 346.6 & 1.07 & 89.12 & 0.15 \\
\hline \multirow{17}{*}{\multicolumn{3}{|c|}{ Intentionally Left Blank: End of Data }} & 90.12 & 0.16 \\
\hline & & & 91.12 & 0.16 \\
\hline & & & 92.12 & 0.15 \\
\hline & & & 93.12 & 0.14 \\
\hline & & & 94.12 & 0.15 \\
\hline & & & 95.12 & 0.16 \\
\hline & & & 97.12 & 0.15 \\
\hline & & & 98.12 & 0.12 \\
\hline & & & 99.12 & 0.11 \\
\hline & & & 100.12 & 0.14 \\
\hline & & & 101.12 & 0.16 \\
\hline & & & 102.12 & 0.11 \\
\hline & & & 103.12 & 0.14 \\
\hline & & & 104.12 & 0.14 \\
\hline & & & 105.12 & 0.18 \\
\hline & & & 106.12 & 0.22 \\
\hline & & & 106.69 & 0.17 \\
\hline
\end{tabular}




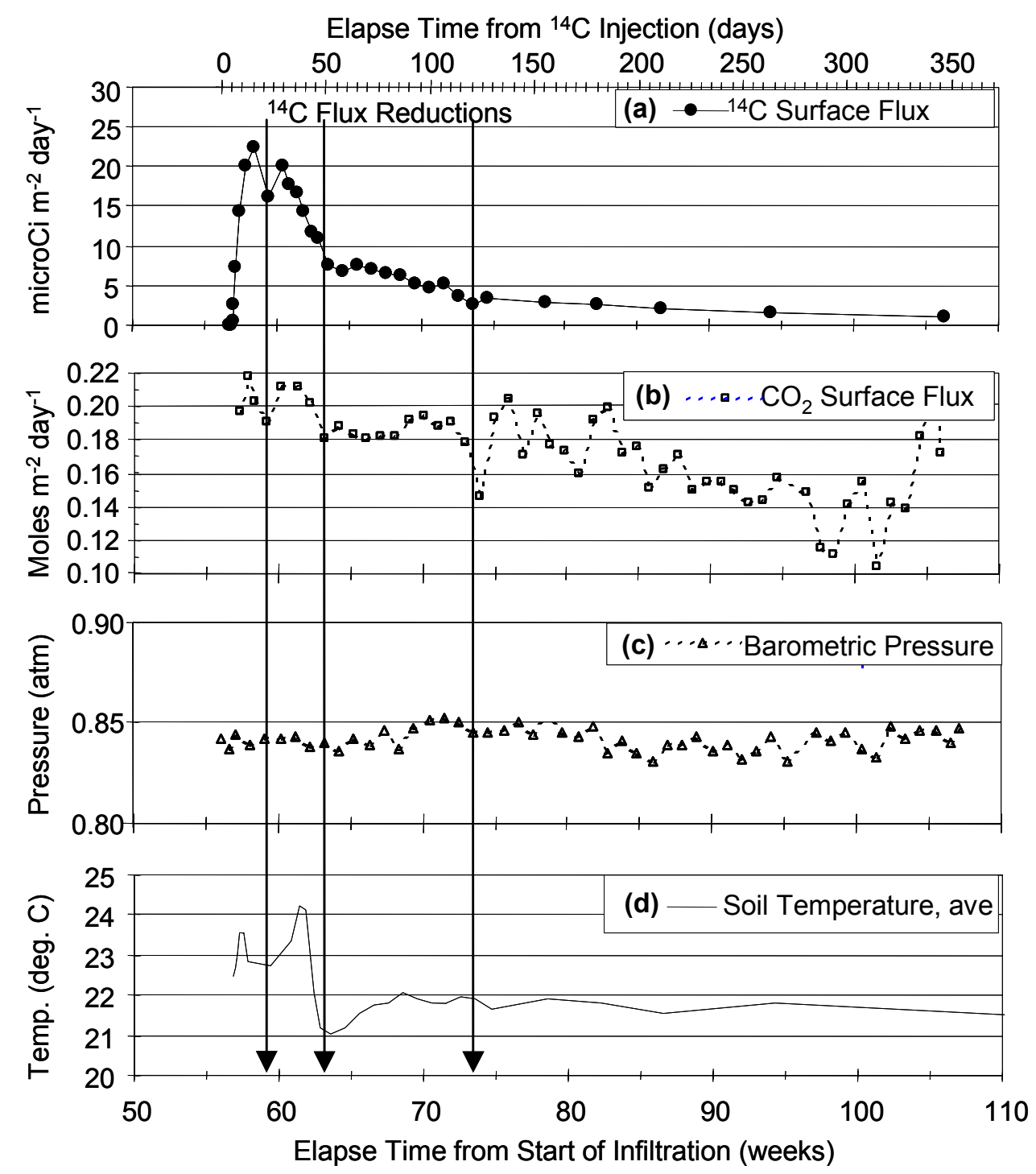

Figure $27 .{ }^{14} \mathrm{C}$ surface flux (a), $\mathrm{CO}_{2}$ surface flux (b), barometric pressure (c), and average sediment temperature (d) time series.

$\mathrm{CO}_{2(\mathrm{~g})}+\mathrm{H}_{2} \mathrm{O} \Leftrightarrow \mathrm{H}^{+}+\mathrm{HCO}_{3}^{-}$

As $\mathrm{CO}_{2(\mathrm{~g})}$ decreases, this reaction moves to the left, consuming $\mathrm{H}^{+}$and raising $\mathrm{pH}$. Although gasphase diffusion of ${ }^{14} \mathrm{CO}_{2}$ is independent of the gas-phase ${ }^{12 / 13} \mathrm{CO}_{2}$ concentration, the higher solution $\mathrm{pH}$ results in more partitioning of gas-phase ${ }^{14} \mathrm{CO}_{2}$ to the aqueous phase. Thus, when the $\mathrm{CO}_{2}$ partial pressure in the column decreases, there is an increase in ${ }^{14} \mathrm{CO}_{2}$ partitioning to the aqueous phase, a decrease of ${ }^{14} \mathrm{CO}_{2}$ in the gas phase, and consequently a decrease in ${ }^{14} \mathrm{CO}_{2}$ flux out of the column. Because temperature plays a key role in microbial $\mathrm{CO}_{2}$ production, and therefore $\mathrm{CO}_{2}$ partial pressure, there is a positive correlation between ${ }^{14} \mathrm{CO}_{2}$ flux and sediment temperature in the column (Figure 27a and d). This relationship between $\mathrm{pH}$ and aqueous/gas phase ${ }^{14} \mathrm{C}$ partitioning is consistent with the observation that the aqueous/gas partition ratio $\left(K_{a g}\right)$ increases near the top of the column as $\mathrm{pH}$ becomes greater and significantly more ${ }^{14} \mathrm{C}$ is contained in the aqueous phase than in the gas phase (Figure 28). As the fraction of injected ${ }^{14} \mathrm{C}$ remaining in the column declines, the response of ${ }^{14} \mathrm{C}$ flux to sediment temperature fluctuations becomes less apparent. 

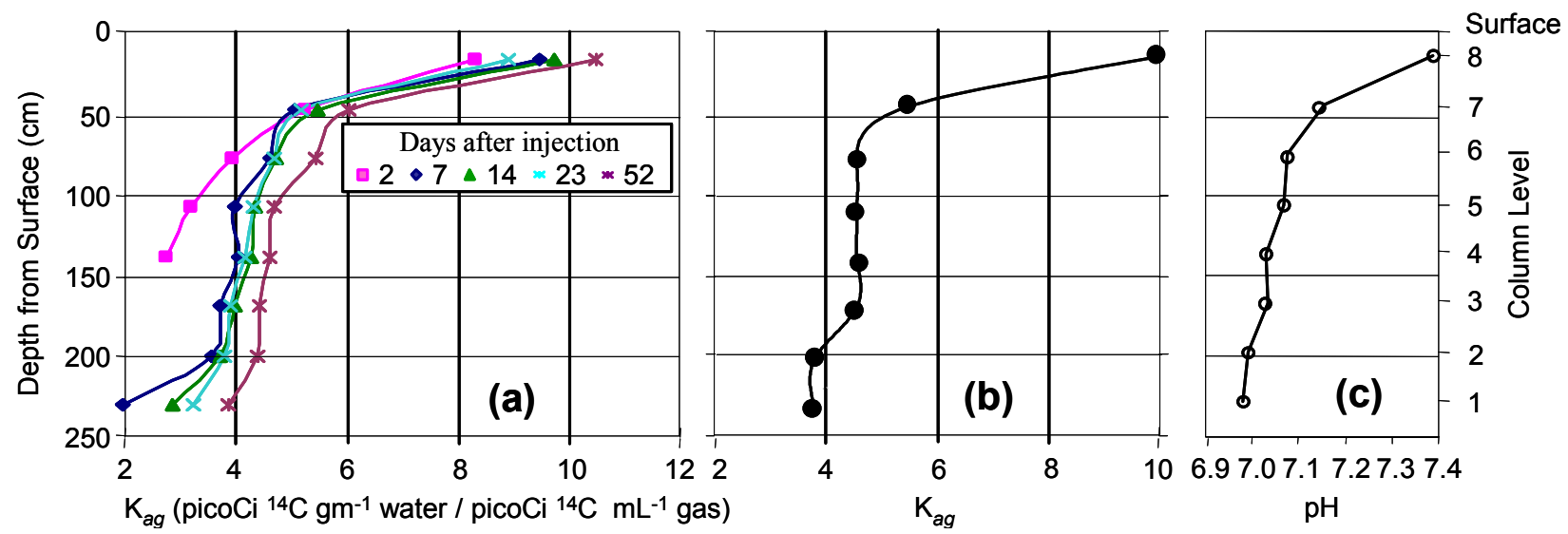

Figure 28. Early time aqueous/gas phase partition ratios $\left(K_{a g}\right)$ based on ${ }^{14} \mathrm{C}$ activity partitioning (a) and carbonate equilibrium (b) with $\mathrm{pH}(\mathrm{c})$.

The simultaneous appearance of aqueous- and gas-phase activity at each column level (Figure 26) indicates diffusive transport with an aqueous/gas phase exchange. This exchange and solid-phase sorption are expected to retard ${ }^{14} \mathrm{C}$ transport. Therefore, accurate estimates of the aqueous/gas partition ratio, $K_{a g}$, and aqueous/solid distribution coefficient $\left(K_{d}\right)$ are critical to predicting ${ }^{14} \mathrm{C}$ transport.

We calculate the dimensionless $K_{a g}$ as the ratio of ${ }^{14} \mathrm{C}$ activity per unit volume of sediment water to the ${ }^{14} \mathrm{C}$ activity per unit volume of sediment gas. The aqueous/solid distribution coefficient, $K_{d}$, is calculated as the ratio of ${ }^{14} \mathrm{C}$ activity per unit weight of dry sediment to the ${ }^{14} \mathrm{C}$ activity per unit volume of sediment water. Column $K_{a g}$ profiles for Days 2, 7, 14, 23, and 52 following the ${ }^{14} \mathrm{C}$ injection are presented in Figure 28a. These activity-based profiles are consistent with the $K_{a g}$ profile (Figure 28b) calculated for measured $\mathrm{pH}$ (Figure 28c) using standard carbonate equilibrium expressions (Langmuir 1997). Therefore, we consider $K_{a g}$ to be well constrained by both measured activity partitioning and measured $\mathrm{pH}$ and carbonate concentrations. $K_{a g}$ increases near the top of the column (i.e., surface to Level 7) as $\mathrm{pH}$ becomes greater and significantly more ${ }^{14} \mathrm{CO}_{2}$ is contained in the aqueous phase than in the gas phase. Throughout approximately $90 \%$ of the column, $\mathrm{pH}$ is between 6.9 and 7.1; higher $\mathrm{pH}$ occurs only relatively near the surface. Excluding near-surface values, the average $K_{a g}$ is thus approximately $4.5( \pm 0.3)$, during the initial few weeks of the transport study, depending on the column height considered.

On July 29, 2003, approximately one year after the ${ }^{14} \mathrm{C}$ injection, we cored the column to measure the solid phase activity profile (Table 24 and Figure 29). The aqueous and gas phase activity profiles had been measured five days prior to coring (Table 25 and Figure 30). $K_{d}$ was calculated for column levels not sampled by linear interpolation and/or extrapolation of measured solid phase activities. We calculated the ${ }^{14} \mathrm{C}$ activity mass balance by combining aqueous phase, gas phase, and average solid-phase activities (Table 25) with activities of material removed by sampling, effluent water, and surface flux (Table 26). The total activity removed by sampling represents a small fraction $(1.8 \%)$ of the total injection; therefore, sampling activities are believed to have had an insignificant effect on ${ }^{14} \mathrm{C}$ movement. An activity mass balance of $93.1 \%$ was achieved, with $6.9 \%$ of the injected ${ }^{14} \mathrm{C}$ unaccounted for (Figure 31 ). The inability to account for $100 \%$ of the injected activity is believed due to the nonuniformity observed in surface samples (Figure 29), inaccuracies associated with activity interpolation/extrapolation, activity remaining within injection tubing, and cumulative measurement error. The relatively great variation of surface sample activity $\left(1.2 \times 10^{-4} \pm 33 \%\right.$ picoCi $\left.\mathrm{g}^{-1}\right)$ is believed due to the formation of evaporation products (i.e., ${ }^{14} \mathrm{C}$ evaporites) at the sediment/atmosphere interface. The speciation of solid phase ${ }^{14} \mathrm{C}$ was not determined, so the potential contribution of biological ${ }^{14} \mathrm{C}$ uptake to surface sample variation is unknown. 
Table 24. Solid phase ${ }^{14} \mathrm{C}$ activity measurements 50 weeks after ${ }^{14} \mathrm{C}$ injection (at end of study).

\begin{tabular}{|c|c|c|c|}
\hline Core Point & Column Level & $\begin{array}{l}\text { Depth from Surface } \\
(\mathrm{cm})\end{array}$ & $\begin{array}{c}\text { Solid Phase Activity } \\
\text { (picoCi } \mathrm{g}^{-1} \text { of dry sediment) }\end{array}$ \\
\hline \multirow[t]{4}{*}{ Core 1: } & Surface & 0.0 & 133.6 \\
\hline & 8 & 15.2 & 126.6 \\
\hline & 7 & 45.7 & 129.0 \\
\hline & 6 & 76.2 & 119.7 \\
\hline \multirow[t]{4}{*}{ Core 5: } & Surface & 0.0 & 80.1 \\
\hline & 8 & 15.2 & 115.6 \\
\hline & 7 & 45.7 & 125.2 \\
\hline & 6 & 76.2 & 121.0 \\
\hline \multirow[t]{4}{*}{ Core 9: } & Surface & 0.0 & 89.3 \\
\hline & 8 & 15.2 & 130.3 \\
\hline & 7 & 45.7 & 118.7 \\
\hline & 6 & 76.2 & Not determined \\
\hline \multirow[t]{4}{*}{ Core 13: } & Surface & 0.0 & 78.8 \\
\hline & 8 & 15.2 & 122.2 \\
\hline & 7 & 45.7 & 126.1 \\
\hline & 6 & 76.2 & 109.9 \\
\hline \multirow[t]{4}{*}{ Core 17: } & Surface & 0.0 & 230.7 \\
\hline & 8 & 15.2 & 126.4 \\
\hline & 7 & 45.7 & 118.9 \\
\hline & 6 & 76.2 & 118.6 \\
\hline \multirow[t]{4}{*}{ Core 21: } & Surface & 0.0 & 120.4 \\
\hline & 8 & 15.2 & 121.8 \\
\hline & 7 & 45.7 & 115.2 \\
\hline & 6 & 76.2 & Not determined \\
\hline Porthole 3: & 3 & 152 & 130.7 \\
\hline Porthole 2: & 2 & 167 & 130.1 \\
\hline
\end{tabular}

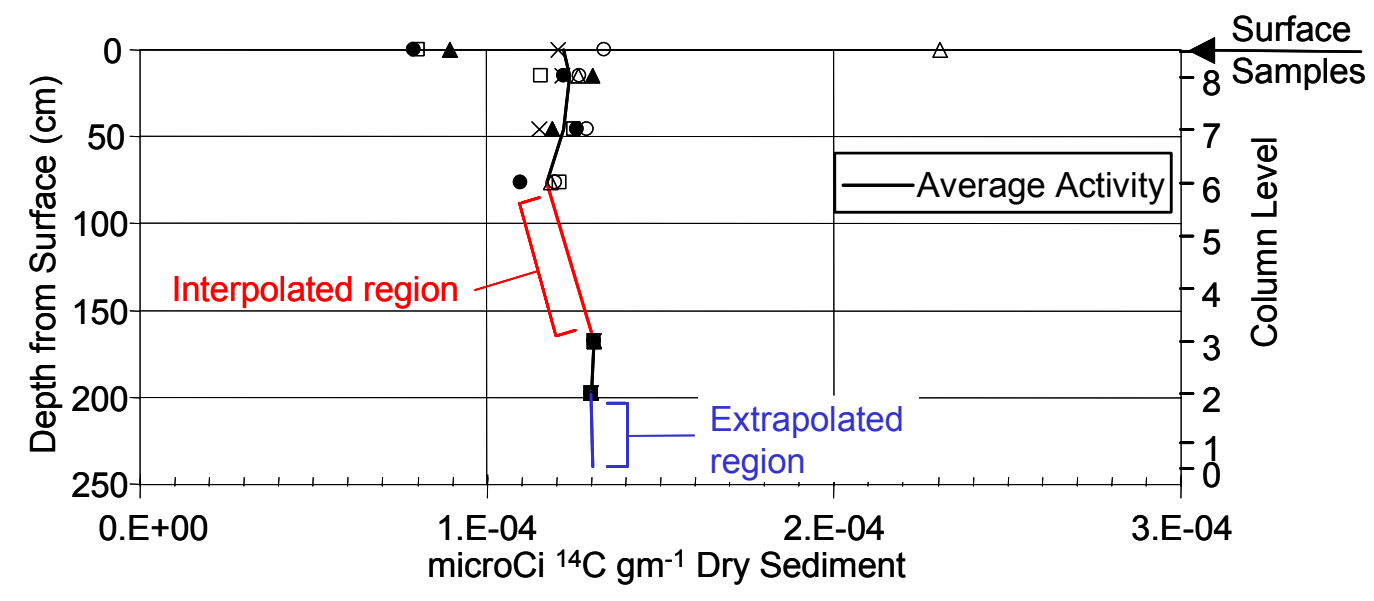

Figure 29. Solid phase ${ }^{14} \mathrm{C}$ activity profile at end of study. 
Table 25. Aqueous, gas, and solid phase ${ }^{14} \mathrm{C}$ activity measurements at end of study.

\begin{tabular}{|l|c|c|c|l|}
\hline $\begin{array}{c}\text { Column } \\
\text { Level }\end{array}$ & $\begin{array}{c}\text { Depth from } \\
\text { Surface } \\
(\mathrm{cm})\end{array}$ & $\begin{array}{c}\text { Aqueous Phase } \\
\left(\mathrm{picoCi}^{-1} \text { water }\right. \\
[7 / 24 / 03])\end{array}$ & $\begin{array}{c}\text { Gas Phase } \\
\left(\text { picoCi } \mathrm{mL}^{-1} \text { gas }\right. \\
[7 / 24 / 03])\end{array}$ & $\begin{array}{c}\text { Average Solid Phase } \\
\text { (picoCi g dry } \\
\text { sediment }[7 / 29 / 03])\end{array}$ \\
\hline Surface & 0.0 & 52 & 6 & 122.2 \\
\hline 8 & 15.2 & 88 & 18 & 123.8 \\
\hline 7 & 45.7 & 100 & 26 & 122.2 \\
\hline 6 & 76.2 & 116 & 30 & 117.3 \\
\hline 5 & 106.7 & 136 & 34 & 126.2 (interpolated) \\
\hline 4 & 137.2 & 152 & 38 & 130.7 \\
\hline 3 & 167.6 & 167 & 39 & 130.1 \\
\hline 2 & 198.1 & 156 & 42 & 130.1 (extrapolated) \\
\hline 1 & 228.6 & 143 & & \\
\hline OC & 243.8 & 129 & & \\
\hline OG & 243.8 & & & \\
\hline
\end{tabular}

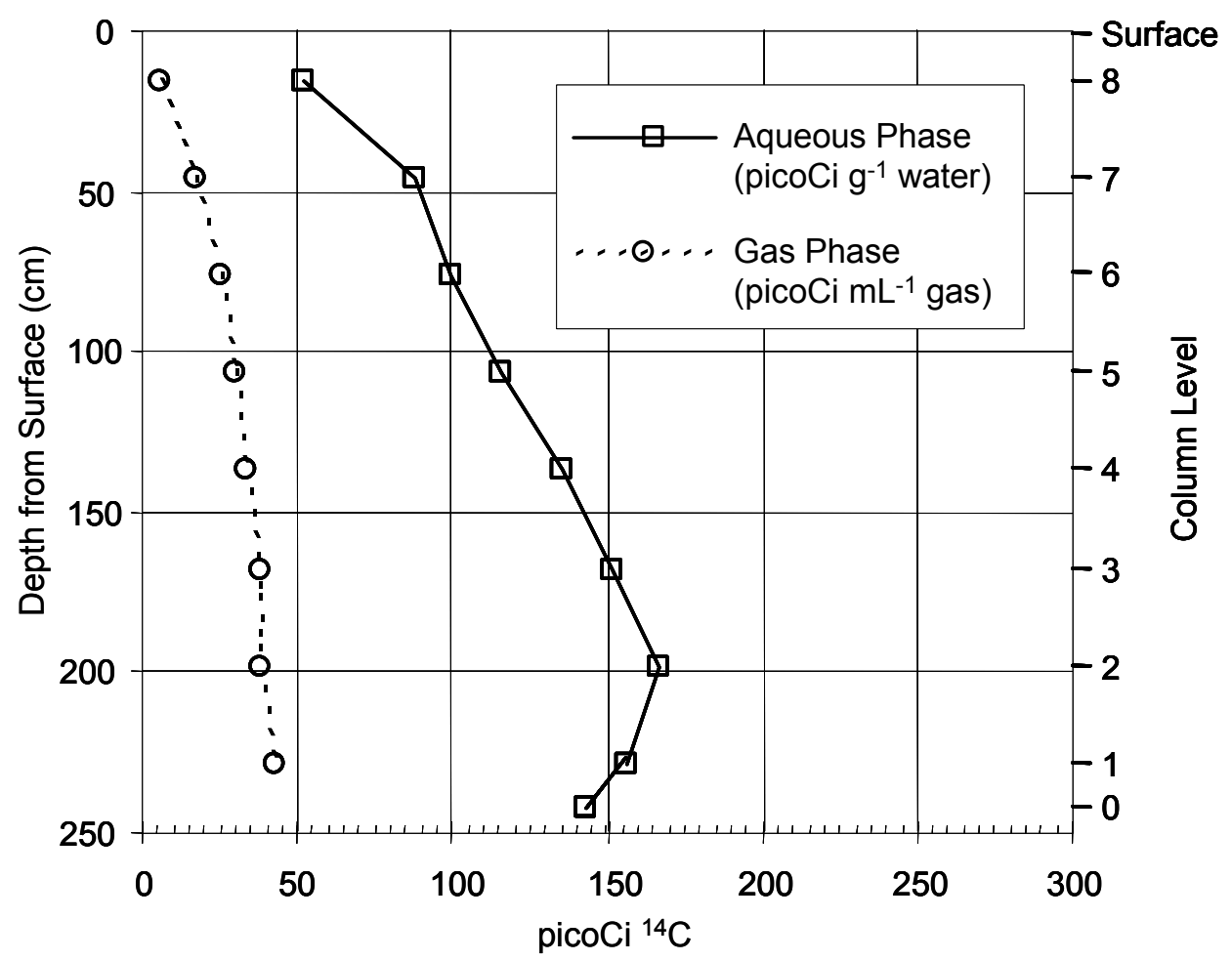

Figure 30 . Aqueous and gas phase ${ }^{14} \mathrm{C}$ activity profiles at end of study. 
Table 26. ${ }^{14} \mathrm{C}$ activity injected, released, removed, and retained (mass balance determination).

\begin{tabular}{|l|c|}
\hline & $\begin{array}{c}{ }^{14} \mathrm{C}, \mathrm{picoCi} \\
\left(\times 10^{6}\right)\end{array}$ \\
\hline Activity Injected & 1609.6 \\
\hline Released by Surface Flux & 1062.8 \\
\hline Released in Effluent Water & 60.2 \\
\hline Removed by Water Sampling & 4.9 \\
\hline Removed by Gas Sampling & 24.0 \\
\hline Retained in Solid Phase & 283.6 \\
\hline Retained in Pore Water & 50.7 \\
\hline Retained in Pore Gas & 12.7 \\
\hline Sum of Released & 1151.9 \\
\hline Sum of Retained & 347.0 \\
\hline Sum of Released and Retained & 1498.8 \\
\hline Activity Mass Balance & $93.1 \%$ \\
\hline
\end{tabular}

\section{$3.7 \%$}

(water discharged from bottom)

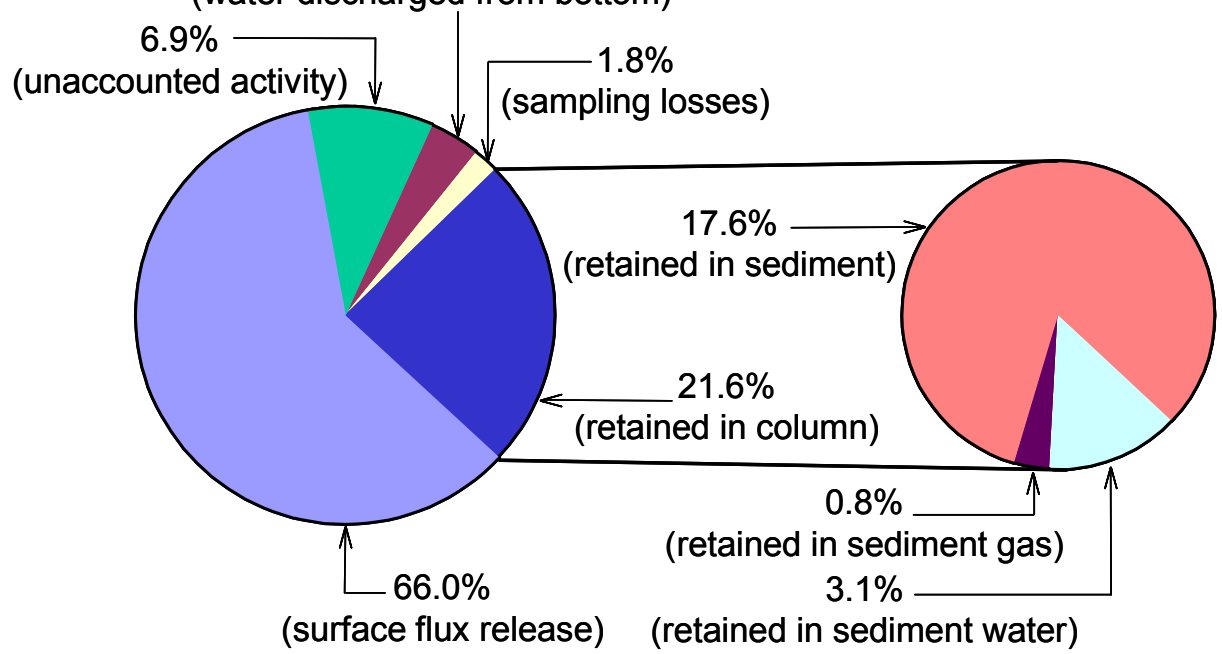

Figure 31 . Graphic representation of ${ }^{14} \mathrm{C}$ activity mass balance. 
After one year, ${ }^{14} \mathrm{C}$ migration from the column was by surface flux $(66.0 \%)$ and discharge of water from the bottom of the column (3.7\%). Of the total injected ${ }^{14} \mathrm{C}, 21.6 \%$ was found in the column with $81.5 \%$ of the residual sorbed to the solid phase.

After approximately one year, the activity-based $K_{a g}$ profile (Figure 32a) was consistent with that calculated using activity partitioning and carbonate-equilibrium-based approaches $\sim 50$ weeks earlier (Figure 28a and b). Measured $K_{d}$ values range from $0.8 \mathrm{~L} \mathrm{~kg}^{-1}$ near the bottom of the column to $2.4 \mathrm{~L} \mathrm{~kg}^{-1}$ near the top of the column with an average of $1.6 \mathrm{~L} \mathrm{~kg}^{-1}$ (Figure 32a). Much higher $K_{d}$ values and a dependence on contact time were observed by Allard et al. (1981) who noted increasing adsorption over time in experiments with calcite, obtaining a $K_{d}$ of $83 \mathrm{~mL} \mathrm{~g}^{-1}$ after six months contact time. However, our range of measured $K_{d}$ values, after 1 year, is consistent with values $\left(0.1\right.$ to $\left.2.0 \mathrm{~L} \mathrm{~kg}^{-1}\right)$ derived for short-term and small-scale batch and column experiments using SDA sediments (Dicke and Hohorst 1997, ${ }^{\text {ee }}$ Hull and Hohorst 2001). Similar to $K_{a g}, K_{d}$ is relatively uniform throughout most of the column but increases near the top of the column, as sediment gas $\mathrm{CO}_{2}$ concentrations decline and $\mathrm{pH}$ becomes greater (Figure 32a and b). These results indicate the need to incorporate effects of nonuniform $\mathrm{pH}$ on $K_{a g}$ and $K_{d}$ into contaminant transport models. For this reason, $\mathrm{pH}$, bicarbonate, and $\mathrm{CO}_{2 \text { (gas) }}$ concentrations at the time of coring are given with activity-based calculations of $K_{a g}$ and $K_{d}$ (Table 27).
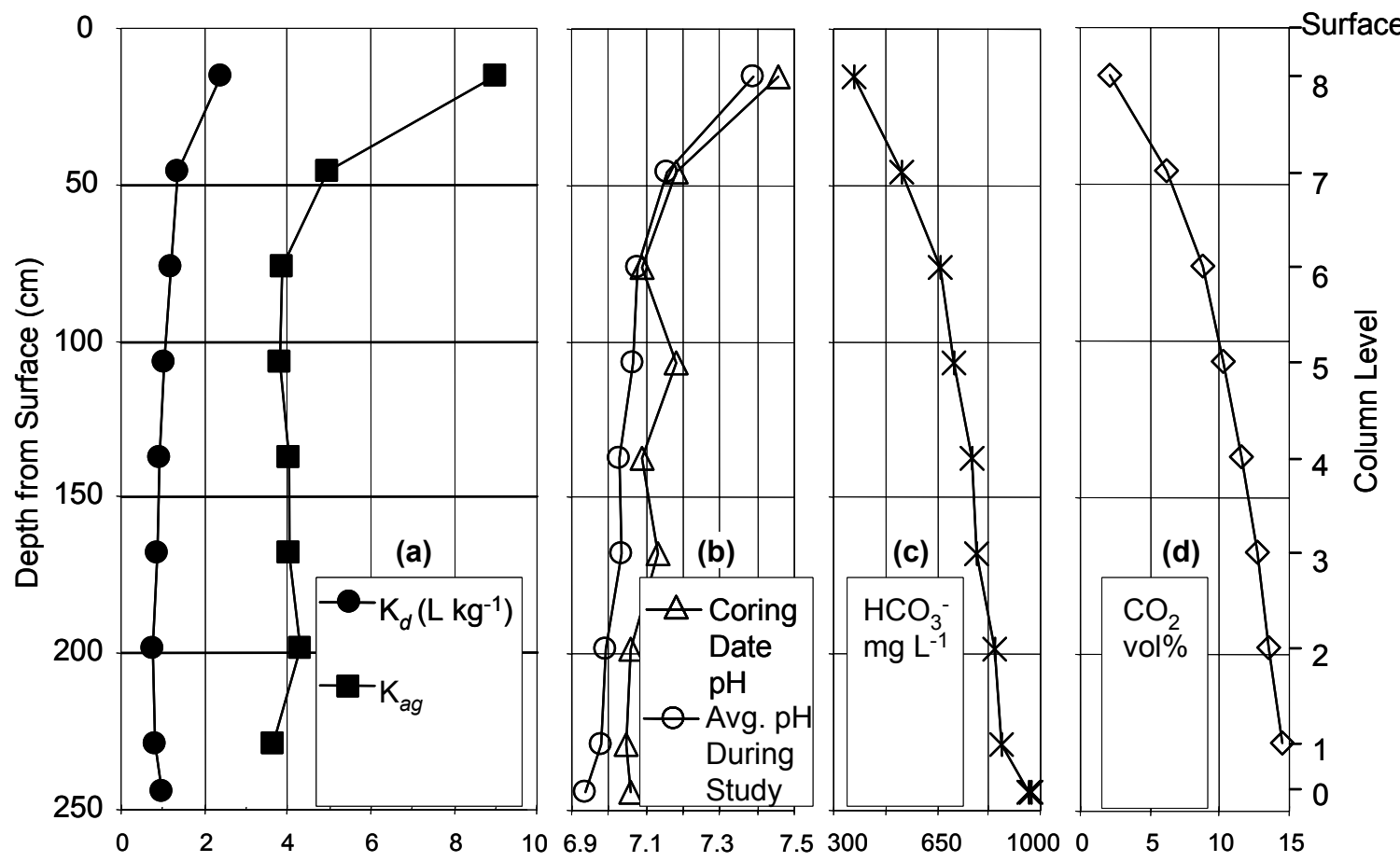

Figure 32. $K_{d}, K_{a g}(\mathrm{a}), \mathrm{pH}(\mathrm{b})$, bicarbonate alkalinity (c), and $\mathrm{CO}_{2}(\mathrm{~d})$ profiles at time of coring (end of study).

ee. Carbon-14 distribution coefficients measured from batch experiments on SDA sediments, Idaho National Engineering and Environmental Laboratory internal report INEEL/INT-98-00068, EDF-RWMC-1011. 
Table 27. $K_{d}, K_{a g}, \mathrm{pH}, \mathrm{CO}_{2}$, and bicarbonate measurements at time of coring (50 weeks after ${ }^{14} \mathrm{C}$ injection).

\begin{tabular}{|c|c|c|c|c|c|c|}
\hline $\begin{array}{c}\text { Column } \\
\text { Level }\end{array}$ & $\begin{array}{c}\text { Depth from Surface } \\
(\mathrm{cm})\end{array}$ & $\begin{array}{c}K_{d} \\
(\mathrm{~L} \text { water } \\
\left.\mathrm{kg}^{-1} \text { sediment }\right)\end{array}$ & $\begin{array}{c}K_{a g} \\
(\text { unitless })\end{array}$ & $\begin{array}{c}\mathrm{pH} \\
( \pm 0.3 \%)\end{array}$ & $\begin{array}{c}\mathrm{CO}_{2} \mathrm{vol}^{2} \\
( \pm 2 \%)\end{array}$ & $\begin{array}{c}\mathrm{HCO}_{3}^{-} \\
\left(\mathrm{mg} \mathrm{L}^{-1}\right)\end{array}$ \\
\hline 8 & 15.2 & 2.4 & 9.0 & 7.46 & 2.16 & 366 \\
\hline 7 & 45.7 & 1.4 & 5.0 & 7.18 & 6.19 & 534 \\
\hline 6 & 76.2 & 1.2 & 3.9 & 7.09 & 8.78 & 661 \\
\hline 5 & 106.7 & 1.1 & 3.8 & 7.18 & 10.28 & 710 \\
\hline 4 & 137.2 & 0.9 & 4.0 & 7.09 & 11.65 & 769 \\
\hline 3 & 167.6 & 0.9 & 4.0 & 7.13 & 12.72 & 781 \\
\hline 2 & 198.1 & 0.8 & 4.3 & 7.06 & 13.56 & 847 \\
\hline 1 & 228.6 & 0.8 & 3.7 & 7.05 & 14.44 & 871 \\
\hline OC & 243.8 & 0.9 & & 7.06 & & 964 \\
\hline OG & 243.8 & & & 7.17 & & 971 \\
\hline
\end{tabular}




\section{CONCLUSION}

Previous efforts to predict ${ }^{14} \mathrm{C}$ migration from activated metals buried at the SDA were based on contaminant transport models that used transport parameters derived from short-term, bench-scale experiments. Those experiments had limited ability to represent the spatially and temporally varying conditions that affect ${ }^{14} \mathrm{C}$ behavior in the subsurface environment. Our primary goal was to determine ${ }^{14} \mathrm{C}$ transport parameters at spatial-temporal scales, and under geochemical conditions, more applicable to the subsurface environment at the SDA. Our results provide the basis for future modeling efforts to both predict the behavior of ${ }^{14} \mathrm{CO}_{2}$ released from activated metals at the SDA and to determine the ability of transport parameters derived from bench-scale experiments to predict ${ }^{14} \mathrm{C}$ behavior at scales approaching that of the field. Our secondary goal was to identify challenges of operating a near field-scale (mesoscale) unsaturated flow column.

To accomplish our goals, we conducted a set of unsaturated flow experiments to examine the movement of water, gas, conservative tracers, and ${ }^{14} \mathrm{C}$ in a $2.6-\mathrm{m}$ high by $0.9-\mathrm{m}$ diameter meso-scale column of surface sediments similar to those at the SDA. We injected a conservative gas tracer, sulfur hexafluoride, both before and after initiation of hydraulic flow and also injected conservative liquid tracers, bromide and tritium, after reaching a quasi steady-state flow. The transport test involved injection of aqueous $1610( \pm 16)$ microCi ${ }^{14} \mathrm{C}$-labeled bicarbonate $0.6-\mathrm{m}$ below the sediment surface (i.e., the sediment/atmosphere interface). For $\sim 12$ months, we monitored headspace and pore gas $\mathrm{CO}_{2}$ and $\mathrm{O}_{2}$ concentrations, sediment surface ${ }^{14} \mathrm{CO}_{2}$ flux, pore gas and pore water ${ }^{14} \mathrm{C}$ migration, pore water chemistry, sediment water content, hydraulic head and/or matric potential, and sediment temperature profiles. During the ${ }^{14} \mathrm{C}$ transport experiment, aqueous/gas ${ }^{14} \mathrm{C}$ partitioning ratios $\left(K_{a g} \mathrm{~s}\right)$ were calculated using two separate methods: aqueous- and gas-phase activity measurements and standard carbonate equilibrium expressions (Langmuir 1997) with measured $\mathrm{pH}$. At the end of the ${ }^{14} \mathrm{C}$ monitoring period, we cored the column and measured solid-phase ${ }^{14} \mathrm{C}$ sorption for calculation of the aqueous/solid ${ }^{14} \mathrm{C}$ partition coefficient $\left(K_{d}\right)$ and ${ }^{14} \mathrm{C}$ mass balance. Results of water content determinations and tracer experiments were used to characterize physical transport parameters affecting ${ }^{14} \mathrm{C}$ movement, including average linear seepage velocity, dispersivity, and aqueous- and gas-phase diffusion coefficients. These physical and phase partitioning parameters (i.e., $K_{a g}$ and $K_{d}$ ) form the basis for subsequent transport modeling efforts.

Our results indicate a relatively constant volumetric water content $(28 \% \pm 3 \%)$ and an average linear seepage velocity of $0.52 \mathrm{~cm}_{\text {day }}{ }^{-1}$ during the ${ }^{14} \mathrm{C}$ transport experiment. An initial (packing) volumetric water content of $\sim 10 \%$ was indicated by analysis of gravimetric, reflectometer, and sulfur hexafluoride tracer data. Results of post-study bulk density determinations, by sediment cores, are consistent with the average bulk density $\left(1.31 \pm 0.05 \mathrm{~g} \mathrm{~cm}^{-3}\right)$ calculated during column packing. Thus, settling did not occur in the column during these experiments. Sediment porosity (51\%) was calculated using average bulk density with an assumed particle density of $2.65 \mathrm{~g} \mathrm{~cm}^{-3}$.

Bromide $\left(\mathrm{Br}^{-}\right)$breakthrough curves were fit to an analytical solution to the advection dispersion equation for equilibrium transport of a conservative ion slug (CXTFIT2, Toride et al. 1995). Analysis of the $\mathrm{Br}^{-}$data indicates that hydraulic flow in the column was effectively one-dimensional with an average linear seepage velocity of $0.52 \mathrm{~cm} \mathrm{day}^{-1}$, an aqueous diffusion coefficient of $1.8 \times 10^{-5} \mathrm{~cm}^{2} \mathrm{sec}^{-1}$, and an average hydraulic dispersion coefficient of $5.7 \times 10^{-6} \mathrm{~cm}^{2} \mathrm{sec}^{-1}$ during the transport experiments. Hydraulic dispersivity was effectively negligible, ranging from 0 to $7 \mathrm{~mm}$.

We found transport of the tritium $\left({ }^{3} \mathrm{H}\right)$ tracer to be retarded and calculated a ${ }^{3} \mathrm{H}$ aqueous/solid partitioning coefficient of $\sim 0.08 \mathrm{~mL} \mathrm{~g}^{-1}$. Therefore, the ${ }^{3} \mathrm{H}$ data was not considered in estimation of aqueous transport characteristics in the column. ${ }^{3} \mathrm{H}$ retardation is significant because ${ }^{3} \mathrm{H}$ is commonly used as a conservative, nonreactive, tracer in aqueous system studies. Knowledge of the mechanisms causing ${ }^{3} \mathrm{H}$ retardation would provide understanding critical to use of ${ }^{3} \mathrm{H}$ as an aqueous tracer in unsaturated flow 
studies. We are currently using data from this study to investigate ${ }^{3} \mathrm{H}$ fixation on clays and other common hydrated sediment minerals as the mechanism of retardation. Results of these investigations will be published later.

We performed a least-squares fit of sulfur hexafluoride $\left(\mathrm{SF}_{6}\right)$ breakthrough curves for the meso-scale column data using the standard Millington expression (Millington 1959) with an analytical solution to the continuity expression for unidirectional transport. These fits included sets of eight curves, each measured at two different water contents. A good coefficient of determination (0.86) was observed for these fits. Therefore, we conclude that the standard Millington expression with the commonly used $m$ value (2.3 or 7/3) adequately describes $\mathrm{SF}_{6}$ transport in SDA sediments. Additional analysis of these $\mathrm{SF}_{6}$ tracer data indicated a gaseous diffusion coefficient of $1.1 \times 10^{-1} \mathrm{~cm}^{2} \mathrm{sec}^{-1}$ during the ${ }^{14} \mathrm{C}$ transport experiment.

Gas-phase ${ }^{14} \mathrm{C}$ breakthrough curves at virtually all levels in the column display the same characteristic shape as the $\mathrm{SF}_{6}$ curves, but lagged, which is consistent with gas-diffusion-dominated transport retarded by exchanges with other phases. ${ }^{14} \mathrm{CO}_{2}$ diffusion, with aqueous/gas phase exchange, allowed ${ }^{14} \mathrm{C}$ to distribute between pore-water and -gas volumes throughout the column within 7 days, with a maximum ${ }^{14} \mathrm{CO}_{2}$ surface flux (22.37 microCi m ${ }^{-2}$ day $\left.^{-1}\right)$ occurring within 25 days of the ${ }^{14} \mathrm{C}$ injection. After $\sim 12$ months, ${ }^{14} \mathrm{C}$ migration from the column was by surface flux $(66.0 \%)$ and discharge of water from the bottom of the column (3.7\%). At this time, $21.6 \%$ of the total injected activity was found in the column, distributed between aqueous, gas, and solid phases. Of this residual, $81.5 \%$ was sorbed to the solid phase. Mass balance calculations accounted for $93 \%$ of the injected ${ }^{14} \mathrm{C}$ activity. The inability to account for all of the injected activity is assumed due to variability of sediment surface sample activities $\left(1.2 \times 10^{-4} \pm 33 \%\right.$ picoCi $\mathrm{g}^{-1}$ sediment $)$ resulting from the apparent formation of evaporation products (i.e., ${ }^{14} \mathrm{C}$ evaporites) at the sediment surface, activity remaining within injection tubing, and cumulative measurement error.

Our results indicate that migration of ${ }^{14} \mathrm{C}$ from the meso-scale column was predominantly by diffusive transport to the sediment surface; there was minimal aqueous phase transport or solid phase retention. Given that the column infiltration rate was greater than that estimated for the SDA (Case et al. 2000) and that the sediment type and geometry of the experiment are applicable to the SDA transport problem, we expect that ${ }^{14} \mathrm{CO}_{2}$ migration from activated metals buried at the SDA will also be dominated by gas diffusion with release primarily to the atmosphere rather than to the underlying Snake River Plain aquifer.

During the ${ }^{14} \mathrm{C}$ transport study, pore gas $\mathrm{CO}_{2}$ concentration $\left(\mathrm{pCO}_{2}\right)$ fluctuated in response to changes in sediment temperature, which was the primary control of microbial $\mathrm{CO}_{2}$ production in the column. We observed a positive correlation between $\mathrm{pCO}_{2}$ fluctuations and diffusive ${ }^{14} \mathrm{C}$ transport. Though Thorstenson et al. (1983) found gas-phase ${ }^{14} \mathrm{CO}_{2}$ diffusion to be independent of $\mathrm{pCO}_{2}$, we find that changes in $\mathrm{pCO}_{2}$ affected $\mathrm{pH}$ sufficiently to affect aqueous/gas phase ${ }^{14} \mathrm{CO}_{2}$ partitioning and, therefore, diffusive transport. As a result, even short-term temperature fluctuations caused significant fluctuations in ${ }^{14} \mathrm{CO}_{2}$ flux from the column. Therefore, subsurface temperature should be considered when predicting ${ }^{14} \mathrm{C}$ behavior in the near subsurface where variation of temperature with season and/or climate has the potential to affect ${ }^{14} \mathrm{C}$ phase partitioning and transport.

Microbial consumption of natural organic matter and oxygen with respiration of $\mathrm{CO}_{2}$ produced an approximately exponential increase in $\mathrm{pCO}_{2}$ and a corresponding decrease in $\mathrm{pH}$ with depth. Typical $\mathrm{pH}$ values near the top and near the bottom of the column range from $\sim 7.4$ to $\sim 6.9( \pm 0.3 \%)$, respectively. The effect of nonuniform $\mathrm{pH}$ is observed in measurements of $K_{a g}$ and $K_{d}$. This nonuniformity increased both $K_{a g}$ and $K_{d}$ near the top of the column, as significantly more ${ }^{14} \mathrm{C}$ was measured in the aqueous phase than in either the gas or solid phase near the top of the column. During the initial few weeks of the transport 
study, $K_{a g}$ values ranged from $\sim 9.0$ near the top of the column to $\sim 4.0$ near the bottom, with an average of $4.5( \pm 0.3)$. After $\sim 12$ months, the activity-based $K_{a g}$ profile was consistent with that calculated using activity-based and carbonate-equilibrium-based approaches $\sim 12$ months earlier. The consistency of activity-based and carbonate-equilibrium-based $K_{a g}$ profile determinations suggests the ability to estimate $K_{a g}$ based solely on carbonate equilibrium. $K_{d}$ values ranged from $2.4 \mathrm{~L} \mathrm{~kg}^{-1}$ near the top of the column to $0.8 \mathrm{~L} \mathrm{~kg}^{-1}$ near the bottom, with an average of $1.6 \mathrm{~L} \mathrm{~kg}^{-1}$. Much higher $K_{d}$ values and a dependence on contact time were observed by Allard et al. (1981). They noted increasing adsorption over time in experiments with calcite, obtaining a $K_{d}$ of $83 \mathrm{~L} \mathrm{~kg}^{-1}$ after six months contact time. However, our range of measured $K_{d}$, after a one year, is consistent with values $\left(0.1\right.$ to $\left.2.0 \mathrm{~L} \mathrm{~kg}^{-1}\right)$ derived for short-term and small-scale batch and column experiments using SDA sediments (Dicke and Hohorst 1997, ${ }^{\mathrm{ff}}$ Hull and Hohorst 2001). This result suggests that bench-scale measurements are a valid means of estimating aqueous/solid partitioning at the much larger spatial-temporal scales considered in this meso-scale experiment. However, the effect of nonuniform $\mathrm{pH}$ on $K_{d}$ and $K_{a g}$ has not been observed in previous bench-scale experiments. Therefore, bench-scale measurements may be a generally valid means of estimating phase partitioning parameters at larger scales but lack the spatial resolution necessary to observe the effect of environmental variables that control those parameters at larger scales.

We achieved our primary goal, to determine ${ }^{14} \mathrm{C}$ transport parameters at spatial-temporal scales, and under geochemical conditions, applicable to the subsurface environment at the SDA. However, establishing steady-state geochemical and hydraulic conditions did require considerable time. Though the high initial hydraulic flux ( $\sim 5 \mathrm{~L} \mathrm{day}^{-1}$ for 84 days) was effective in minimizing the time required to establish unsaturated flow and remove excess dissolved salts from the column, 45 weeks (313 days) of steady hydraulic flux $\left(\sim 1 \mathrm{~L} \mathrm{day}^{-1}\right)$ was needed to stabilize the hydraulic potential gradient following the high flux period.

Maintenance of steady-state geochemical conditions (i.e., microbial $\mathrm{CO}_{2}$ production and pore water $\mathrm{pH}$ ) was hampered by the long-term depletion of microbial substrate (i.e., easily metabolized organic carbon). Due to rapid ${ }^{14} \mathrm{CO}_{2}$ discharge from the column, long-term changes in $\mathrm{pH}$ were insignificant to the ${ }^{14} \mathrm{C}$ transport portion of this study. However, substrate depletion would be a significant factor in designing transport experiments involving extended periods sensitivity to $\mathrm{pH}$ (e.g., for uranium). Though measurement of uranium mobility was an initial component of this study, and uranium was injected into the column, the effect of long-term $\mathrm{pH}$ changes on uranium mobility could not be observed because aqueous phase uranium was not detected at the lysimeter located $\sim 15-\mathrm{cm}$ below the injection plane. This suggests a uranium $K_{d}$ greater than $2.5 \mathrm{~L} \mathrm{~kg}^{-1}$. The extent of uranium migration and the uranium $K_{d}$ are the focus of ongoing analysis of sediment core samples. These analyses are the subject of a forthcoming publication.

Meso-scale transport experiments are rarely conducted due to their length and considerable cost. However, meso-scale experiments are a valuable means of observing complex behavior under conditions applicable to the field. We demonstrated this value by measuring nonuniformities of $K_{a g}$ and $K_{d}$ and observing that sediment temperature controls ${ }^{14} \mathrm{CO}_{2}$ diffusion. These measurements and observations were possible because the meso-scale experiment allowed spatially- and temporally-varying conditions, as would occur in the field, to affect ${ }^{14} \mathrm{C}$ behavior. Furthermore, the consistency of the transport parameters we determined with those of previous bench-scale experiments provides increased confidence in the ability of bench-scale methods to predict contaminant behavior in the natural environment. This confidence is invaluable when making regulatory decisions concerning contaminant migration at the SDA and elsewhere.

ff. Carbon-14 distribution coefficients measured from batch experiments on SDA sediments, Idaho National Engineering and Environmental Laboratory internal report INEEL/INT-98-00068, EDF-RWMC-1011. 


\section{REFERENCES}

Allard, B., B. Torstenfelt, and K. Andersson, 1981, "Sorption Studies of $\mathrm{H}^{14} \mathrm{CO}_{3}{ }^{-}$on Some Geologic Media and Concrete," In J. G. Moore (ed.) Scientific Basis for Nuclear Waste Management III, Plenum Publ. Corp, New York, p. 465-472.

Ames, L. L., and D. Rai, 1978, Radionuclide Interactions with Soil and Rock Media, Volume 1: Processes Influencing Radionuclide Mobility and Retention, Element Chemistry and Geochemistry, and conclusions and Evaluation, EPA 520/6-78-007A, prepared for the U.S. Environmental Protection Agency by the Pacific Northwest Laboratory, Richland, Washington.

Bond, W. J., B. N. Gardiner, and D. E. Smiles, 1982, "Constant-Flux Absorption of a Tritiated Calcium-Chloride Solution by a Clay Soil with Anion Exclusion," Soil Science Society of America Journal, Vol. 46, No. 6, pp. 1133-1137.

Case, M. J., A. S. Rood, J. M. McCarthy, S. O. Magnuson, and B. H. Becker, 2000, Technical Revision of the Radioactive Waste Management Complex Low-Level Waste Radiological Performance Assessment for Calendar Year 2000, INEEL/EXT-2000-01089, Idaho National Engineering and Environmental Laboratory, Bechtel BWXT, Idaho Falls, ID.

Hartsough, P. S., W. Tyler, J. Sterling and M. Walvoord, 2001, “A 14.6 kyr Record of Nitrogen Flux from Desert Soil Profiles as Inferred from Vadose Zone Pore Waters," Geophysical Research Letters, Vol. 28, No. 15, pp. 2955-2958.

Hull, L. C. and C. W. Bishop, 2003, Fate of Magnesium Chloride Brine Applied to Suppress Dust from Unpaved Roads at the INEEL Subsurface Disposal Area, INEEL/EXT-01-1173, Idaho National Engineering and Environmental Laboratory, Bechtel BWXT, Idaho Falls, ID.

Hull, L. C. and F. A. Hohorst, 2001, Transport Models for Radioactive Carbon Dioxide at RWMC, INEEL/EXT-01-00894, Idaho National Engineering and Environmental Laboratory, Bechtel BWXT, Idaho Falls, ID.

James, R. V. and J. Rubin, 1986, "Transport of Chloride-ion in a Water-Unsaturated Soil Exhibiting Anion Exclusion," Soil Science Society of America Journal, Vol. 50, No. 5, pp. 1142-1149.

Langmuir, D., 1997, Aqueous Environmental Geochemistry, Prentice-Hall, Inc., New Jersey.

McCarthy, J. M., B. H. Becker, S. O. Magnuson, K. N. Keck, T. K. Honeycutt, 2000, Radioactive Waste Management Complex Low-Level Waste Radiological Composite Analysis, INEEL/EXT-97-01113, Bechtel BWXT Idaho, LLC, September 2000.

Millington, R. J., 1959, “Gas Diffusion in Porous Media,” Science, Vol. 130, pp. 100-102.

Olmsted, J. and G. M. Williams, 1994, “Chemistry: The Molecular Science,” Mosby, p. 221.

Thibault, D. H., M. I. Sheppard, and P. A. Smith, 1990, A Critical Compilation and Review of Default Soil Solid/Liquid Partition Coefficients, $K_{d}$, for Use in Environmental Assessments, AECL-10125, Whiteshell Nuclear Research Establishment, Pinawa, Manitoba, Canada. 
Thorstenson, D. C., E. P. Weeks, H. Haas, and D. W. Fisher, 1983, "Distribution of Gaseous ${ }^{12} \mathrm{CO}_{2}$ in the Sub-Soil Unsaturated Zone of the Western U.S. Great Plains," Radiocarbon, Vol. 25, pp. 315-346.

Toride, N., F. J. Leij, and M. T. van Genuchten, 1995, The CXTFIT Code for Estimating Transport Parameters from Laboratory or Field Tracer Experiments, Version 2.0. Research Rep. 137. U.S. Salinity Lab., USDA, Riverside, CA.

Walvoord, M. A., F. M. Phillips, D. A. Stonestrom, R. D. Evans, P. C. Hartsough, B. D. Newman and R. G. Striegl, 2003, “A Reservoir of Nitrate Beneath Desert Soils,” Science, Vol. 302, No. 5647, pp. 1021-1024. 
Appendix A

Measurement Accuracy 


\section{Appendix A}

\section{Measurement Accuracy}

\section{Associated Error Analyses}

The relative accuracy of methods used for chemical and radiological determinations is expressed in terms of precision (i.e., uncertainty) and bias. The uncertainty associated with each measurement type is presented as the percent average-difference of standard and/or average duplicate sample measurements, Equation (A-1). Cumulative uncertainty and errors associated with standard laboratory procedures are not addressed.

$\%$ Uncerta int $\mathrm{y}=\left(\frac{\frac{\sum \mathrm{d}_{\mathrm{i}}}{\mathrm{n}_{\mathrm{i}}}}{\text { Value }}\right) * 100$

where
$\%$ Uncertaint $\mathrm{y}=$ percent of average difference
$\sum \mathrm{d}_{\mathrm{i}} \quad=\quad$ sum of the differences between each measurement and the either the measurement-standard or the average value for duplicate samples (absolute
values)
$\mathrm{n}_{\mathrm{i}} \quad=\quad$ the number of observations (i.e., samples)
Value $\quad=\quad$ the measurement-standard value or the average duplicate-sample value.

\section{Aqueous Measurements}

Uncertainties associated with aqueous species analyses are contained in laboratory reports and are not presented here. However, electro neutrality \% errors are given in Table 16. Iron and carbonate were assumed to have a negligible charge balance contribution. Alkalinity was considered to be as bicarbonate in change calculations. Conductivity and $\mathrm{pH}$ measurement uncertainties were established in relation to duplicate sample analysis of conductivity and $\mathrm{pH}$ standards, Table A-1. The accuracy of alkalinity measurements may be accessed using an alkalinity standard. This assessment was not performed because turbidity and/or chlorine interference were not expected. Instead, we choose to determine the method error and compare it to the published error. The comparison was performed by blind analysis of duplicate samples. A maximum deviation from the mean of $10.3 \mathrm{ppm}$ was measured. The HACH Company defines the method error as $10 \mathrm{ppm}$.

Table A-1. Alkalinity, electrical-conductivity, and $\mathrm{pH}$ measurement uncertainty.

\begin{tabular}{|l|c|c|}
\hline & $\begin{array}{c}\text { Performance Samples/ } \\
\text { Sampling Days }\end{array}$ & $\%( \pm)$ \\
\hline Alkalinity & $15 / 1$ & $10 \mathrm{ppm}$ \\
\hline Electrical-Conductivity (average) & $10 / 193$ & $1 \%$ \\
\hline PH & $43 / 286$ & $0.3 \%$ \\
\hline
\end{tabular}




\section{Gas Concentration Measurements}

The uncertainty of $\mathrm{SF}_{6}$ analysis is given by the manufacturer to be $1 \%$. A duplicate sample was used as an additional measure of method precision. The duplicate was made using $\sim 0.3 \mathrm{~cm}^{3}$ of the certified $\mathrm{SF}_{6}$ gas standard (99.995\%) in a Tedlar bag containing $\sim 3 \mathrm{~L}$ of UHP nitrogen gas. Five measurements produced a mean concentration of 107 ppmv. The uncertainty associated with $\mathrm{SF}_{6}$ measurements is presented as the percent average-difference of each duplicate sample and the average duplicate sample value. The accuracy of $\mathrm{O}_{2}$ measurements is established in reference to room air at 209,500 ppmv $\mathrm{O}_{2}$ (i.e., the performance evaluation sample or PES). The uncertainty associated with $\mathrm{O}_{2}$ measurements is presented as the percent average-difference of each calibrated PES measurement and the actual PES value.

The accuracy of $\mathrm{CO}_{2}$ measurements is established in reference to low and high range PESs. The uncertainty associated with $\mathrm{CO}_{2}$ measurements is presented as the percent average-difference of each calibrated PES measurement and the actual PES value. $\mathrm{SF}_{6}, \mathrm{O}_{2}$, and $\mathrm{CO}_{2}$ measurement uncertainties are given in Table A-2.

Table A-2. $\mathrm{SF}_{6}, \mathrm{O}_{2}$, and $\mathrm{CO}_{2}$ concentration measurement uncertainty.

\begin{tabular}{|l|c|c|}
\hline \multicolumn{1}{|c|}{ Species } & $\begin{array}{c}\text { Performance Samples/ } \\
\text { Sampling Days }\end{array}$ & $\%( \pm)$ \\
\hline $\mathrm{SF}_{6}$ & $15 / 1$ & 1 \\
\hline $\mathrm{CO}_{2}$ low range & $76 / 500$ & 1 \\
\hline $\mathrm{CO}_{2}$ high range & $76 / 500$ & 1 \\
\hline $\mathrm{O}_{2}$ & $76 / 500$ & 0.2 \\
\hline
\end{tabular}

\section{Isotope Measurements}

Accuracy of the liquid scintillation counting is often obscured by matrix quenching effects. To put it simply, quenching is an interference that can bias measurement results and prevent direct comparison of samples to standards. To minimize quenching and enable sample and standard comparisons, isotope standards were prepared in a matrix consistent with sample matrices. Nevertheless, quenching was found to introduce a low measurement bias. Analysis of carbon-14 $\left({ }^{14} \mathrm{C}\right)$ and tritium $\left({ }^{3} \mathrm{H}\right)$ standards produced measurements of $5.9 \%$ and $16.2 \%$ below actual values, respectively. Method bias was also verified by independent laboratory analyses (INTEC/CCP). ${ }^{14} \mathrm{C}$ and ${ }^{3} \mathrm{H}$ activities presented here were corrected for measurement biases of 5.9 and $16.2 \%$, respectively. Background activities were considered insignificant and were not included in activity calculations. The uncertainty associated with ${ }^{14} \mathrm{C}$ and ${ }^{3} \mathrm{H}$ measurements is presented as the percent average-difference of duplicate sample measurements and the average sample measurement. Measurement uncertainties are presented along with background activities in Table A-3.

Table A-3. Sample background activities.

\begin{tabular}{|l|c|c|}
\hline & $\begin{array}{c}\text { Carbon-14 } \\
(\text { microCi g }\end{array}$ & $\begin{array}{c}\text { Tritium } \\
\left(\text { microCi g }^{-1}\right)\end{array}$ \\
\hline Sediment Water Background & $4 \mathrm{E}-06$ & $8 \mathrm{E}-06$ \\
\hline Head Gas Background & $4 \mathrm{E}-06$ & $5 \mathrm{E}-06$ \\
\hline Sediment Gas Background & $4 \mathrm{E}-06$ & $5 \mathrm{E}-06$ \\
\hline Dry Sediment Background & $6 \mathrm{E}-06$ & not determined \\
\hline Uncertainty (31 samples/ 177 days) & $1 \%$ & $1 \%$ \\
\hline
\end{tabular}




\section{Carbon-14 Soil Surface Flux Measurements}

The uncertainty of ${ }^{14} \mathrm{C}$ surface flux determinations is related to headspace flow (ventilation) rate, $\mathrm{CO}_{2}$ trap flow rate, and $\mathrm{CO}_{2}$ trap efficiency measurements. The uncertainty of each aforementioned measurement is presented to aid interpretation of the ${ }^{14} \mathrm{C}$ surface flux data, Table A-4. The uncertainty introduced into surface flux determinations by headspace and $\mathrm{CO}_{2}$ trap flow measurements is presented as the average percentdifference of individual and the average flow ratios (i.e., $\mathrm{Q}_{\text {total }} / \mathrm{Q}_{\text {trap }}$ in Equation (A-2)). The uncertainty of $\mathrm{CO}_{2}$ trap efficiency measurements is presented as the average percent difference of individual and average trap efficiency determinations (i.e., this is the $\mathrm{CO}_{2}$ trap efficiency term in Equation (1)). Additionally, the uncertainty of headspace ventilation rates is presented as the average percent-difference of individual and average headspace ventilation rate measurements. The period of flow control loss, during the later portion of the transport study, is not included in these calculations. ${ }^{14} \mathrm{C}$ activity flux, $\mathrm{F}_{14 \mathrm{c}}$, is given by

$$
\mathrm{F}_{14 \mathrm{c}}=\frac{\mathrm{Act}_{\text {Sample }} * \mathrm{Q}_{\text {Total }} * \mathrm{~m}_{\text {Trap }}}{\Delta \mathrm{t} * \mathrm{Q}_{\text {Trap }} *\left(\frac{\mathrm{EFF}}{100 \%}\right)}
$$

where

$$
\begin{aligned}
& \text { Act }_{\text {Sample }}=\text { activity per gram of aliquot, microCi } \mathrm{g}^{-1} \\
& \text { C }=\text { conversion factor, } 4.5 \mathrm{E}-7 \text { microCi disintegration }{ }^{-1} \mathrm{~min}^{-1} \\
& \mathrm{DPM}=\text { disintegration's per minute (liquid scintillation counts) } \\
& \mathrm{m}_{\text {Sample }} \quad=\quad \text { mass of aliquot, } \mathrm{g} \\
& F_{14 \mathrm{C}} \quad=\quad{ }^{14} \mathrm{C} \text { flux, microCi day }{ }^{-1} \\
& \mathrm{~m}_{\text {Trap }} \quad=\quad \text { total mass of } \mathrm{CO}_{2} \text { trap solution, } \mathrm{g} \\
& \mathrm{Q}_{\text {Total }}=\text { total headspace flow (ventilation), liters } \min ^{-1} \\
& \mathrm{Q}_{\text {Trap }}=\mathrm{CO}_{2} \text { trap flow (split of total headspace flow), liters } \mathrm{min}^{-1} \\
& \Delta \mathrm{t} \quad=\quad \text { period of } \mathrm{CO}_{2} \text { trapping, days } \\
& \mathrm{EFF}=\mathrm{CO}_{2} \text { trap efficiency, \%. }
\end{aligned}
$$

\begin{tabular}{|c|c|c|c|}
\hline & $\begin{array}{c}\text { Flow Ratio, } \mathrm{Q}_{\text {total }} / \mathrm{Q}_{\text {trap }} \\
\left(\mathrm{L} \mathrm{min}^{-1} \text { Total } / \mathrm{L} \min ^{-1} \text { Trap}\right)\end{array}$ & $\begin{array}{c}\text { Headspace } \\
\text { Ventilation Rate } \\
\left.(\mathrm{L} \mathrm{min})^{-1}\right)\end{array}$ & $\begin{array}{c}\text { Trap Efficiency } \\
(\%)\end{array}$ \\
\hline Measurements/Days & $12 / 182$ & $12 / 182$ & $12 / 182$ \\
\hline Mean Value & 1.83 & 7.06 & 96.0 \\
\hline Uncertainty (\%) & 2.7 & 0.1 & 1.4 \\
\hline
\end{tabular}

Table A-4. Uncertainty of ${ }^{14} \mathrm{C}$ surface flux measurements. 


\section{Appendix B Sample Preparation Procedures}




\section{Appendix B}

\section{Sample Preparation Procedures}

\section{Head Gas Samples ( $\mathrm{CO}_{2}$ Trap System) for Liquid Scintillation Counting (LSC)}

You will need the $2 \mathrm{M} \mathrm{NaOH}$ solution to be analyzed, concentrated nitric acid, ethanol, nano-pure DI water, $20 \mathrm{~mL}$ scintillation vials $\mathrm{w} / \mathrm{lids}$, a $250 \mathrm{~mL}$ disposable beaker, a disposable dropper, paper wipes, analytic balance, fume hood, and appropriate PPE.

1. Prep $\mathrm{CO}_{2}$ trap samples for ${ }^{14} \mathrm{C}$ counting

a. Label sample vial lids (do not mark the vial's sides).

b. Place $5 \mathrm{~g}( \pm 0.01)$ of DI water in the sample vial, record weight.

c. Place a $5 \mathrm{~g}( \pm 0.01)$ aliquot of $2 \mathrm{M} \mathrm{NaOH}$ trap solution (sample) in the vial, record sample weight.

d. Add $10 \mathrm{~mL}$ of Ultima-Flo AF scintillation cocktail to sample aliquot in vial. To prevent phase separation, do not exceed this final molarity (i.e., $0.5 \mathrm{M} \mathrm{NaOH}$ ).

e. Tightly cap vial and wipe clean with ethanol.

2. Prep $\mathrm{CO}_{2}$ trap samples for tritium counting

a. Label sample vial lids (do not mark the vial's sides).

b. Place a $2.9 \mathrm{~g}( \pm 0.01)$ aliquot of $2 \mathrm{M} \mathrm{NaOH}$ trap solution (sample) in the vial, record sample weight.

c. In a fume hood, add $500 \mu \mathrm{L}$ of concentrated nitric acid $\left(\mathrm{HNO}_{3}\right)$ to $\mathrm{NaOH}$ sample in vial. This will lower the $\mathrm{pH}$ to $\sim 2$, thus liberating $\mathrm{CO}_{2}$ from solution. Caution: $\mathrm{CO}_{2}$ gas will be violently liberated. Leave vial in fume hood until the liberated $\mathrm{CO}_{2}$ gas has been evacuated from the solution and the vial. Limit sample evaporation by leaving lid on vial loosely.

d. Add $13 \mathrm{~mL}$ of Ecolume scintillation cocktail to the acidified sample. To prevent phase separation, do not exceed $3.0 \mathrm{~g}$ of aqueous sample per $13 \mathrm{~mL}$ of cocktail.

e. Tightly cap vial and wipe vial clean with ethanol.

\section{Soil Water Samples for LSC and Kinetic Phosphorescence Analysis (KPA)}

You will need a $30 \mathrm{~mL}$ disposable syringe for each lysimeter sampled, a $0.2 \mu \mathrm{m}$ syringe filter for each syringe, $5 \mathrm{M} \mathrm{NaOH}, 10 \%$ nitric acid, ethanol, paper wipes, $20 \mathrm{~mL}$ scintillation vials w/lids, 50 and $300 \mu \mathrm{L}$ disposable pipetters (one each), analytic balance, fume hood, and appropriate PPE.

1. Prep soil water samples for ${ }^{14} \mathrm{C}$ counting

a. Label sample vial lids (do not mark the vial's sides). 
b. Place $2 \mathrm{~g}$ of $5 \mathrm{M} \mathrm{NaOH}$ in a sample vial. This is done to trap $\mathrm{CO}_{2}$ in solution.

c. Immediately after sample extraction, place an $8 \mathrm{~g}( \pm 0.01)$ aliquot of sample water in vial, record weight.

d. Add $10 \mathrm{~mL}$ of Ultima-Flo AF scintillation cocktail to the sample in vial. To prevent phase separation, do not exceed this final molarity (i.e., $0.5 \mathrm{M} \mathrm{NaOH}$ ).

e. Tightly cap vial and wipe clean with ethanol.

2. Prep soil water samples for tritium counting

a. Label sample vial lids (do not mark the vial's sides).

b. Place a $2.9 \mathrm{~g}( \pm 0.01)$ aliquot of sample water in a vial, record weight.

c. In a fume hood, add $50 \mu \mathrm{L}$ of $10 \% \mathrm{HNO} 3$ to the sample water. This will lower the $\mathrm{pH}$ to $\sim 2$, thus liberating $\mathrm{CO}_{2}$ from solution. Leave vial in fume hood until the liberated $\mathrm{CO}_{2}$ gas has been evacuated from the solution and the vial. Limit sample evaporation by leaving lid on vial loosely.

d. Add $13 \mathrm{~mL}$ of Ecolume scintillation cocktail to the acidified sample. To prevent phase separation, do not exceed $3.0 \mathrm{~g}$ of aqueous sample per $13 \mathrm{~mL}$ of cocktail.

e. Tightly cap vial and wipe vial clean with ethanol.

3. Prep soil water samples for uranium analysis by KPA

a. Label sample vials.

b. Place $10 \mathrm{~g}$ of sample water in a vial $( \pm 0.01)$.

c. In a fume hood, add $100 \mu \mathrm{L}$ of $10 \% \mathrm{HNO}_{3}$ to sample water. This will lower the $\mathrm{pH}$ to $\sim 2$ (assures U suspension). Record pre- and post-acidification dilution volumes for future calculation of concentration.

Note: To make respective background and blank samples, substitute surrogate vadose zone and DI water for the sample aliquots above.

\section{Soil Gas Samples for LSC}

You will need a $1 \mathrm{~L}$ Tedlar gas bag for each gas port sampled, a $20 \mathrm{~mL}$ disposable syringe, a $16 \mathrm{G}$ to $25 \mathrm{G}$ hypodermic needle, a $200 \mathrm{~mL}$ gas syringe, $0.5 \mathrm{M} \mathrm{NaOH}, 10 \%$ nitric acid, ethanol, paper wipes, $20 \mathrm{~mL}$ scintillation vials w/lids, a $50 \mu \mathrm{L}$ disposable pipetter, analytic balance, fume hood, and appropriate PPE.

1. Prep of soil gas sample bag and collection of sample

a. Label sample bag.

b. Weigh empty sample bag, record weight. 
c. Inject $\sim 16 \mathrm{~cm}^{3}$ of $0.5 \mathrm{M} \mathrm{NaOH}$ into the empty sample bag. Make sure that the bag's valve is closed. Take care not to pierce the side of the bag opposing the septa.

d. Reweigh the sample bag and $\mathrm{NaOH}$, record weight.

e. Draw exactly $200 \mathrm{~mL}$ of gas sample into the gas syringe and transfer to the sample bag immediately.

f. Add free space to the bag by adding ultra pure nitrogen gas $(\sim 500 \mathrm{~mL})$. Take care not to over fill and rupture the bag.

g. Tighten and lock the bag's valve, then shake the sample bag vigorously until small $\mathrm{NaOH}$ droplets are dispersed about the bag's inner surfaces $(\sim 15 \mathrm{~s})$.

h. Let $\mathrm{CO}_{2}$ dissolve into $\mathrm{NaOH}$ droplets for a minimum of 15 min before removing sample aliquots. The sample solution will evaporate through the bag material at a relatively high rate, so do not store sample in bags.

2. Prep soil gas samples for ${ }^{14} \mathrm{C}$ and tritium counting

a. Label sample vial lids (do not mark the vial's sides).

b. Weigh empty vials with lids, record weight.

c. Open the bag's valve and lightly squeeze:

(1) $10 \mathrm{~g}( \pm 0.01)$ of the sample/ $\mathrm{NaOH}$ solution into a vial labeled for ${ }^{14} \mathrm{C}$ counting.

(2) $2.9 \mathrm{~g}( \pm 0.01)$ of the sample/ $\mathrm{NaOH}$ solution into a vial labeled for tritium counting. After adding sample to each vial, immediately place the lid on vial and tighten.

d. Weigh the vials and contents, record weight.

e. Add $10 \mathrm{~mL}$ of Ultima-Flo AF scintillation cocktail to the vials for ${ }^{14} \mathrm{C}$ counting. Wipe the vials clean with ethanol.

The soil gas tritium samples require one additional step:

f. In a fume hood, add $125 \mu \mathrm{L}$ of concentrated $\mathrm{HNO}_{3}$ to the sample water. This will lower the $\mathrm{pH}$ to $\sim 2$, thus liberating $\mathrm{CO}_{2}$ from solution. Leave vial in fume hood until the liberated $\mathrm{CO}_{2}$ gas has been evacuated from the solution and the vial. Limit sample evaporation by leaving lid on vial loosely.

g. Add $13 \mathrm{~mL}$ of Ecolume scintillation cocktail to the vials for tritium counting. To prevent phase separation, do not exceed $3.0 \mathrm{~g}$ of aqueous sample per $13 \mathrm{~mL}$ of cocktail.

h. Wipe vials clean with ethanol.

\section{Carbon-14 and Tritium Performance Evaluation Samples (PES)}

We are using a ${ }^{14} \mathrm{C}$ standard solution (HOHOC14ST021202; $506.60 \mathrm{~d} / \mathrm{m} / \mathrm{g}$; analysis date 11/19/96), a tritium standard solution (Amersham TRY68, $11.87 \mathrm{microCi} / \mathrm{g}$; analysis date $6 / 1 / 81$ ), $5 \mathrm{M} \mathrm{NaOH}, 10 \%$ 
nitric acid, ethanol, paper wipes, $20 \mathrm{~mL}$ scintillation vials w/lids, 50 and $1000 \mu \mathrm{L}$ disposable pipetters (one each), surrogate ground water, analytic balance, fume hood, and appropriate PPE.

1. Prep of soil water and gas trap ${ }^{14} \mathrm{C}$ PES

a. Label sample vial lid (do not mark the vial's sides).

b. Place $5 \mathrm{~g}( \pm 0.01)$ of $2 \mathrm{M} \mathrm{NaOH}$ in a sample vial.

c. Add $2 \mathrm{~g}( \pm 0.01)$ of surrogate vadose zone water ( $\mathrm{DI} \mathrm{H}_{2} \mathrm{O}$ for gas trap standards) to the vial.

d. Add $2.9 \mathrm{~g}( \pm 0.01)$ of ${ }^{14} \mathrm{C}$ and $0.005 \mathrm{~g}( \pm 0.001)$ of tritium standards to the vial, record weight and activity of standards added.

e. Add $10 \mathrm{~mL}$ of Ultima-Flo AF scintillation cocktail to this $1 \mathrm{M}$ solution. To prevent phase separation, do not exceed this final $\mathrm{NaOH}$ molarity.

f. Tightly cap vial and wipe clean with ethanol.

2. Prep of soil water tritium PES

a. Label sample vial lid (do not mark the vial's sides).

b. Place $2.9 \mathrm{~g}( \pm 0.01)$ of ${ }^{14} \mathrm{C}$ and $0.005 \mathrm{~g}( \pm 0.001)$ of tritium standards in the vial.

c. In a fume hood, add $50 \mu \mathrm{L}$ of $10 \% \mathrm{HNO}_{3}$ to the vial, record weight, age, and activity of standards used. Leave vial in fume hood until $\mathrm{CO}_{2}$ gas has been evacuated from the solution and the vial. Limit sample evaporation by leaving lid on vial loosely.

d. Add $13 \mathrm{~mL}$ of Ecolume scintillation cocktail to the acidified solution. To prevent phase separation, do not exceed $3.0 \mathrm{~g}$ of aqueous sample per $13 \mathrm{~mL}$ of cocktail.

e. Tightly cap vial and wipe vial clean with ethanol.

Note: To make respective PES background/blanks, substitute surrogate vadose zone or DI water for the standard solutions above.

\section{Preparation of Sediment Samples for Carbon-14 and Uranium Analysis}

You will need the sediment samples to be analyzed, $2 \mathrm{M} \mathrm{HCl}, 2 \mathrm{M} \mathrm{NaOH}, 125 \mathrm{~mL}$ serum bottles with septa and crimp lids, $5 \mathrm{~mL}$ test tubes, tweezers, $250 \mathrm{~mL}$ disposable beakers, $\sim 2 \mathrm{~mL}$ disposable transfer pipettes, $30 \mathrm{cc}$ disposable syringes, $0.2 \mathrm{um}$ syringe filters, ethanol, nano-pure DI water, $20 \mathrm{~mL}$ scintillation vials w/lids, paper wipes, analytic balance, fume hood, plastic-backed plotter paper, shaker table, metal drying pans, sample drying oven, 26G hypodermic needle connected to a ridged tube ( $\sim 30 \mathrm{~mm}$ long with $1 \mathrm{~mm}$ ID) and appropriate PPE.

1. Extract ${ }^{14} \mathrm{C}$ and uranium from sediment samples.

An aggregate gaseous, aqueous, and solid phase ${ }^{14} \mathrm{C}$ activity is measured for bulk sediment samples. The contribution of gaseous ${ }^{14} \mathrm{C}$ to aggregate activity is assumed to be insignificant. Delineation of aqueous and solid phase activity is achieved by splitting each sample prior to analysis. Aggregate aqueous and solid phase ${ }^{14} \mathrm{C}$ activity is measured and sample water content is 
determined. Knowledge of in situ aqueous phase activity is combined with sample water content to subtract aqueous phase activity from the aggregate. Split water contents are determined, simultaneously with procedures below, using a drying oven in a fume hood and standard laboratory techniques.

a. Label serum bottles.

(1) Add $20 \mathrm{~mL}( \pm 0.1)$ of $2 \mathrm{M} \mathrm{HCl}$ to serum bottle.

(2) Add $5 \mathrm{~mL}( \pm 0.1)$ of $2 \mathrm{M} \mathrm{NaOH}$ to test tube.

b. Place $5 \mathrm{~mL}$ test tubes in serum bottles, resting upright against the bottle's side.

c. Tare balance for serum bottle, septa, and crimp lid.

d. Add $5 \mathrm{~g}$ ( $\sim 40 \mathrm{~mm}$ long by $\sim 10 \mathrm{~mm}$ diameter piece) of sediment sample to acid in serum bottle (immediately affix septa and crimp lid to prevent escape of $\mathrm{CO}_{2}$ gas), record weight of sediment sample. Note: Slightly shaping sediment sample will facilitate adding the sediment to the serum bottle.

e. $\quad$ Place serum bottle on shaker table and mix slurry for $24 \mathrm{~h}$ at $100 \mathrm{RPM}$.

f. Check serum bottle gas pressure to verify that $\mathrm{CO}_{2}$ gas is fully dissolved in base. Hold index finger over the ridged tubing end, containing a water droplet, and insert the hypodermic needle into the bottle septa. Slowly move index finger to vent the tubing and watch water droplet movement. Continue mixing until gas pressure is negative (i.e., water droplet moves toward the bottle). Do not allow water droplet to be drawn from the ridged tubing into the serum bottle.

2. Prep carbon-14 samples for scintillation counting

a. Label scintillation vial lids for ${ }^{14} \mathrm{C}$ counting (do not mark the vial's sides).

b. Place $5 \mathrm{~g}( \pm 0.01)$ of DI water in the scintillation vials.

c. Transfer $5 \mathrm{~g}^{14} \mathrm{C}$ samples (i.e., the $\mathrm{NaOH}$ solution in serum bottle test tubes) to scintillation vials using transfer pipettes.

d. Add $10 \mathrm{~mL}$ of Ultima-Flo AF scintillation cocktail to the $\sim 10 \mathrm{~g}$ sample aliquot. To prevent phase separation, do not exceed an aliquot molarity of $1 \mathrm{M} \mathrm{NaOH}$ (0.5 final molarity).

e. Tightly cap vial, shake vial to mix contents, and wipe vial clean with ethanol.

3. Prep uranium samples for analysis

a. Label scintillation vials for uranium samples.

b. Remove and discard empty test tube from serum bottle using tweezers.

c. Decant sediment-acid slurry supernatant into disposable $250 \mathrm{~mL}$ beaker. 
d. Draw supernatant into a $30 \mathrm{cc}$ syringe. Do this soon after decanting to minimize evaporative loss.

e. Dispense filtered supernatant from syringe into scintillation vials for analysis. 